PIEASURABLE

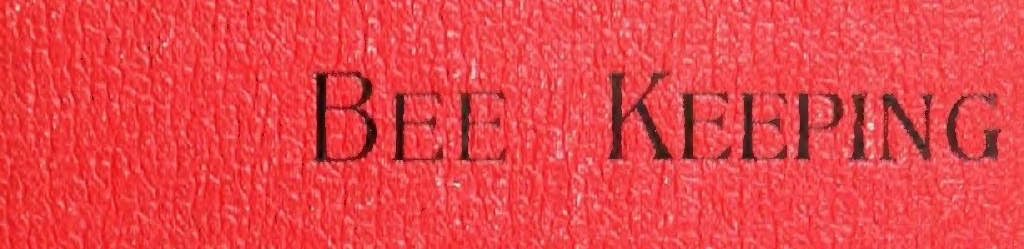

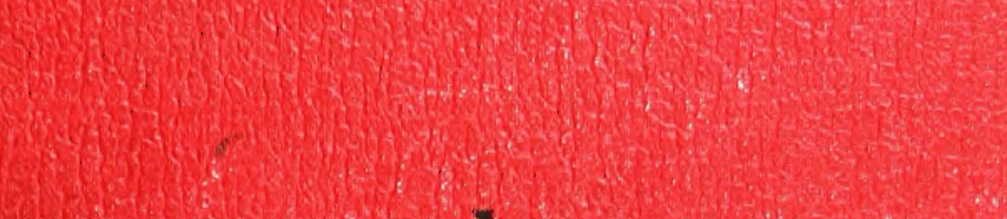
(2)

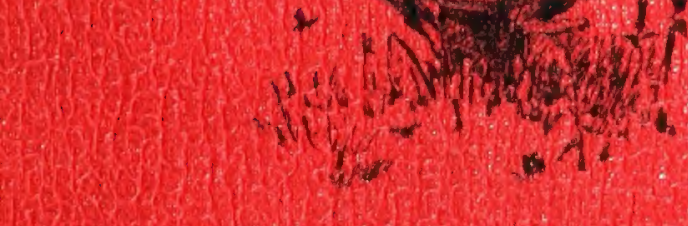

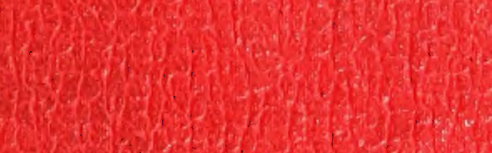

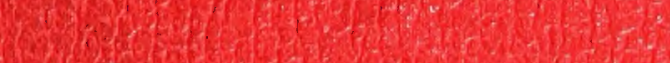

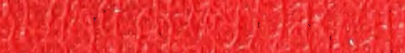

-2.

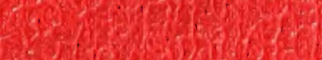

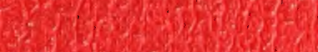
ate

C. N.White 
$5 F 523$

W $5+3$

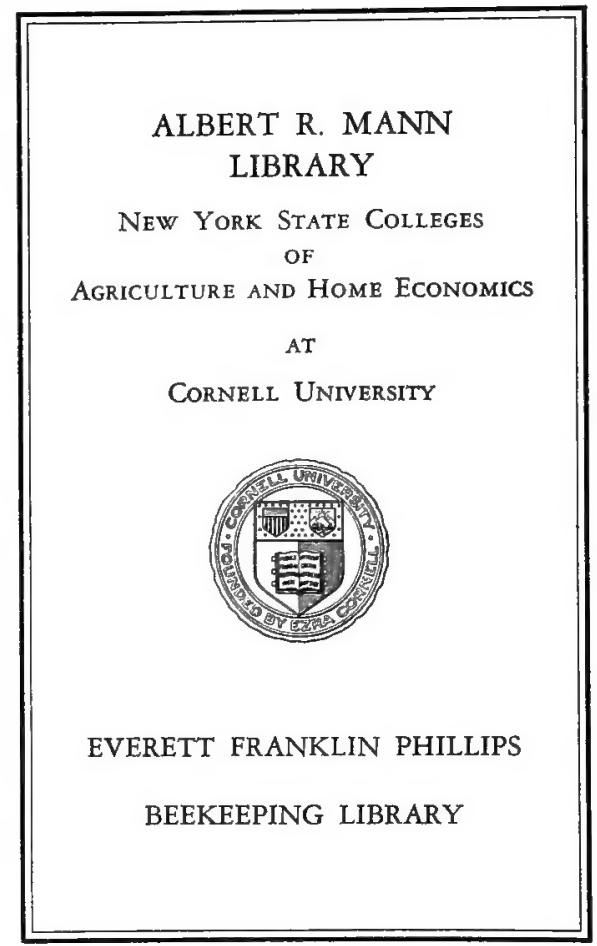




\section{Cornell University Library}

The original of this book is in the Cornell University Library.

There are no known copyright restrictions in the United States on the use of the text.

http://www.archive.org/details/cu31924003258161 



\section{PLEASURABLE BEE-KEEPING.}





\section{PLEASURABLE}

\section{BEE-KEEPING}

BY

\section{CHARLES NETTLESHIP WHITE}

First-class Certificated Expert of the British Bee-keepers' Association: Author of "Bee-keeping for Cottagers," etc.; and Lecturer zunder the Technical Education Schemes of the Hunts, Cambs, Isle of Ely, and other County Councils

WITH ILLUSTRATIONS

\section{LONDON}

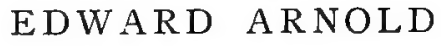

37, BEDFORD STREET, STRAND, W.C. 
(a).

SF523

W 583 


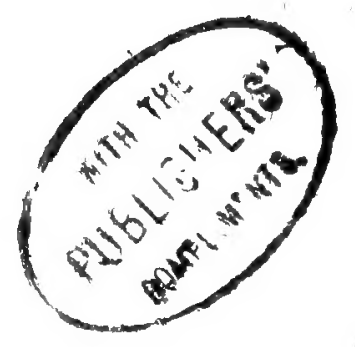

\section{CONTENTS.}

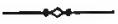

PAGE

INTRODUCTION

CHAP

I. BEES AND FLOWERS . . . . 11

II. WHY KEEP BEES ? - 16

III. THE CONTENTS OF THE HIVE . 19

IV. NATURAL INCREASE 29

V. RACES OF BEES . . . . 36

VI. SUBDUING AND HANDLING BEES . . 41

VII. HIVES $\quad$ - $\quad$ - $\quad$ - $\quad$. $\quad . \quad 51$

VIII. AIDS TO SUCCESS . . . . . 74

IX. COMMENCING BEE-KEEPING . . . . . 99

X. HONEY PRODUCTION . . 112 
CHAP.

XI. BEE-ESCAPES AND SUPER-CLEARING

XII. QUEEN RAISING AND INTRODUCING .

XIII. DISEASES . . . . . 145

XIV. ENEMIES OF BEES .

XV. WINTERING. . . . . 155

XVI. DRIVING, TRANSFERRING, UNITING . 161

XVII. MARKETING HONEY . . . 168

$\begin{array}{ll}\text { XVIII. WAX EXTRACTING . } & 176\end{array}$ 


\section{INTRODUCTION.}

\section{THE PROGRESS OF BEE-CULTURE.}

IN writings dating from the earliest times of which we have any record, frequent allusion is made to bees and honey. As a food honey stands unrivalled for its delicate aroma, and it is also recognised as a valuable force producer. Early British History abounds in references to the keeping of bees, and to the value of the homey and wax they produce; and it may be inferred that even in those times bee-culture had assumed sufficient importance to rank as a rural industry.

The seventeenth century was very prolific in writers on bee-culture, and from that time onwards great attention has been paid to the culture of the honeybee in rural districts. Very little real progress, however, in the art was made until the movable-comb hive was invented nearly fifty years ago. To the Rev. L. L. Langstroth in America, and Baron Von 
Berlepsch in Germany, belongs the credit for this remarkable invention, which proved the beginning of a new era in bee-keeping.

Bee-culture was henceforth a subject of absorbing interest, and, apart from the pecuniary benefit that followed its introduction, the invention has doubtless had the greatest possible influence on the development of the science as well as the art of Beekeeping. Movable combs render the modification of the brood-nest possible to suit varying circumstances, and though in the hands of the novice, who pulls his stocks to pieces to satisfy his curiosity, they are no boon, to the great majority of bee-keepers they have been of immense advantage.

By the invention of the smoker, of which there are various forms, due to the inventive genius of American bee-keepers, another step was taken towards bringing bees under that complete control without which the bee-keeper could hardly be styled " a bee-master."

Step by step advances were made in designing and improving appliances, by means of which the beekeeper is enabled to reap the large harvests so often recorded, until there now appears little room for further exercise of the inventive faculty. The "Little Wonder" extractor, invented by the late C. N. Abbott, was, in its day, considered a marvellous machine, in that the combs were emptied of their contents by centrifugal force, in order to be returned to the hives for refilling. A cylinder extractor next came into favour, and, though many excellent machines are now produced, the "Cowan," as im- 
proved in America, may be said to most nearly approach perfection.

Then noting the loss of honey to the bee-keeper when comb-building took place, inventive genius gave the foundation mill, and sheets of wax with impressions of worker cells to be rapidly converted by the bees into perfect combs.

For many years disease has, in England and in other countries, decimated apiaries and made the dread of infection a powerful deterrent to the spread of apiculture. But scientific research has resulted in bee-keepers becoming conversant with the origin, propagation, prevention, and cure of the only disease that need be feared.

The strides that have been made in apicultural knowledge have in great measure been due to those who, by their writings and advocacy through the British and affliated Associations, have assisted in making "Bee-keeping" what it now is, one of the most important and not the least valuable of the minor rural industries. In 1874 the late Mr. C. N. Abbott started the first Bee-Journal, and plain and earnest advocacy helped forward the work very materially. With the establishment of the British Bee-keepers' Association a very powerful means was provided for doing good work, which, with the cooperation of the affiliated Associations, has been energetically carried forward by all, from the Baroness Burdett-Coutts, who presides over the central Association, to the cottager who pays his 1s. subscription.

By means of its great exhibitions, held annually in connection with the Royal Agricultural and other 
shows, the British Bee-keepers' Association brings prominently before thousands of visitors the capabilities of an industry that is comparatively speaking neglected by the agriculturist, who is directly as well as indirectly calculated to benefit by its extension. To the various shows judges and examiners are sent by the British Bee-keepers' Association, and now it is possible for any one who takes sufficient interest in the work to pass the three examinations, and at least earn a certificate testifying to the ability of its possessor, not only to assist in, or direct the operations of an apiary, but to fill the position of lecturer under the Technical Education Schemes of the various County Councils. 


\title{
PLEASURABLE BEE-KEEPING.
}

\author{
CHAPTER I.
}

BEES AND FLOWERS.

No one who has watched the busy bee flitting from flower to flower can fail to have been struck with the idea that it has some special duty to perform while gathering from the nectaries of flowers the sweetness that is to be used as a food for itself and for the myriads of other bees in the colony from which it has flown. In the economy of nature it is not too much to say that there is not a busier insect, or one which is directly as well as indirectly of more value to the agriculturist.

Bees and flowers are inseparable. Flowers are fertilised almost wholly by wind and insect agency, but by far the greater number require the risits of insects for the proper fertilisation of bloom. Man's efforts to improve nature by cross-fertilisation would be of little avail without the bee. That it was 
intended for the bee to play an important part in the fertilisation of bloom, is evident from the arrangement of the flowers. The bees must rub against the pollen, and so carry it away to the other flowers, while they are searching for nectar secreted at the bottom of the flower. The nectaries are usually placed so as to secure fertilisation, while the stigma is protected in order that the rain shall not wash away the sweet secretion covering it. To prevent self-fertilisation the stamens and pistils are on different flowers, or, when both are on the same flower, the former are not in a receptive condition at a time when the latter are ripe, and scatter their pollen. When a bee enters a flower in search of nectar, if the anthers are ripe, the pollen is scattered over its body, and adheres to it. Subsequently some of this pollen is left adhering to the stigmata of other flowers, thus effecting proper fertilisation while the bulk is taken to the hive where it is used as a food.

The colour of the flower as well as the nectar is in itself a provision for attracting insects. Sir John Lubbock has at much pains tested the preference of bees for coloured flowers. Again, the odour of certain crops is most powerful and certainly attractive. In passing along a road the traveller recognises the presence of bean or clover fields long before he reaches them, by the scent borne upon the breeze, and this is undoubtedly detected by bees much more readily than by human beings.

The influence of bees in the production of fruit is sometimes very great. In California there are extensive cherry orchards, and the crops have recently been 
far from satisfactory, though years ago abundance of fruit was gathered. The failure of the crops was attributed by some to winds and rains, but the Messrs. Bassford, of Cherry Glen, Vaca Valley, Solano County, attributed it to the absence of bees, for they had remarked that when wild bees were plentiful in the valley the crops were good. To test the matter they placed several colonies of bees in their orchards in 1890. The result was striking; their crop was good while others were entire or partial failures. In 1891 they had sixty-five colonies of bees, and Mr. H. Bassford, writing to the Entomologist, said, "Our crop was good this season, and we attribute it to the bees. Since we have been keeping bees our crop has been much larger than formerly; while those nearest us, five miles away, where no bees are kept, have produced light crops."

Mr. Cheshire, in "Bees and Bee-keeping," draws attention very forcibly to the necessity for bees in the fertilisation of apple bloom. "The apple," he says, "as its blossom indicates, is strictly a fusion of five fruits into one-hence called pseudosyncarpous-and demands for its production in perfection no less than five independent fertilisations. If none are effected, the calyx, which really forms the flesh of the fruit, instead of swelling, dries and soon drops. An apple often develops, however, though imperfectly, if four only of the stigmas have been pollen dusted; but it rarely hangs long enough to ripen. The first severe storm sends it to the pigs as a wind-fall. I had two hundred apples, that had dropped during a gale, gathered promiscuously for a lecture illustration; and 
the cause of falling in every case but eight was traceable to imperfect fertilisation. These fruits may be generally known by a deformity-one part has failed to grow because there has been no diversion of nutrition towards it. Cutting it across with a knife, we find its hollow cheek lies opposite the unfertilised dissepiment."

The American poet Bryant, who was a keen observer of Nature and her work, says in "The Planting of the Apple Tree":

"What plant we in this apple tree?

Sweets for a hundred flowery springs, To load the May-winds' restless wings;

When from the orchard now he pours

Its fragrance at our open doors

A world of blossom for the bee."

The effect of the introduction of the bumble-bee into New Zealand forms the most convincing proof of the importance of insects as fertilisers of bloom. Previous to 1881, when the first attempt to introduce these bees to the colony was made, though crops of redclover were grown, no seed was produced. In December, 1883, and January, 1884, 55 bumble-bees packed in dry moss were sent to New Zealand, but all died. In the autumn of 1884 special precautions were taken in the packing of 282 shipped in November and 260 in December, and they were liberated near Christchurch in January and February, 1885. The following year Mr. S. C. Farr, Hon. Sec. of the Acclimatisation Society of Christchurch, writing of these bees, says their number is legion, and they abound over a radius of one hundred miles from Christchurch. In several 
cases the farmers, who previously had been unable to produce red-clover seed reported their crops to be full of seed.

Professor Cooke, a noted American apiarian, is responsible for the following: "Inasmuch as red-clover can only be fertilised by the bumble-bee, a gentleman has made this statement: the safety of England depends upon the number of cats she keeps. He proves his proposition thus: without the aid of the bumble-bees the red-clover cannot be fertilised. Bumble-bees make their nests on the ground, where they are the prey of mice. Cats destroy the mice and give the bees a chance to live. Hence he reasons, no cats, many mice; many mice, no bumble-bees; no bees, no clover; no clover, no cattle; no cattle, no beef; and without beef where would the Englishman be?"

With regard to the value of the bee as a fertiliser, Darwin says, when speaking of their visits to clover and heartsease, "No bees, no seed; no seed, no increase of flower. The more visits from the bees the more seeds from the flower; the more seeds from the flower the more flowers from the seed." He also gives the following result of an experiment: "Twenty heads of white clover, visited by the bees, produced 2,990 seeds; while twenty heads so protected that bees could not visit them produced not one seed." 


\section{CHAPTER II.}

\section{$W H Y \quad K E E P \quad B E E S$ ?}

AMPLE reasons for the extension of bee-culture are adduced in the chapter on "Bees and Flowers," but the direct financial results in a well-managed apiary furnish probably a much greater inducement to many persons to take up and prosecute successfully such a well-paying hobby. In many industries the products are of a perishable nature. Not so, however, with bee-products, honey and wax. They may, when properly packed, be transported to all parts, and at the same time, should the state of the market render it advisable, they may, without detriment to quality, be stored away for sale at a future date.

While no industry connected with rural occupations is so interesting, from an intellectual standpoint, as bee-culture, there is none which approaches it in the profits on the outlay, when the time spent on the work in the apiary is taken into consideration. The beekeeper has only to provide a home for his bees, and receptacles in which they may store their surplus, and they will roam afield, gathering honey in abundance from morning till night. In most districts some honey- 
producing crops are griown, and in many localities, in addition to acres of orchards and a sprinkling of white clover in the pastures, crops of white and alsike clover are regularly grown for seed, while sainfoin, nustard, turnip, cabbage, and other profusely-flowering crops are abundant. Then, again, in the neighbourhood of moors where heather is abundant, there is another excellent source of late honey.

The late Mr. H. M. Jenkins, secretary to the Royal Agricultural Society of England, some years ago gave an address in the Lecture Hall, Dublin, on "Some of the duties of a farmer's wife," and referred to the keeping of bees as advisable, and instanced the success of a lady well known among practical beekeepers, Miss Gayton, of Much Hadham, Herts, who wrote, saying, "From my own experience I am sure that almost every cottager might make his bees pay his rent and more; and with five or six hives the trouble of attending to them is not more than he and his wife could find time for. One thing, however, is absolutely necessary for success in bee-keeping, namely, to thoroughly study and understand the habits and requirements of bees, and to bestow on them as much care and attention as would be required for any other pursuit or occupation in order to be successful. Having but small means I began bee-keeping with the hope of making it a profitable business. I have kept a strict account of every expense, and as my statement shows I have found bee-keeping profitable." Miss Gayton, who resides in a good honey district, commenced bee-keeping with one stock in 1876, and her initial expense was $£ 1$ 12s. 6d. She increased her 
stock to twenty-eight hives, and her average profit at the end of eight years was $£ 20$ per year.

F. In the British Bee Joumal for 1885 a cottager wrote: "I am only a cottager, I have taken nearly $900 \mathrm{lbs}$. of honey, all from supers without touching the stock hives." Another, whose daily work occupies him from six to six, said he had taken over 400 lbs., nearly all in sections, and sold it for the nice sum of $£ 22$ 10\%.

During the last few years the prices of all kinds of agricultural produce have fallen below what was formerly realised, but from bee-keeping equally good results in comparison with other industries are still obtained. A young man, the son of a farmer at Wainfleet, Lincolnshire, who has been favoured of late years with crops that have bloomed in splendid weather, took an average of $109 \mathrm{lbs}$. of honey from each of his three stocks in 1892, and an average of 156 lbs. per hive in 1893. Near him another beekeeper had an average of over 90 lbs. per hive. Results in other parts of the same neighbourhood were disheartening. But evidently this was due to lack of attention, without which success cannot be expected.

These are only fair specimens from hundreds of examples that might be quoted; and they may be taken as evidence that, given a good district and favourable climatic influences, it must be the fault of the bee-keeper himself if his enterprise does not prove to be of an exceedingly profitable character. 


\section{CHAPTER III.}

\section{THE CONTENTS OF THE HIVE.}

Is order that bee-keeping may give the greatest amount of enjoyment and pleasure, and, at the same time, the largest profit, it is necessary to study carefully the natural history of the honey-bee so far as it is applicable to the practical work of the apiary.

In commencing this study we should naturally first make an examination of the hive to learn about the structure of the combs and their varied contents.

\section{The Combs.}

The combs are found in all hives or other cavities where bees have built according to their own devices, at an almost uniform thickness, viz., a trifle under an inch from face to face, when containing sealed "worker brood." The space between the combs is about half an inch, consequently the distance from centre to centre of the combs is just under $1 \frac{1}{2}$ inches, or, to be exact, $1 \frac{9}{20}$ inch.

Combs are made of wax, a secretion resulting from the consumption of honey or an equivalent food. The wax oozes out from beneath the scales of the 
abdomen, on the underside of the body of the bee, and assuming a solid form, is drawn away in very thin flakes by the bee, and used for the making of the comb, the cell walls of which are $\frac{x}{180}$ inch in thickness. The work of comb-building is very trying to the bee. The amount of honey consumed in the elaboration of one pound of wax is variously estimated,

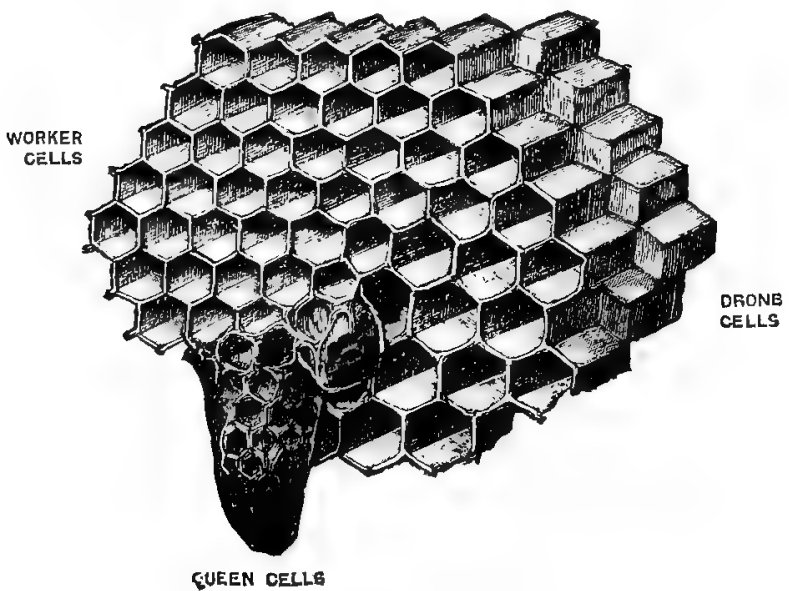

Fig. 1.

some authorities putting it as high as twenty pounds, while others say not more than ten pounds are used. It is, however, certain that the weight must be several times that of the wax produced, so that if a substitute be given, a great deal of honey may be saved to the bee-keeper.

The combs are composed of Worker cells and Drone cells, built horizontally on each side of a mid-rib. 
Worker cells are small, measuring five to the inch across the mouths of the cells, and drone cells four to the inch. The thickness of the comb when containing worker-brood is $\frac{7}{8}$ inch; and when containing drone brood $1 \frac{1}{4}$ inch. By cutting through a comb from top to bottom, and dividing the cells, it will be noticed that in building the combs the bees give a slight upward pitch to the cells. This peculiarity it is necessary to bear in mind, when combs in a box or skep are being transferred and fitted into frames.

Queen cells are found in a hive, as a rule, only at swarming time. They are acorn-shaped, and are usually built on the bottom edges of the comb. If the bees lose their queen during the summer, queen-cells are built on the face of the comb in any part where the cells contain worker eggs.

\section{HONEY.}

Honey is found in the combs in quantity varying according to surrounding circumstances. This, the most delicious of sweets, forms the natural food of the insects that produce it. The substance of which it is composed, as originally secreted by the flowers, is termed nectar, and not until it has undergone chemical change within the body of the bee, and been stored in the combs, is it known by the familiar name of honey.

Having already passed through certain digestive processes it is, as food for man, of great value, inasmuch as it is at once taken directly into the system as a force-producer, without passing through the stages 
necessary in the case of many other foods. Honeys vary greatly according to the source from which the thectar is gathered, some kinds having a delicate aroma, which causes them to be particularly sought after. Clover honey in England is considered the standard quality, but even this honey exhibits considerable variation according to the soil upon which the clover is grown and the surrounding climatic conditions. For instance, at a large show in the West of England, where I acted as judge of the honey exhibits in the autumn of 1893, it was noted as a remarkable fact that in nearly every instance, though some classes were open, the prizes were awarded to samples of honey taken from apiaries on or near the tops of the neighbouring hills. To the Scotsman, and many English bee-keepers resident near the moors, there is nothing to equal heather honey.

\section{Pollen.}

Pollen, which is the fertilising dust of the flowers, is carried by the bee, in its search for nectar, to those blooms where its presence is required to cause the production of fruit and seeds. Nature provides this fertiliser in a most lavish manner on certain flowers, and the bees, therefore, becoming dusted with more than is needed for the fructification of bloom, cleanse their bodies of the surplus, pack it away in the "pollen-baskets" formed by projecting hairs on the hindmost pair of legs, and carry it to the hive. Here it is stored in the cells to furnish, in conjunction with honey, a perfect bee-food, whether required, by the 
workers, the grubs that are their special care, or the queen. Pollen is also used in the formation of the cappings to the cells contrining the grubs, and plays an important part in the making of wax.

M. de Layens, a French bee-keeper and author of note, was the first to notice that the colour of wax varied with the source of the pollen; and it is not the light-coloured honey that is responsible for the wax of a light shade. Very often the contrary is the case, for, though heather honey is dark, the wax made from it is light yellow. In 1886, Dr. A. Von Planta, a famous Swiss chemist, proved the colour of the wax to be due to the presence of various coloured pollen grains.

Propolis is also gathered by the bee, but at present it has been put to no commercial use by the beekeeper. It is of a resinous nature, and exudes from certain trees. The bees use it as a cement for filling cracks and crevices, and for covering intruders, such as the snail, that they are unable to remove. In the building of the combs propolis is employed to increase the tenacity of the wax, but it is used to the greatest extent at the close of the honey-flow, in daubing the sections and the crates, which, if left on the hive too long, become firmly fixed, and difficult to remove.

\section{The Bees.}

Every colony of bees in a normal condition will, during the summer months, contain three kinds of bees which are easily distinguished one from the other. They are the Queen, Drones, and Workers 
The queen (Fig. 2) is the mother of all the bees in the hive, and she has really only one duty to perform, viz., that of egg-laying. From early in the season to some time after the close of the honey-flow, a good queen will be busy depositing eggs in the various cells, out of which will proceed in due course a Queen, a Drone, or a Worker. A very large amount of work is thus of necessity the share of the queen bee, but the beekeeper, with a view to large returns, will endeavour, by careful and systematic management, to regulate the egg-laying of the queen in such a manner that the

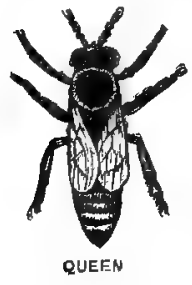

FIG. 2.

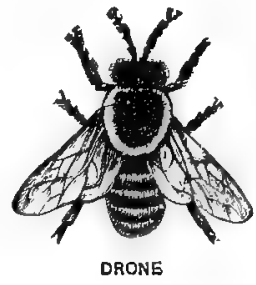

Fia. 3.

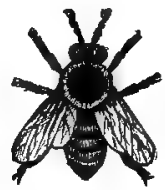

WORKEB

Fig. 4.

hive shall be full of bees at the commencement of the honey-flow, and that, instead of ceasing to lay at the close of the honey-flow, she shall continue her work until about the middle of September, thus ensuring the presence of a large proportion of young bees when the stock is closed for the winter about the 1st of October.

The queen is produced in sixteen days from an egg exactly similar to that from which a worker issues. In order that a queen and not a worker may be produced, the egg is deposited in an acorn-shaped cell, usually built, on account of its size, on the bottom edges of 
the combs. Sometimes, however, they are found on the face of the comb among the worker cells.

The queen may live three or four years, but it is generally admitted that she is in her prime, and consequently of most value to the bee-keeper, in her second season. It is for this reason that some beekeepers make it a rule not to allow a queen to remain more than two years at the head of a colony, except in rare cases. When it is considered what an enormously increased number of eggs above the natural average the queen may be induced to lay each season, by the management of the bee-keeper, her remoral at the close of her second season appears to be a matter of necessity, if the colony is to be kept up to a proper standard of strength.

During manipulations in the summer, a bee-keeper may have the misfortune to crush or drop a queen outside the hive. Deprived of its queen the colony will naturally diminish in numbers, and would ultimately die out were it not for the fact that at such times there are eggs in the worker cells. From these eggs, as has already been stated, if they are deposited in queen cells, queens will be produced. It is, therefore, only necessary for the bees, upon the loss of a queen, to produce another from an egg in a worker cell. As the grub will require more space for full development than a worker cell provides, the cell walls, around the egg, or grub, are cut down, and then over the larger space thus given a queen cell is built. The grub then receiving exactly similar treatment to that of a grub in an ordinary queen cell, will be converted into a perfect queen in from twelve to sixteen 
days. The difference in the time of issue from-the cell is regulated mainly by the age of the egg or grub on the loss of the queen. Queens should be raised from a newly-hatched egg, or a grub not more than a day old, in order that it can have full and proper treatment. Unless the queen accompanies the swarm, she only leaves the hive once during her life, and that is four or five days after she issues from the cell, for the purpose of mating with a drone or male bee. If successful in her wedding flight she will in about fortyeight hours be found depositing eggs in worker cells.

\section{Drones.}

Drones (Fig. 3) are the male bees, and they are easily distinguished from the workers by their large size, and, when flying, by their loud hum. They are produced in twenty-five days from an unfertilised egg deposited by the queen in the larger horizontal or drone cells. Drones appear early or late according to the season and the strength of the colony, usually about April. They are particularly numerous in cottagers' apiaries, where thousands are to be found, although as many hundreds would be ample. They are often known as the lazy bees and great consumers of honey, consequently their production should in all well-managed apiaries be limited. This is an easy task to the beekeeper who uses "foundation," for with that valuable aid to success he can in a day or two ensure combs of worker cells only. The drones are only allowed to exist during the summer months; and as soon as the honey-flow is over the bees turn them out of the hive to die, 
Very frequently a massacre of drones takes place earlier in the season, but this is a sign that food is running short owing to unfavourable weather; and if in addition to the turning out of the drones white grubs are found outside the hive, that circumstance may be taken as a sign that food is absolutely necessary to save the stock, if not from actual starvation, at any rate from being rendered practically useless for the season. The weight of a stock at such times is not a safe guide to the amount of stores, as the hive may be weighty in consequence of the presence of a large quantity of brood in various stages.

\section{WORKERS OR NEUTERS.}

Workers (Fig. 4), or as they are sometimes termed neuters, are really undeveloped females. As such they have not the power normally of egg-laying. The worker is produced in twenty-one days from an egg deposited in one of the small horizontal cells. Upon bees of this class devolves the work of the hive. For the first fortnight or thereabouts of their existence, they remain at home, preparing, in their capacity of nurses, the food for the grubs and queen. When this duty ceases, a work commences that, comparatively speaking, soon terminates their existence. Henceforward the worker bees labour unceasingly from morning to night, weather permitting, in gathering nectar and pollen from honeyproducing flowers. The life of a worker bee is in the summer time at the most only seven or eight weeks, the average length of life being forty-six days. Those bees which are hatched in the autumn, say, in Sep- 
tember, and having little work to do, will, as a rule, pass through the winter and come out strong and vigorous in the spring.

\section{Fertile Workers.}

It occasionally happens that when a queen dies or is killed, and the bees have not the power, for want of worker eggs, to replace her with another queen of their own raising, a worker is found to have the power of egg-laying. This is thought to result from the bees hatched near queen cells having, when in their larval state, received a share of the queen jelly, as the food administered to the queen is termed; but whatever may be the cause of so extraordinary a change in their functions, they are useless for the reproduction of species, as the eggs they lay only produce drones.

The presence of a fertile worker in a hive may be detected by the irregular manner in which she deposits her eggs in the cells, and also by the fact that the cappings of the worker cells will be found to project when the bees begin sealing over the grubs which will produce drones.

A stock may be freed from a fertile worker by taking the hive some distance away from the site it occupies, and then shaking all the bees from the combs. In a queenless hive all bees, except the fertile workers, fly daily. Therefore, when they are shaken from the frames, they will return to their old site, while the fertile worker will be rendered homeless and meet with her fate if she attempts to enter any other hive. 


\section{CHAPTER IV.}

\section{NATURAL INCREASE.}

\section{Egg-Production.}

Ir a strong colony be examined early in the new year the centre combs will be found to contain small patches of brood. These are extended as the season advances, provided there is an ample supply of food, until by the time of the honey-flow the queen is laying over two thousand eggs daily.

The first eggs of the season are deposited in the small horizontal cells, and, after being exposed to the heat of the hive, they hatch in three days, a small white grub appearing. The grubs are then fed by the nurse bees, with a food composed of honey and pollen, for five days, by which time they will have increased in size to such an extent that they almost fill the cells. The bees then cover the mouths of the cells with a capping, differing from that placed over honey in that it is not air-tight. Behind the capping the grub is gradually transformed into the perfect insect, which eats its way out of the cell in about thirteen days, or twenty-one days in all from the laying of the egg. The queen continues to deposit eggs in the worker cells until the hive is becoming crowded with worker bees, 
then eggs - unfertilised - are placed in the larger horizontal or drone cells from which issue drones in twenty-five days.

Later on, as the population of the hive gradually increases, and there is no more room for workers or drones, cells shaped somewhat like an acorn are built on the lower edges of the combs, and in these the queen deposits eggs exactly like those placed in the worker cells; but in consequence of the grub being supplied with a food richer in the nitrogenous element contained in pollen, and greater in quantity than that supplied to the worker grubs, and also because the cell gives more space for full development of the organs, in sixteen days a perfect queen issues.

\section{SWARMING.}

When, for want of room, the bees form queen cells it will not be many days before a part of the population of the hive leaves for a new home. This exodus is known as swarming, and it usually takes place as soon as the new queen cells are sealed over. When the bees leave the hive they are accompanied by the queen, and they fly about in the air until some begin to settle on the branch of a tree or elsewhere. In a very short time a large cluster is formed, which should be dislodged and placed where it is to stand for the rest of the season.

Hiving the swarm is not a difficult operation, unless the bees, instead of forming, as they usually do, a large pear-shaped cluster hanging from the branch of a tree, spread themselves round the trunk, or choose some other place from which they cannot easily be 


\section{NATURAL INOREASE.}

transferred into the skep. Presuming that the swarm is hanging from the branch of a tree, a skep should be held in the left hand under the cluster, while the right hand is used to shake the branch sharply and thus cause all or the bulk of the bees to fall into the skep. Many bees will doubtless fly about in the air, but the skep must at once be turned over gently, and placed either on the ground, if the bees clustered on a low branch, or on a table, if higher on the tree. Under one side of the skep must then be placed a stone or brick to give access for the bees flying about, and also for ventilation, which will be much needed, as the temperature of the cluster is very high during the commotion which ensues. The queen must be secured in the skep, otherwise the bees will return to the branch. When the bees cluster round the hive and some form themselves into lines at the entrance fanning with their wings we may conclude that the queen is safe inside.

Should the bees desert the skep and return to the tree the operation must be repeated. There may still be several bees flying about the spot and settling on the branch. This is because of the scent left behind. As soon, therefore, as the swarm is hived, that part of the tree upon which the bees settled should be well syringed with water; or a few handfuls of soil should be thrown over it to destroy the scent. As soon as the swarm has been safely hived the skep should be moved carefully to its stand, there to remain unless it is to tenant an "Ivo" or movable-comb hive. In either case re-hiving had better be deferred until evening, as swarms when much disturbed during a 
hot day occasionally take flight and may be lost to the bee-keeper.

In hiving swarms it is of the utmost importance that the skep should not be left in the rays of the sun, or the great heat may cause the bees to leave their temporary home. If the swarm must remain for some time where it has been hived, and cannot be placed in the shade, a white sheet should be thrown over the skep, except on the shady side where the bees enter.

It is also advisable, supposing the swarm to settle half a mile, more or less, away from the apiary, to bring it home as soon as the bees have become settled in the skep; for as soon as clustering is completed the bees will be busy for the rest of the day, going to and fro in search of nectar, and the following morning after their first journey to the fields they will return to the spot they had become accustomed to the previous day. If, however, the hive had been taken home the previous night many bees would be lost; and the loss might be great, in case a storm came on while they were clustering on the ground, where the skep had been placed the day before.

\section{Casts.}

"A swarm of bees in May

Is worth a load of hay:

A swarm of bees in June

Is worth a silver spoon;

A swarm of bees in July

Is not worth a fly."

The above familiar rhyme will be admitted by most 
bee-keepers to be near the truth, so far as the first two lines are concerned; but the other lines convey information that is far from correct, for casts or afterswarms may be and often are of great value. In the first place they are headed by a young queen, which is a matter of prime importance, and, if the bees are fairly numerous, a fair amount of surplus may be gathered during the honey-flow.

After a swarm has issued from a stock the latter is queenless for eight days, at the end of which period the young queens commence to issue from their cells. The first to appear will endeavour to reach the cells containing the other queens for the purpose of killing them; if prevented she makes a peculiar noise, which may often be heard by the bee-keeper. This " peep, peep," heard on the evening of the eighth day, has long been taken as an almost sure sign that on the morrow a second swarm or cast will issue.

The issue of a cast may be confidently expected from a strong stock that has lost with the swarm a vigorous laying queen, for during the eight days following the issue of the swarm, two thousand or more bees will have been hatching daily, and therefore only bad weather would stop a cast. Though only one queen is found in a swarm, casts frequently contain several that have escaped during the excitement of swarming. In the evening only one queen will be left as the result of several battles.

\section{Controlling Swarming.}

To a bee-keeper swarming is a charming sight, 
though the issue of a swarm from a particular stock may cause annoyance. It is safe to say that, as a rule, swarming means the loss of much honey, for the bees are lazy for some days previous to the issue of a swarm. This is not their fault, for they only prepare for swarming when they are in want of room, and all this laziness comes at a time when the work of every bee is required in the storing of surplus.

Swarming may be controlled, but not entirely prevented. Seeing that want of room is invariably the cause of swarms issuing, space for the storing of surplus in advance of requirements must be given. Occasionally, in spite of supers, swarms issue; but why seems to be a decided puzzle to the novice. After supers are placed on the hives, and the bees have commenced work therein, it will, in the majority of cases, be continued unless there is, owing to drought, a seriously diminished income, or dull, cold, and wet weather has driven the bees from the supers to the brood chamber. In both cases, but more particularly the latter, the crowding of the bees in the brood chamber causes the formation of queen cells, and, though a change may take place in the weather favourable to the secretion of nectar, a swarm is almost sure to issue as soon as the queen cells are sealed over.

Cutting out all queen cells but one is a means of preventing swarming often advocated; but it is much better to give that attention to the brood nest which will tend to prevent the formation of queen cells.

As soon as the bees are driven from the supers to the brood chamber by a change of weather, more room 
in the shape of empty cells must be given by removing the outside combs and placing frames containing full sheets of foundation in the centre of the hive. The supers may be returned, as they will have the effect of keeping down the temperature, and will also be accessible to the bees immediately the gathering of surplus again takes place.

Nadiring, that is, placing the extra chamber below the brood chamber, will invariably prevent the preparations for swarming, but the brood combs will then be used as receptacles for the surplus honey to a greater extent than is advisable. During the honeyflow, providing there is a continuance of fine weather, storing will go on uninterruptedly, consequently additional supers after the first must be given. Each extra super should be placed between that or those already on and the brood chamber, so that the honey may be ripened in the new combs and then carried above to complete the upper super or supers. 


\section{CHAPTER V.}

\section{RACES OF BEES.}

As the development of bee-culture progressed, the most advanced or the most expert bee-masters looked around for a means of improving the native English black, or, as it is commonly called, the German brown bee. To this end stocks, swarms, and queens have for a great number of years been imported from various parts of the European continent and the shores of the Mediterranean Sea. That in and in breeding causes the deterioration of stock is well known, and it is equally true that unless fresh blood be introduced from districts beyond bee-flight, so as to avoid the evils of consanguineous intercourse, an enfeebled race of bees is inevitable.

Imported bees may be divided into two kinds, the yellow-banded (Ligurian, Cyprian, Syrian, and Holyland), and the silver-banded (Carniolans).

\section{The Ligurian.}

The first foreign bees to attract the notice of English bee-keepers were the Ligurian (Apis Ligustica), or 
Italian Alp bees, which show the three upper bands of the abdomen a bright yellow. This peculiarity, though generally found to exist, is subject to variation, and occasionally Ligurians are inclined to be leathercoloured. This may be, and most probably is, due to crossing with bees that do not show the yellow bands.

The first Ligurians to reach these shores were two queens sent by Mr. Hermann, a Swiss bee-keeper, one to Mr. T. W. Woodbury, and the other to Mr. A. Neighbour, on August 3rd, 1859. From that time queens and swarms, particularly the former, have been imported annually.

Whether the object, improvement of the native bee, has, by the introduction of these bees, thereby been attained, is a point upon which opinions vary, many deciding in the affirmative, though some beekeepers maintain that the only effect perceptible has been to increase the irritability of the native bees. This is a charge that in varying degree may be laid upon any race introduced, as the crossing of races may, and undoubtedly does, result in many instances in the stinging capability of the bee being increased, though at the same time it has frequently been noted that the worst stingers have almost invariably been the best workers.

The testimony of many famous bee-keepers, among whom may be mentioned the late Rev. G. Raynor and Mr. T. W. Cowan, is decidedly in favour of this race, not only on account of the advantages resulting from crossing with the native bee, but chiefly on account of its ability to gather honey from flowers from which the 
native bee, owing to its having a shorter tongue than the Ligurian, cannot extract the coveted nectar.

Ligurians are very prolific and have had a great influence on the native bee wherever introduced. They are superior to the natives when stocks are being worked for extracted honey, but when storing in sections the capping is too close upon the honey, and consequently the comb has a dark and damp appearance.

\section{Cyprians.}

These handsome bees were first introduced into this country, and the continent of Europe generally, in 1880 by Mr. Frank Benton, who wrote of them as follows:- "They are smaller and more active than the Ligurians, and exceedingly prolific, and excellent honey-gatherers. A stock of Cyprians belonging to Mr. B. F. Carroll, Dresden, Texas, in 1885 is said to have gathered that season 1,000 lbs. of honey." $\mathrm{Mr}$. Benton afterwards wrote, "Cyprians are the bees for the skilled specialist."

My experience of this race is sufficient to enable me to warn bee-keepers against introducing into their apiaries the most beautiful but at the same time the most irritable of all races of bees. At times, when bee-keepers have visited my apiary, I have exhibited pure Cyprians without veil or intimidant, but on other occasions it was apparently sufficient to show one's self in the garden to have a warm reception from the Cyprian or Cyprian hybrids. This, therefore, is a race that bee-keepers will do well to let severely alone. 
The Holylands are found in the Holy Land-hence their name; while the home of the Syrians is further north. Of these bees it may be said that they are somewhat like the Cyprians, and equally to be aroided.

At the time of their introduction to the Western parts of the continent, much was said in regard to their wonderful powers, and much was proved both for and against them. The late Mr. C. N. Abbott, soon after the introduction of these races, recorded a profit from a cross-bred colony of Syrians of $£ 20$ in one season. Their bad qualities, however, showed up so abundantly that the Messrs. Abbott Brothers announced subsequently that they had swept their apiary clear of such truculent pests. It is very rarely that these races from the extreme east of the Mediterranean are now met with, or even heard of, bee-keepers of experience being satisfied with the native bee, the Ligurian, or the Carniolan.

\section{Carniolans.}

These have been called the ladies' bees from the fact that compared with other bees they are much less disposed to sting during manipulations. Mr. E. Cori, of Bruz, Bohemia, first made known the desirable qualities of these bees to Europeans. Mr. F. Benton, who has perhaps had as much experience of this race as any bee-keeper in Europe, remarks that they may be considered a variety of our own black or German bee. Its home is in Carniola, a province in South Illyria, S.W. Austria. Mr. A. Neighbour was the pioneer 
in their introduction to this country; but, though the queens are extremely prolific, and the bees good honeygatherers, they exhibit a most undesirable quality in being prone to excessive swarming.

As desirable qualities may with care be propagated, the undesirable can, of course, in time be eliminated. In filling and sealing sections the Carniolans have no rivals. Judicious crossing with these bees cannot but be productive of good results, though stocks showing the least inclination to swarm, and possessing other desirable qualities, should always be selected for breeding. 


\section{CHAPTER VI.}

\section{SUBDUING AND HANDLING BEES.}

BeEs have a means of defence which they bring into instantaneous use when provoked, and it is therefore wise that a bee-keeper should become acquainted with the peculiarities of bees, their likes and dislikes, and thus be able to manage them with ease while reducing stinging to a minimum. There are frequently individual stocks that show a great propensity for stinging at all times when they are approached; but if such be the case the remedy is clear. The queen must be removed and another introduced, bred in a colony the bees of which are amiable while showing other desirable characteristics. In country districts many an old bee-keeper is looked upon by his neighbours as a great wonder, inasmuch as he goes uncovered amongst his bees and hives swarms without being stung.

The ease with which bees are handled at such times is due to the fact that they are bent upon the object of clustering, preparatory to moving off with their queen to a new home. If hiving takes place as soon as the bees have clustered, or hang in a pear-shaped mass from the branch of a tree, or elsewhere, it is seldom 
that a bee will sting, particularly if they are not roughly handled or crushed. When bees leave the hive as a swarm, they have a two or three days' supply of food on which to exist, and also to use in the formation of wax with which to build combs in their new home.

As it is known that bees are most easily managed at swarming time, and during the honey-flow, it follows that we must endeavour to put them into a similar quiet and apparently contented condition whenever the examination of a colony is deemed necessary. The first step to this end is frightening the bees. This no doubt sounds odd, but it is none the less true; and we find that when bees are frightened they rush to the honey cells and commence gorging themselves with honey. It is when the bees are thus engaged that the examination of the combs may take place. An occasional puff of smoke along the tops of the frames will quiet any bees that show signs of attacking the manipulator. In all operations carried on in the apiary, confidence is essential to success. Without it, jerky movements and clumsy manipulations must occur to irritate the bees.

\section{INTIMIDANTS.}

The commonest method adopted to frighten the bees is by introducing into the hive smoke, produced by burning brown paper, fustian, touchwood, or anything that will smoulder. The bee-keeper who indulges in the fragrant weed has at all times a powerful intimidant. Those who cannot, or do not, use a pipe, must 
invest in a smoker, the price of which ranges from 2s. 6d. to 10 s. $6 \mathrm{~d}$.

The Binghim pattern smoker, as shown in use above, is convenient and very generally used. It consists of a barrel, open at the top to receive fuel, and has a small hole near the bottom, into which a draught is blown by the bellows to which this barrel is attached. A piece of coarse brown paper loosely rolled, and occa-

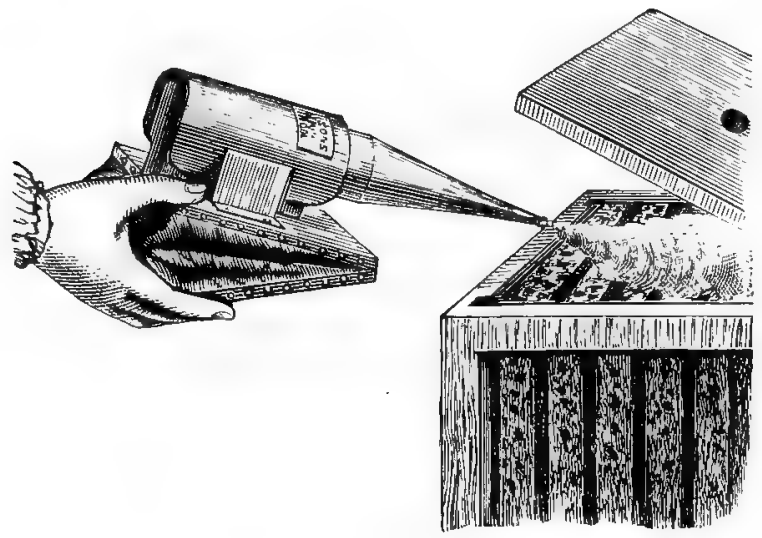

Fro. 5.

sionally doubled back in the rolling, will furnish a capital fuel. The lighted end of the paper or other fuel must be put first into the barrel, otherwise the draught will put out the fire, as has often occurred when the lighted end has been put in last. To keep the smoker alight stand it in a vertical position with the funnel acting as a chimney, and when no longer required in a horizontal position. 
The " Hill" smoker lately invented is thus described: "The fire-hox is three inches in diameter, and when full of good hard chips or bark affords as much fire and smoke as any one can desire. The bottom of the fire-box is solid, not perforated like a grate. The vent is through holes in the side, consequently the bottom holds the ashes, which aid in keeping the smoker alight for a long time when not in use. Its greatest convenience is the ease and readiness with which one can build a fire in it, on account of the ample vent at the bottom. Light a match, stand it up inside the

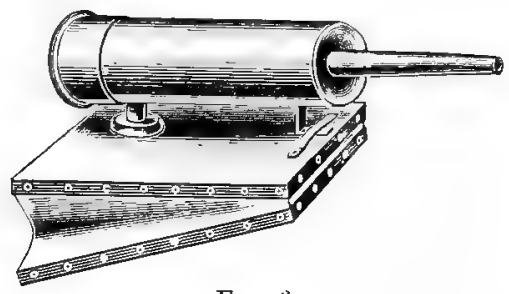

FIG. 6.

fire-box, drop in a few shavings, making them coarse as the fire increases, and finally top with hardwood. Work the bellows and you have a fire before you can read these directions."

In some apiaries it has been found possible to discard smoke altogether since $\mathrm{Mr}$. Webster introduced a means, always at hand, of producing an effective intimidant. The barrel of a smoker (Fig. 6) is made the receptacle for a sponge that has been saturated in a carbolic solution, the recipe for which has not been divulged; but a bottle of the preparation can be purchased for a few pence and lasts some months. 
The carbolic spray, as first used and advised by Mr. Howard, is produced by a special atomiser (Fig. 7) which throws a very fine spray of dilute carbolic acid. By a special arrangement it is continuous in action, and the spray subdues the bees instantly. The solution is prepared by mixing one part of Calvert's No. 5 carbolic acid with twenty parts of water.

Carbolic cloth. The use of carbolic acid as an intimidant was introduced by the late Rev. G. Raynor,

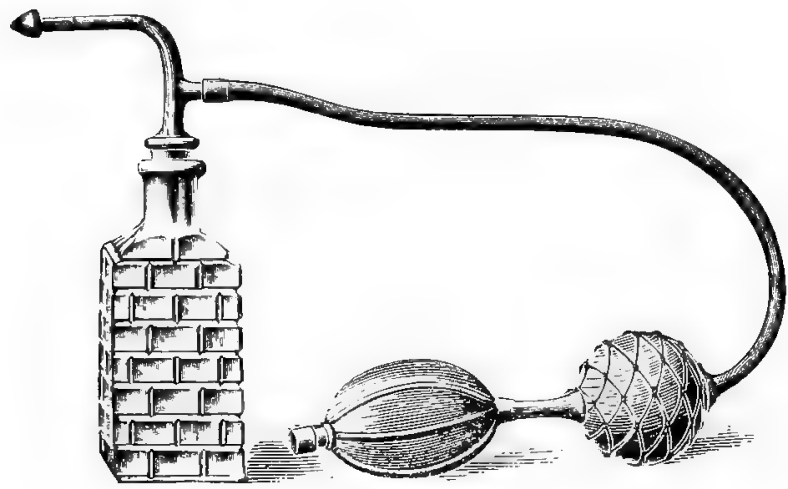

FIG. 7.

who, for a number of years, used in his apiary only carbolic acid and the carbolic solution during manipulations. He was one of the gentlest of bee-masters, and in this respect his example might be more generally copied. His invariable practice, when opening à hive, was to dip a feather into the acid and smear the tops of the frames as he removed the quilts. The bees at once retreated and manipulations were proceeded with. 
For removing supers a solution prepared according to the following recipe was placed in a basin. A cloth saturated with the solution, and then wrung tightly, was placed upon the frames as the quilts were removed. In a few minutes most of the bees would have gone below, leaving the super ready for removal. If, on being removed, any bees are found among the combs, they will quickly leave, provided that the super is placed on end, and the cloth is so hung that the breeze can blow through and carry the fumes among

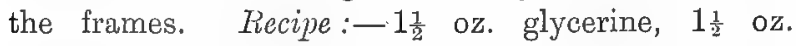
Calvert's No. 5 carbolic acid, 1 quart of warm water. The glycerine and acid must first be mixed and then the water added.

The above quantities of glycerine and acid placed in a three-gill (ordinary wine or spirit) bottle, will, with water added to fill the bottle, make a most effective solution. The glycerine may be omitted, but in that case the bottle must be well shaken, or a solution will not be formed.

\section{Bee-Veil.}

The novice in bee-culture will in all probability commence active operations in fear and trembling, and may feel inclined to protect himself with veil and gloves. Though gloves of various materials are some times recommended, and often used, the practice of covering the hands is strongly deprecated, for as soon as clumsy handling and the consequent jarring of the combs in replacing them in the hive, irritate the bees, stinging commences. The odour then arising from the 
poison ejected by the sting has a most exasperating effect on the colony, and scores or even hundreds of stings may be sheathed in the gloves or other parts of the clothing not capable of being withdrawn by the bees, thus causing a needless loss of bee life. The timid bee-keeper may, however, rub his hands with Grimshaw's apifuge, which, according to the testimony of many who have tried it, has a wonderful effect on irritated bees, in that they decline to sting the part over which this charm has been rubbed.

While there is a strong objection to the use of gloves, there can be none to the use of a bee-veil made of light material, to protect the face. Some bee-keepers neglect even this precaution, the time and manner of their manipulations rendering such protection unnecessary. As a rule a veil should be worn. In fact, the work, whatever it may be, to be performed with an open hive, will generally proceed in a more satis-

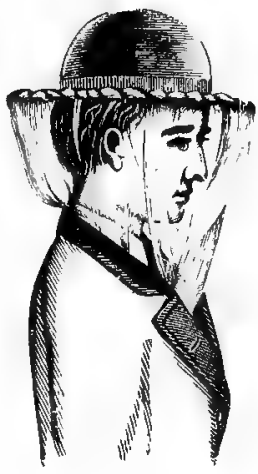

Fiğ. 8. factory manner from the consciousness that the face is protected. Cumbersome dresses should be avoided; a veil of white mosquito net with black silk net front being all that is necessary. Such a veil with an elastic band running through a slot at the top, fits easily round the hat, while the lower part is tucked under the coat, the projecting rim of the hat keeping the veil at a convenient distance from the face, as in Fig. 8. 


\section{Handling Bees.}

Frequenters at agricultural and other shows, where the bee-tent is erected, in which to exhibit and give an explanation of the best methods of bee-management, will know how simple a matter it is literally to handle the driven bees and scoop them up with the hands, like so many currants. It is seldom, however, that the actual handling of bees will be needful, while the moving of frames of one hive or another may be of frequent occurrence. In approaching a hive, attention must first be directed to those bees on guard at the entrance, which a slight puff of smoke will drive into the hive, and also have the effect of preparing the colony for manipulation. The roof and lift must next be removed, the latter in order that the frames may be moved with greater ease. The operator should stand on one side of the hive, with the entrance at his left hand, or at the back, if the frames run parallel with the front of the hive.

When the quilts are rolled back a puff of smoke should be driven across the tops of the frames, but it is not advisable to expose all the frames unless a thorough examination is to be made. When the quilts are removed there will be, as a matter of course, a draught through the brood nest. This may be prevented by turning the "Ivo" entrance block, so as to close the entrance, or otherwise block it up. The bees returning from the fields will crowd at the place of ingress, but, as the hive should be open for a very short time, they may remain there until the quilts are replaced, and the entrance is again opened. 
The judicious use of smoke or other intimidant, for manipulations at a woll-chosen time, and the quick but gentle handling of combs will usually ensure the operator escaping without a sting. The proper time for opening a hive, is when the bees are returning home from the fields with a merry contented hum; and never, if it can be avoided, in cold, stormy weather, or immediately after a storm.

Whenever the hand is stung draw it gently away, at the same time giving the bees and the hand stung a puff of smoke. Then push out the sting with the finger-nail, or rub it out by passing the hand across the clothes, and give a little more smoke to destroy the scent of the poison. A bee-keeper must get used to a few stings, and in time the removal of the sting will be performed so that work is hardly interfered with. Any one who dreads the effect of a sting will do well to follow the advice

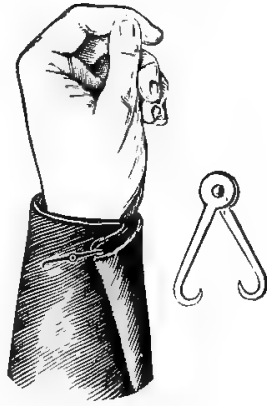

F1G. 9. given above for its removal, and then eject the poison from the wound by pressing the barrel of a small key over the place. If this be done before the poison has had time to spread, after effects and much swelling will thereby be avoided.

\section{Gauntlets.}

During manipulations bees are apt to get up the manipulator's sleeves, when a slight pressure of the 
clothes upon them will cause their presence to be felt. A pair of simple gauntlets (Fig. 9) fastened around the wrists, or the use of sleeve hooks will effectually prevent annoyance from this cause. 


\section{CHAPTER VII.}

\section{HIVES.}

Cottager Hives.

THE results obtained by systematic management are, as may be readily imagined, such as recompense the bee-keeper for expenditure of time and money, and prove the absurdity of the let-alone system that has been so much in vogue. More depends upon the style of hive adopted than is generally supposed, for, whereas a swarm weighing, say 4 lbs., if put into a straw skep, may give a surplus the first season of 20 or $30 \mathrm{lbs}$., and the second season $40 \mathrm{lbs}$. or more, if put into a bar-frame hive, and treated as yet to be explained, under equally favourable circumstances, it might be expected to give 40 or $50 \mathrm{lbs}$. the first season, and 50 to 100 or more the second year. Many cases might be quoted to prove that when bee-keeping is taken up with a view to profit, the style of hive to adopt requires very careful consideration.

To many cottagers and labourers, whose ideal hive is the straw skep, advice on the more advanced systems of bee-culture will be, at any rate for a time, 
of little use, and therefore, in order that each class of bee-keeper may receive benefit by the perusal of this work, three styles of hives on the different systems of bee-culture will be described. All hives are kept on the fixed or movable-comb principles.

\section{Fixed-comb Hives.}

The straw skep. The original dome or conicalshaped skep is fast going out of fashion, as the manufacturers of straw hives find the demand now wholly for those of a more modern pattern, upon which supers may be used. In such receptacles the surplus honey may be stored in its purity, and remain free from any contamination. Fig. 10 shows the parts required to manage bees properly on the skep system.

The floor-board should be made of stout boards and clamped to prevent warping. If the alightingboard, which should project at least four inches and be slightly bevelled, be fixed under the floor-board, the entrance may be cut in the latter, as shown. This is preferable to cutting away a part of the lower rim of the hive, in order to form the entrance. The hive $(a)$ is termed the brood-chamber, because it is the hive in which brood-rearing is to be solely carried on. The queen does frequently enter the super and spoil the combs by depositing in them eggs, but that is generally due to bad management. The dimensions of the brood-chamber and supers here given will be found to produce a hive suitable for any ordinary district.

If this system of bee-keeping is adopted, one brood- 
chamber and two supers must be provided for every colony of the dimensions given below, each having a hole in the middle of the crown about three inches in diameter. The brood-chamber is sixteen inches in diameter and ten inches deep, the supers $(b)$ and $(b)$

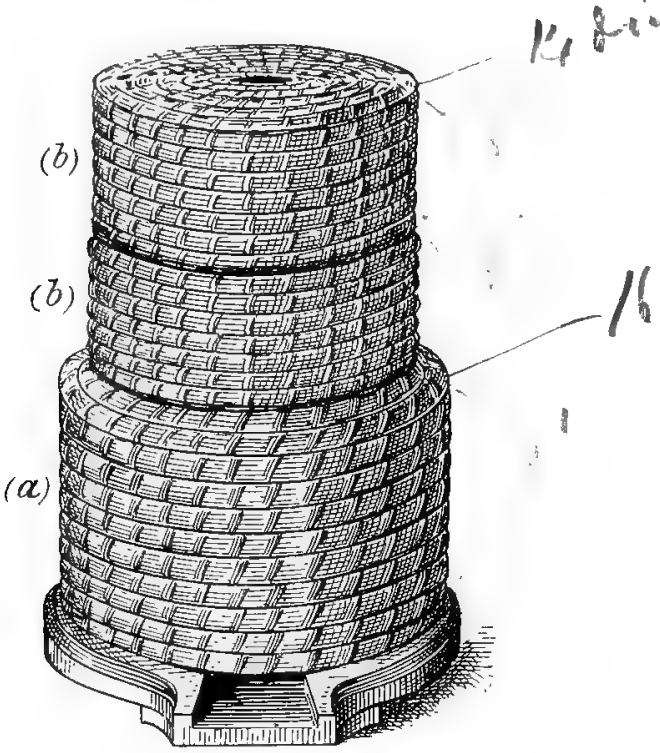

FIG. 10.

being fourteen inches in diameter and six inches in depth. All dimensions are outside measure. If all stock hives and supers are respectively of exactly the same size 'throughout the apiary, any super may be placed upon any stock hive, or above or below any other super. A coat or two of paint on the stock 
hive, particularly on the bottom ring of straw, will considerably lengthen the period of usefulness.

Management. The floor-board, placed upon four bricks, should first be set perfectly level both ways, and then, to secure the combs being built from front to back, the floor-board must be raised slightly behind, as the direction of the combs depends upon the pitch of the floor-board, and not according to the preference of the bees.

Some bee-keepers who have found numerous cases of combs in skeps, running from side to side, state that the system of hanging frames in bar-frame hives parallel with the front is to be preferred, because bees choose that method of building their combs, and therefore the preference of the bees should guide the beekeeper in fixing the direction in which the frames should hang in a movable-comb hive.

If wooden tops are provided for the skeps, four holes $\frac{3}{8}$ inch wide, 8 inches long, and $1 \frac{1}{4}$ inches apart, should be made in the middle. By placing the brood-chamber so that the openings in the crown-board run from side to side, the bees will be compelled to build their combs across the openings and from front to back, thus increasing the ease of access from the brood-chamber to the super, while to some extent doing away with the inducement for the queen to enter the super, which a large central hole affords.

Hiving the swarn. When the floor-board has been set as directed, the skep may be removed and the swarm hived into it. As soon as the bees have settled the skep must be moved on to the floor-board with great care so as not to disturb the cluster. As the bees carry 
with them a plentiful supply of honoy with which to start in their new home, food should be given sparingly unless untoward weather prevents their leaving the hive. In that case a liberal, but not too rapid, supply is needed. Should food be deemed necessary a supply of Porto Rico sugar will furnish the best means of saving the lives of the bees, and assisting them in the building of new combs.

When to super. Too often stocks and swarms are allowed to remain days and even weeks without supers, a practice that should be abandoned, for, not only is there a loss, and sometimes a great one, but, by the storing of surplus in the brood-chamber, the queen is "crowded out"-that is, the cells in which the queen should be depositing eggs are used by the bees for the storage of honey. The consequence is that, at the end of the season, such a stock will contain a very large amount of honey, but a very small number of bees, mostly old ones. Thus the progress of the colony the following spring will usually be unsatisfactory. As soon as a swarm is hived into an empty skep the bees cluster, and having obtained a sufficiently high temperature commence secreting wax with which to build their combs. The combs should, in the main, be composed of worker cells, otherwise a superabundance of drones each summer while the hive is in use will be inevitable.

Building combs of worker cells alone by the swarm will continue if the income of food is only moderate, but if the honey-flow is on, and there is a large inflow of honey, the bees will build combs mostly of drone cells for storing purposes. The necessity for a means 
of compelling the bees to build combs composed of worker cells only is manifest, and must be accomplished by the use of foundation, for which a provision is made in the hives next to be described.

In about a week or ten days after hiving, a strong swarm will have filled three-fourths or more of the brood-chamber with combs. If a super is then placed on the hive with the needful precaution to prevent the escape of heat, the bulk of the daily income will be carried above and deposited in combs mainly composed of drone cells. The building of drone comb in the super for the storage of surplus is economical to the bees, and immaterial to the bee-keeper. Below, in the brood-chamber, the combs will be kept for breeding purposes, and they will be completed with worker cells as a rule. The advantage of this method of procedure will be seen in the full supers and the crowded broodchamber at the close of the honey-flow.

In supering, swarms and stocks are similarly treated, and when strong colonies are supered early in the honey-flow the second super, supposing there be a continuance of fine weather, will be required in a very few days after the first has been given. In the case of a stock a second super will generally be necessary to prevent swarming, inasmuch as the bees when crowded commence building queen cells, with a view to swarming, as soon as the ordinary cells in the hive are occupied, whether it is with bees, grubs, honey, or pollen.

This moving out of the worker bees in search of a new home may be avoided by supplying a second super under the first. Give a gentle puff of smoke at the entrance to the hive, and then gently separate the 
super from the brood-chamber. To keep the bees quiet puff a little smoke in between the super and the brood-chanber as the former is raised. Lift up the super and place between it and the brood-chamber another super. More room having been given the bees will concentrate their energies upon furnishing the lower super with combs. In the new combs much of the freshly-gathered nectar will be stored for ripening previous to being carried above to complete the upper super.

Remoring supers. As soon as the upper super is completed it should be removed and placed on the super clearer, and, when emptied first of the bees and subsequently of the honey, it may be returned to the hive for placing below the remaining super or on any hive where more super room is required. Should the honey-flow be on the wane, when the top super is removed the lower super should not be interfered with, unless it is to give a little extra covering with sacks or other heat-retaining material adding to the protecting power of the straw. The bees are then more likely to complete work in the super instead of being driven down into the brood-chamber by the lowering of the night temperature.

\section{The "Iro" Cottager Bar Hive.}

The second style of hive which may be adopted is still on the fixed-comb principle, but greatly ahead of the skep, in that the results obtained by its use may, by the use of foundation, be increased to a very great extent. What may be done by a stock in a straw skep is well known by bee-keepers of experience. In order 
to show the superior results of working with this style of hive, a record of a late swarm may not be out of place.

A strong swarm was put into a hive, properly prepared with foundation, on June 23, 1892. On June 26th the foundation in the brood-chamber, and also that in the super, was found worked out by the bees into perfect

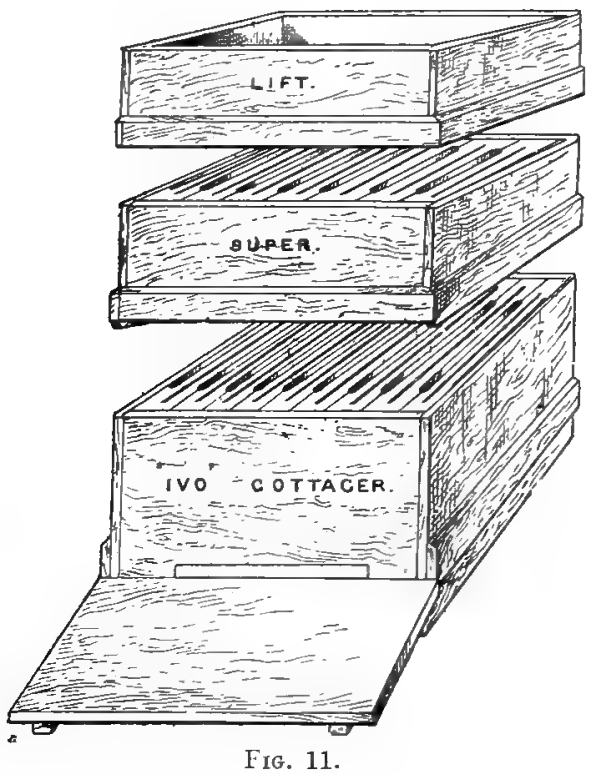

combs; and in the super there was even then a fair quantity of honey stored. At the end of the honeyflow the net weight of honey taken from the supers was 37 lbs. 4 oz., and an ample supply for winter use was left in the brood-chamber. In 1893 the stock sent out a 5-lb. swarm, and as the hive was standing in a 
garden two miles away, another hive had been placed ready for a swarm in case one issued. The lady, in whose apiary the hive stood, sent for a shoemaker to hive the swarm. Being one of the old school who cannot bear the "new-fangled notions," he took the foundation out of the bars, made a ball of it, and threw it into a pan as useless. He then hived the swarm, giving the bees access to super as well as brood-chamber; in fact the hive from floor-board to roof was at their service. When examined a few days later crooked combs were found in the brood-chamber far too advanced in building to be disturbed. The bees were, therefore, driven out of the super, so that they might first complete the combs below. This they did, and at the end of the season the honey-return from the supers was as follows: from the stock hive $51 \mathrm{lbs} .14$ oz., and from the swarm $27 \mathrm{lbs} .1 \mathrm{oz}$.

Here is a most significant fact. While the stock hive, after sending out a large swarm, stored in supers nearly $52 \mathrm{lbs}$, the swarm gave about half the quantity, though combs in the brood-chamber had to be produced in the ordinary way from wax which the bees secreted. $\mathrm{Had}$ the hiver of the swarm allowed the sheets of foundation to remain in the bars of brood-chamber and super, the bees would have had honey representing more than a week's work to carry into the super, producing a total surplus that must have equalled if it did not considerably exceed that stored by the stock.

The "Ivo," which has been designed by the writer, is intended to take the place between the straw skep and the bar-frame hive. It is an undoubted fact that many bee-keepers who have been induced to adopt the 
bar-frame hive have managed their bees so unsuccessfully that they have given up bee-keeping in disgust. Their want of success was not, however, due to the system of bee-keeping which they adopted, but rather to the want of acquaintance with the methods of working such hives successfully. Although, taking one season with another, a fair profit may be obtained by managing bees properly in skeps, the full benefit of the work of the bees can only be obtained by the use of foundation; and it is with that one object primarily in view that this hive has been designed.

The hive consists of floor-board, brood-chamber, supers, lift, and roof. Two supers will at all times be necessary, but three may be needed in good districts. The brood-chamber consists simply of four walls, the front and back being $\frac{7}{8}$ inch in thickness, and the sides the same or $\frac{3}{4}$ inch. The tops of the front and back walls are rabbeted inside to admit the ends of the bars, and allow the tops to lie level with the tops of the walls. In other words, when the bars are in position the top of the hive should present a flat surface being broken only by the $\frac{1}{4}$-inch openings between the bars. The depth of the walls is eight inches.

Supers. The supers are in all respects, except depth, similar to the brood-chamber. The depth is only $4 \frac{1}{2}$ inches for the following reasons: (1) Shallow supers are more readily entered by the bees; (2) when full they are more easily moved by the bee-keeper; and (3) because, though the hive is to be worked for run honey only, the supers will be of a size to be converted into crates for sections in a few minutes.

Lift. This is an absolute necessity with all wooden 
hives in which the tops of the frames are level with the tops of the hive sides. It allows of quick and secure packing of quilts, and it also raises a shallow roof sufficiently to allow of a feeder being placed above the frames. The lift for this hive is simply a super without the bars, which may be used whenever required.

Bars. As the combs in both brood-chamber and

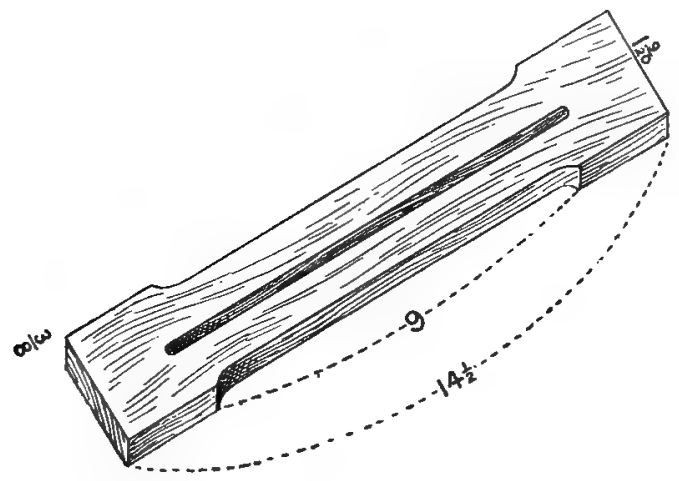

Fig. 12.

supers are, when built, to be attached to the front and back walls, bars, not frames, as in the movable-comb hive, are provided.

The bars are $14 \frac{1}{2}$ inches long, $1 \frac{9}{20}$ inches wide, and $\frac{3}{8}$ inch thick. In the centre of the bar, and running nearly from end to end, is a saw-cut to receive the sheet of foundation. The ends of the bars only are $1 \frac{9}{20}$ inch wide, and they fit close together so that the combs when built will be the correct distance apart, 
viz., $1 \frac{9}{20}$ inch from centre to centre. On each side of the bar a piece 9 inches by $\frac{1}{8}$ inch is taken out, so that when the bars are in position there will be access to the supers through holes 9 inches long and $\frac{1}{4}$ inch wide.

After the hive is stocked with bees and the combs are built, the brood-chamber should never again be interfered with except to renew old combs. If any examination of the interior of the brood-chamber should be deemed advisable, it must be inverted and treated as are the fixed combs in a straw skep. To remove combs, each end alternately of the hive should be raised to an angle of about $45^{\circ}$ to allow of a knife being passed from side to side to sever the comb attachments. On returning the hive to the horizontal position, the bars with the combs attached are easily removed, and others prepared with foundation may at the same manipulation be placed in the vacant spaces.

The bars as described above are for use in the brood chamber alone; those for use in the supers are $1 \frac{8}{7}$ inches in width. Wider bars are provided in the supers because when storing surplus, bees invariably build combs much thicker than those used for breeding purposes. The width of the brood-chamber and supers is 13 inches full, to accommodate in the former nine narrow bars and in the latter seven wide bars.

Preparing the hive. The first thing to be done after making or purchasing, with the necessary parts, a hive of good sound material well and accurately put together, is to give two or three coats of white or a lightcoloured paint. It is an error to think that any coloured paint is suitable for bee-hives. Probably any coloured 
paint of good quality will be equally effective for the purpose of protecting the wood from the effect of weather, but whether the paint shall be coloured or white is a very important matter to the bee-keeper. Black is the worst of all, because that colour is known to absorb the heat rays of the sun. Hence the lighter the colour the less influence will the sun have upon the hive and its contents. This question may be tested by any one placing in the rays of the sun, on a hot summer day, a board, half of which is painted white and half black. After being exposed for some time it will be found, by applying the palm of the hand first to one half, then to the other, that the black part has absorbed more of the heat rays than the white, and is therefore hotter. Mr. A. I. Root, one of the foremost of American bee-keepers, some years ago, in reply to. a correspondent who complained of the heat melting the combs in his hives, said that he had met with the same trouble, but that since he had painted his hives white he had not had a single break-down from that cause.

The next step in preparing the hive for the swarm is to fit sheets of foundation into the bars. The sheets of foundation, as received from the manufacturers for fitting into the frames for the movable-comb hive, measure, or should measure, $13 \frac{1}{4}$ inches wide by $7 \frac{3}{4}$ inches deep. If each sheet be cut into two pieces $4 \frac{3}{8}$ and $3 \frac{3}{8}$ in depth, the former, when fitted into the narrow bars for use in the brood-chamber, will hang down 4 inches, and the latter, placed in the wide bars for the supers, will hang down 3 inches. In the brood-chamber there will then be a space below the 
foundation of over 3 inches. The building of drone comb in this space from the bottom edges of the foundation will be prevented, should the honey-flow be at its height, first by the giving of a super, but in addition and effectually by a board, or two inch-boards clamped together, to cover the bottom of the hive except for about half an inch in the front. This block, or false bottom, will have the effect of crowding the bees upon the sheets of foundation thus accelerating the work of comb-building so much that the first super might be given on the evening following that on which the swarm was hived. The queen will by that time be busy depositing eggs in the newly worked-out combs, and be less likely to go into the super with the rush of worker bees. But all fear of the queen leaving her own compartment may be avoided by using a sheet of queen-excluding zinc (Fig. 34) upon the bars of the brood-chamber.

As soon as the super becomes warm, by the heat ascending from the brood-nest, the bees will commence work in it, and in a few days, when they are working well, the hive might be lifted gently off the floor-board to allow of the false bottom being removed. As the bees will then be busily carrying their surplus stores into the super, brood-rearing will be continued below, and combs of worker cells will be extended downwards nearly to the floor-board. This may be confidently expected if the queen is a young one. A second super will, in all probability, be required even with a swarm, and if strong and hived early in the season, there is no reason why, with fine weather and abundant forage close at hand, it should not give three supers or 75 lbs. 
The first super must never be quite completed before the second is placed between it and the brood-chamber, otherwise preparations for swarming will be commenced.

Removing supers. These supers may be cleared of bees by placing them on the box-clearer or by raising the super to be removed and placing under it a cloth to sever the connection between it and the lower super or the brood-chamber, if only one super is on the hive. See Chapter XI.

When the super is raised, one or two of the combs may occasionally be found attached to the bars below; and the force exerted in raising the super will cause a piece of comb to be broken off. Should this happen, puff a little smoke under the super or place it over a board that has been slightly sprinkled with dilute carbolic acid. The fumes of the acid will keep the bees in the super while the pieces of comb are being removed from the bars of the brood-chamber with a knife or spatula. The dripping honey and comb should be put along with the knife into a can provided with a lid, so that robbing is not induced while the cloth is being spread and the super returned. The bees in the super, finding themselves cut off from the broodchamber, will be in great commotion, and glad to escape by the perforated zinc cone placed in the roof.

When free of bees the super may be removed to the house and then tilted up to allow of the comb attachments being severed with a knife. The bars may be lifted out with the combs attached, then holding a bar by one end pass a sharp knife downwards close to the 
bar to cut off the comb, which allow to fall into a pan. The combs should then be sliced with a knife and put into a sieve or strainer in order that the honey may be drained therefrom. The broken combs when melted

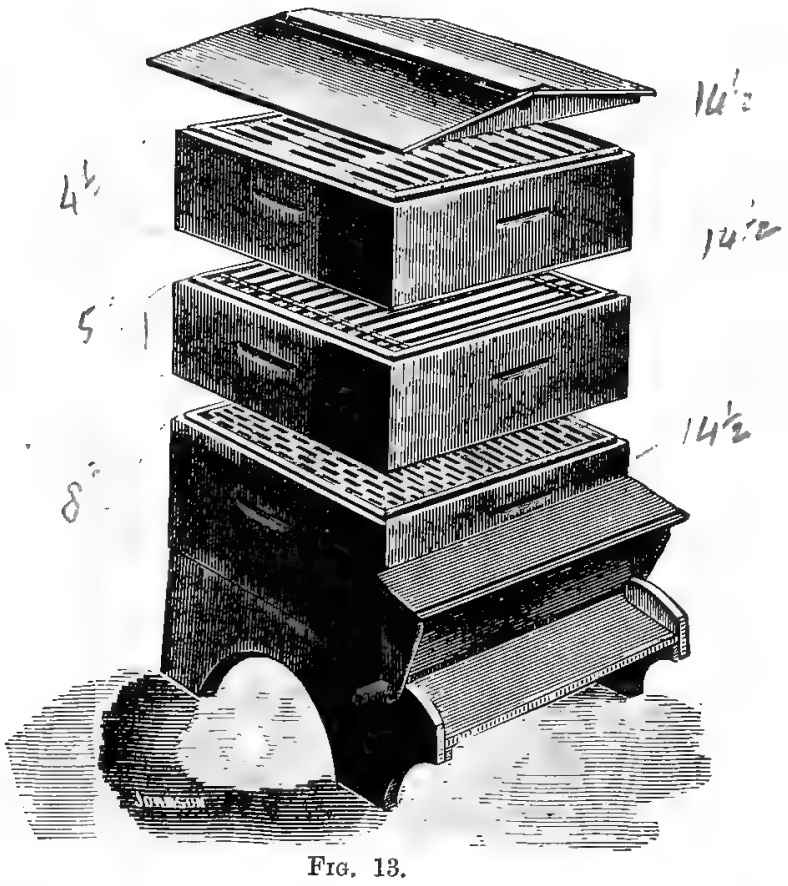

will produce more wax than will pay for the foundation which must be inserted in the bars each time a super is used.

Amateur Hives.

The movable-comb system. The bee-keeper who 
decides to keep bees on this, the most improved of all systems of bee-culture, will be puzzled as to which pattern hive to select, out of a multiplicity of styles shown by various manufacturers. He will do well to insist on having his hives made of well-seasoned wood, and accurately put together; at the same time aiming at simplicity of construction. The cheapest hives are by no means the best; very often such wares prove to be "cheap and nasty." The movable-comb hive is

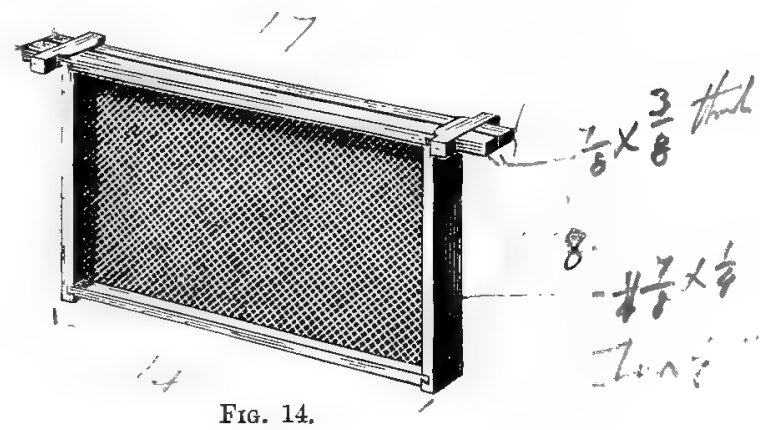

attributed to the inventive genius of the Rev. L. L. Langstroth, the pioneer of bee-culture in America.

In England, the first frame hive that came into general use was the "Woodbury," named after the designer, Mr. T. W. Woodbury, who was not slow to recognise the importance of the movable-comb system. This hive was $14 \frac{1}{2}$ inches square and 9 inches deep, and the frames were 13 inches long and $7 \frac{1}{4}$ deep.

Frames. Up to 1882, when the British Bee-keepers' Association, through their Committee, gave the dimensions of what has since been known as the British 
Standard, frames of various sizes were in use. The inconvenience of so many different sized frames induced the Committee of the British Bee-keepers' Association, in the interest of bee-culture, to consider and resolve upon the most convenient sized frame for general use.

The following Committee was appointed: Messrs. C. N. Abbott, T. W. Cowan, F. Cheshire, J. G. Desborough, J. M. Hooker, A. Neighbour, Revs. G. Raynor and F. T. Scott, and the result of their deliberations was that the frame should be $14 \times 8 \frac{1}{2}$ outside measure, the top bar being 17 inches, thus extending beyond the sides at each end and affording, by the projection, an easy means of lifting the frame. The width, $\frac{7}{8}$ inch, and the thickness of the wood as follows : top bar $\frac{3}{8}$, side-bars $\frac{1}{4}$ inch, and bottom bar $\frac{1}{b}$ inch. The advantage of a standard frame cannot well be over-estimated, for by its use stocks may be quickly changed without trouble or inconvenience into new or clean hives, frames of honey or brood may be given to stocks requiring such help, and, above all, stocks on frames, particularly if the foundation has been wired, may be sent from one apiary to another or to any part of the country.

Shallow frames. In addition to the standard frame, which should be used exclusively as a brood frame, a shallow frame, $5 \frac{1}{2}$ inches deep, really the standard frame 3 inches less in depth, as recommended and first used by Mr. W. Broughton Carr, is now extensively used in most apiaries on stocks that are worked for extracted honey. Mr. Carr first advised that two sets of shallow frames should constitute the brood-chamber, 
but some years' experience resulted in a return to a brood-chamber furnished with standard frames which would give a compact brood-nest.

Distance-keepers. As the combs are built in frames $\frac{7}{8}$ inch thick, various devices are adopted to keep the combs the proper distance apart. Mr. C. N. Abbott, in connection with his well-known combination hive, introduced the wide-shouldered frame, with which the hives still sent out by Abbott Bros. are fitted. The top bar is cut in such a manner that a shoulder to act as a distance-keeper is left on alternate sides.

In addition to this provision for keeping the frames at the correct distance apart there is also, by reducing the thickness of the bar, at each end on the underside,

\section{FIG. 15.}

what may be termed a shoulder, fitting exactly inside the inner walls which stand $14 \frac{1}{2}$ inches apart. There is then the necessary $\frac{1}{4}$ inch space between the ends and the hive walls. These frames are all that can be desired in the hands of a careful bee-keeper. Propolis, with which the bees busy themselves in cementing all cracks and crevices, becomes a nuisance when by careless fitting it finds a lodgment between the frame and the shoulder of the next frame.

The next contrivance as a distance-keeper, which attracted much attention, was the metal end designed by Mr. F. Lyon. Of metal ends there are now many varieties, though in their main features they are very similar. The end is made to slide over the end of the 
top bar, and is kept in position either by a slight top bar, as in Fig. 14, or by projections on the inner sides which press into the side of the top bar (Fig. 16).

The above metal ends have very generally given way before the tin ends known as the "W. B. C." (Fig. 14), MIr. W. Broughton Carr having designed these ends so that they could be made out of one piece of tin, and be easily slipped on the end of the frame. If

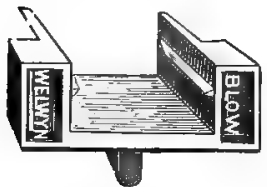

FIG. 16. pushed close up to the side bars the frames are kept $1 \frac{9}{20}$ inch apart.

For various reasons it is thought desirable by some bee-keepers to be able to space frames $\frac{1}{4}$ inch apart. To do this the alternate ends of this pattern are pushed back a little towards the end of the bar, and when the frames are pushed together the metal ends overlap each other, and a distance of $\frac{1}{4}$ inch only between the frames is obtained.

\section{The Howard Exd.}

The Howard metal end, which differs somewhat from the "W. B. C.," was introduced to meet the following requirements: " 1 . To reduce the brood-chamber surface so that an ordinary section rack may be used between the walls of an extra body when storified, as a lift, so that the escape of heat and bees is rendered impossible. 2. That every frame shall be kept distanced strictly within the inside of the hive, thus entirely preventing propolisation on the resting surface of the underside of the frame, and-3. That the bars may be kept at right angles to the top bar." 


\section{Belu-Stiples.}

A very effective and at the same time economical distance-keeper is the bell-staple. This is the only kind now found in "Ivo " apiary. It should be made of fine wire, and driven into alternate sides of the top bar, horizontally, just above the side bars. By using a gauge the frames are quickly prepared with these distance-keepers. Beginners adopting the movablecomb system of bee-keeping should certainly use some kind of distance-keeper, for if hives are moved about, or the frames are spaced carelessly with the eye, complications are almost certain to arise.

\section{The "Ivo" Simplicity Frane Hive.}

Hives of accurate workmanship and in every way satisfactory may be obtained from well-known manufacturers of bee appliances, but there are many beekeepers who, through the interest they have in the work, or with a view to lessen the expense, wish to make their own hives.

This will be found to be a type of hive suitable for general use. The inside dimensions only are given, so that the thickness of the wood may be left to the bee-keeper. At the same time it is well to point out that only pine or red deal, not less than 5 inch thick, should be used. In its complete form the hive will consist of floor-board, brood-chamber, supers, lift, roof, and entrance block. The brood-chamber is 15 inches from side to side and $14 \frac{1}{2}$ inches from back to front between the inner walls. The distance between the outer walls is 17 inches full, 
to allow the top bar to fall in, and, not having much play, keep the distance of $\frac{1}{4}$ inch between the frame ends and the hive sides. The inner walls are $8 \frac{1}{2}$ inches deep, including the metal runners, which are $\frac{1}{4}$ inch in depth. The outer walls are $8_{8}^{7}$ inches deep: the frame ends then rest on the runners of the inner walls, and the tops of the framęs are level with the tops of the hive sides. Between the bottom bars of the frames and the floor-board there will be a space of $\frac{3}{8}$ inch. A full entrance is given from side to side by cutting off the front outer wall $\frac{3}{4}$ inch, and off the inner front wall $\frac{3}{8}$ inch. Between the two walls there will be a space to be filled with a plain piece of wood, but that used between the front walls at the bottom must be cut so as to be level with the bottom of the inner wall, and in the front leave a space $\frac{3}{4}$ inch square. This space is to receive an entrance block, in which holes of 2 inches and 6 inches in length, by $\frac{3}{8}$ inch deep, are cut on alternate sides. The 2 -inch entrance is for use in the spring and autumn; the 6-inch entrance for winter, if a wider entrance for efficient ventilation is thought desirable, and also for summer, while by removing the block the full entrance may be given during the honeyflow. Porches are dispensed with, as they are no more required on a movable-comb hive than they are on a skep. The illustration (Fig. 13) will assist the amateur in carrying out the instructions for making a typical tiering hive, that is, a hive so arranged that the surplus chambers are placed above the brood-chamber, and may be fitted above or below each other as required.

Supers. For this hive the supers are in all respects, except depth, and in being without entrances, exactly 
the same as the brood-chambers. They are made to accommodate frames $5 \frac{1}{2}$ inches in depth, and as there must always be a space of 3 inch below the frames, the depth of the super will be $5 \frac{7}{8}$ inches.

The lift is 6 . inches deep; but if sectional supers are to be used instead of shallow frames, another lift 9 inches in depth will also be required in order that sufficient accommodation for an adapting board, three crates of sections, and quilts may be provided.

\section{Metal Runners.}

Metal runners are strongly recommended, for if the inner walls upon which the frame ends rest are simply bevelled, the top bars will be fastened to them with an abundant supply of propolis, and then jarring the hive and disturbing the bees during manipulations cannot well be avoided. On the other hand, by the use of metal runners, frames are moved with the greatest ease, either singly or in numbers, and the irritation of the bees is thus avoided. 


\section{CHAPTER VIII.}

AIDS TO SUCCESS.

\section{Foundation.}

Next to the invention of the movable-comb hive nothing has tended more to the development of the bee-keeping industry than the invention of comb-foundation. When it became known that the production of wax meant the consumption of a large quantity of

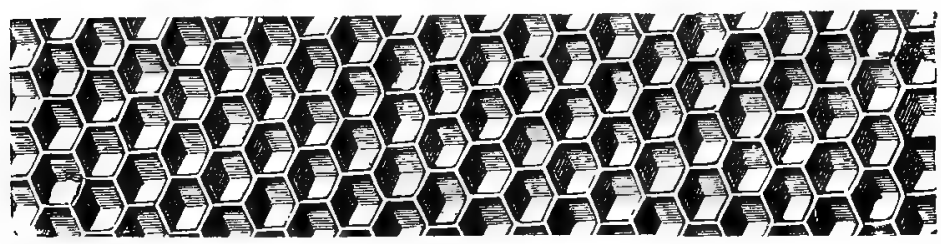

Frg. 17.

honey, as well as a large expenditure of time and energy on the part of the bees, bee-keepers cast about for a more economical method of comb production. Wax guides were first devised-more, however, as a means of guiding the bees in the building of combs from bars in a regular manner than to save the honey needed for the secretion of wax. 
The next step was the production of casts or moulds with which the first sheets of foundation were produced. The late Frank Cheshire in his great work records that a swarm, hived upon ten of these sheets of foundation, in sixty-two hours from the time of hiving converted them into perfect combs. This method of producing foundation was tedious and slow work, and it was before long superseded by elaborate machinery.

The first foundation machine was invented by a

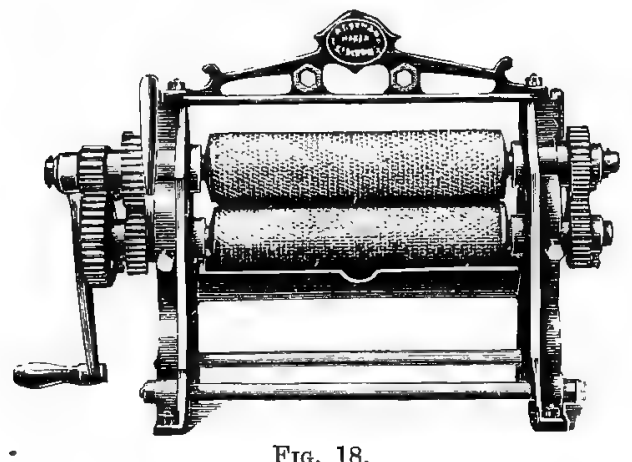

German in 1857, but it was left to Mr. A. I. Root in America to make the manufacture of these machines a commercial success. The first foundation mill used in America was in 1861, and two years later saw their introduction into Great Britain, Messrs. Raitt in Scotland and Neighbour in England being the first to manufacture foundation for the market. There was, and still is, much complaint respecting the difficulty of obtaining uniformly successful results, both by producing 
evenly filled frames and preventing breakdowns. To remedy this, and secure the building of regular and perfect combs, Captain Hetherington, in America, the owner of the largest apiary in the world, invented flat-bottomed wired foundation. Wired foundation, known as the Van Deusen, because patented by Van Deusen and Son, of New York, has been extensively used in America, but not to any great extent in this country, owing to the cost, about 3s. per lb. There are in "Ivo" apiary, now in use, several

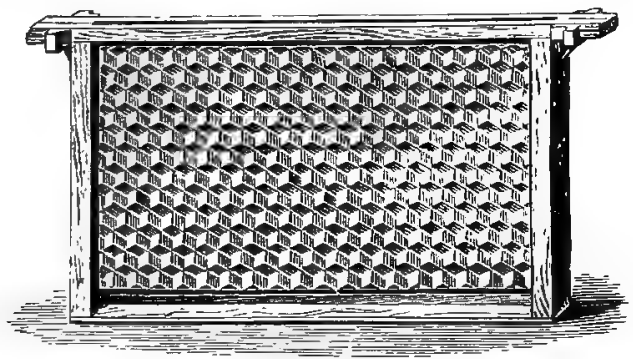

Fig. 19.

frames of comb worked from this foundation more than ten years ago; and though combs may be found in many apiaries that have been several years in use, it is best to renew them as soon as, by continual use, they become overloaded with pollen, or have in the cells too great an accumulation of cocoons left by the young bees.

Supposing the cells to be used only three times in a season for the raising of brood, the number of cocoons left behind will in course of time very greatly diminish 
the size of the cells. It may therefore safely be said that five or six years is a sufficient length of time to allow combs to be in regular use.

In advising the use of foundation, full sheets must be insisted upon as the most economical, for if starters, that is, sheets only an inch or two in depth, be given, drone cells in abundance will be produced, particularly if the hiving of the swarm takes place in the middle of the honey-flow. In an apiary several stocks were examined by an expert in 1893. Two or three in movable-comb hives had for several years done literally nothing; while from one close by, a very satisfactory quantity of honey each year had been taken. The owner, a lady, could not account for this difference, as she took little interest in the apiary; it was, therefore, left to the expert to explain matters. His task was an easy one, for visiting the apiary on a fine summer day he saw, before opening the hives, the bees freely on the wing. From the hives that had such a bad record issued hundreds of drones, while matters were exactly reversed when the hive with the good record was examined. On opening the former hives nearly the whole of every comb-that is, excepting about two inches from the top made from the starter of foundation-was composed of drone cells. In such hives good returns could not be expected, for there always was a superabundance of drones instead of the desirable workers. In the other hive the swarm had been provided with full sheets of foundation, simply because the preparations were made by a friend, a clergyman living near by, who was a successful bee-keeper. 
Foundation, as supplied by dealers, is usually made about six sheets to the pound, though for wiring sometimes nine are used. Thin or super foundation is rolled out until one pound of wax will give sufficient surface to be cut into from 100 to 110 squares, each fitting into the 1-lb. sections, and $4_{4}^{1}$ inches square.

Fixing foundation securely in frames was first accomplished by simply attaching the top sheet to the underside of the top bar with melted wax. This slow and insecure method gave place to a saw-cut run along and through the top bar nearly from end to end, as advised by Mr. Cowan, and this plan was quickly and generally adopted. Various methods have of late years been devised for holding the foundation securely in the top bar, while doing away with the opening above the foundation, in which the wax grub is frequently found; but no method, save wiring, is as reliable as that by fixing in the saw-cut.

To fix the foundation proceed as follows:-Place the sheet on a board, cut off the corners, and take a small triangular piece out of the middle of the top. Then press with the flat part of a knife about two inches of the top of the sheet near the ends. Next take a small screw-driver, not more than $\frac{1}{4}$ inch in width, fix it in the centre of the top bar, and turn it at right angles to the saw-cut, or about a quarter round. It will then remain holding the sides of the bar apart, and the sheet of foundation as prepared may, with ease, be lifted up into the saw-cut. As soon as the top of the sheet of foundation is level with the top of the bar, withdraw the screw-driver, 
and then the sides of the bar attempting to return to their former position will hold the foundation securely.

Another method is to drive two wire nails into the centre of a board, $\frac{1}{8}$ inch or so apart, and then file off the heads. If the frame be then held bottom upwards, and placed on the board so that the nails pass through the saw-cut about the middle of the bar, a slight turn either way will cause the saw-cut to open, and then the sheet of foundation, held upside down, may be gently dropped into the saw-cut till it is stopped by touching the board. On turning the frame back again the sides of the bar will press upon the foundation and hold it securely.

In order to do away with the saw-cut while at the same time providing a means of holding the foundation securely in the middle of the top bar, Messrs. Abbott Bros. devised and patented the following

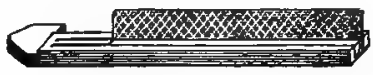

Fig. 20. method as shown in Fig. 20. A saw-cut is run in the middle of the underside of the top bar, nearly through; and by the side of that groove, another but wider is cut. The edge of the sheet of foundation is then placed in the former, and to hold it securely a wedge is driven into the latter, which forces the thin wall between the two grooves upon the foundation and holds it as in a vice.

Mr. Howard provides in one frame saw-cuts or grooves in the side bars and one in the top bar (Fig. 21). While the frame is being held in the frameblock, complete, except for the bottom bar, the founda- 
tion is inserted; the bottom bar is then adjusted and

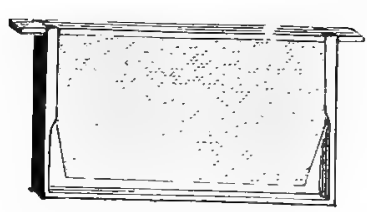

FIG. 21.

a little melted wax is run along the top bar, while the frame is inverted, to secure the sheet to the bar. By fixing the foundation in the side grooves it is held in the middle of the

bar until the bees secure it firmly, which is an advantage if the hive does not stand perfectly level.

Mr. Meadows nearly severs the top bar by a sawcut running the full length of the bar. In putting the frame together only one side of the top bar is nailed to the side walls. The foundation is then inserted, and the sides of the bar are brought together by placing on the ends a "W.B.C." or other metal-

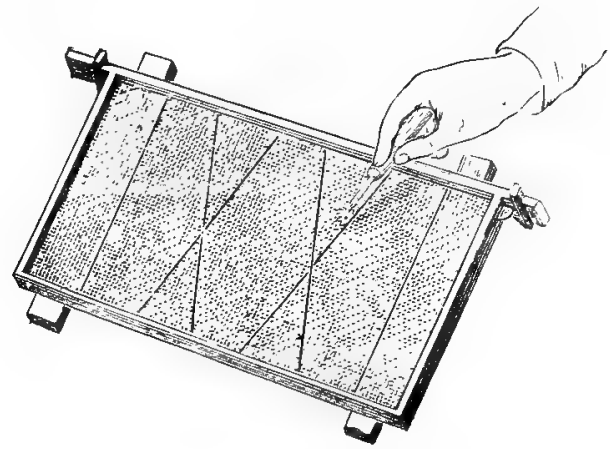

FiG. 22.

end. Any carelessness on the part of the bee-keeper in fixing the sheets by this method must result in 
the falling of the foundation, and a muddle in the brood-chamber, one that only an expert can put right.

Wiriny foundation. All the difficulties that are possible when plain sheets of foundation are fixed in the frames, or when the hives do not stand level, may be avoided by using wired foundation, or by wiring the sheets into the frames. For the latter purpose a plain top bar will, of course, be used, and then it is a matter of opinion as to the way in which the wires shall run. The method described below

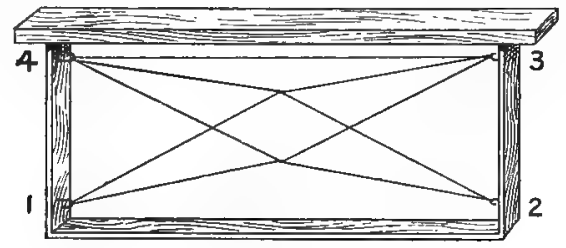

FIG. 23.

will be found perfectly satisfactory. Before putting the frame together, two French nails are driven through each side bar near the top and bottom, and turned round at the ends to form hooks. The frame is then put together with or without the assistance of a frame-block. The wire, No. 30 tinned, is hooked to No. 1 (Fig. 23), then passed through hooks 2, -3 , and 4 , and returned to No. 3 , which thus leaves two wires under the top bar. The wire is now drawn tight and passed under the first length from 1 to 2 . It is again tightened and passed over No. 4, carried next through No. 1, and then between the wires 
running from 3 to 4 . By passing it finally to No. 2, and there fixing, a diamond is formed in the centre. More wire is used by this, than by other methods, but as the combs, when the foundation has been properly fixed, are absolutely secure, and the wires no detriment, I strongly recommend it.

The wiring of frames not only makes the combs, when built upon the wires, more secure, but it allows the bee-keeper to use less foundation, as he may then use two or three more sheets to the pound. As the sheets are thin the bees will not have to expend as much labour upon them as when thicker, and at the same time in lengthening the cell walls they will be able to draw upon the wax that is naturally secreted in large quantities during the honey-flow. To give some idea of the extent to which wired frames are used in America, Mr. A. I. Root states in "Gleanings," an American bee-paper which he edits, that from his depôt over two tons of No. 30 tinned wire had been sold during 1892. As it takes 6 to $10 \mathrm{oz}$. of wire to 100 frames there must have been 700,000 to $1,000,000$ frames wired. But this only represents the output of one large manufacturing firm.

Wiring the foundation. To properly fix the wires into the foundation a board must be used half the thickness of the frame, and of a size to just fit inside the frame. By nailing laths 18 inches long underneath the board, the wired frame, when placed upon the board, will rest with the wires resting upon it (Fig. 22). The frame is then slightly raised so that the sheet of foundation is laid upon the board. On returning the frame the wires will rest on the foundation to be 
embedded by means of a "Woiblet spur embedder," as shown in Fig. 22. This instrument is heated either in the tlame of a candle or in hot water, and then the wheel is run along the wires, which sink into the foundation up to the mid-rib. The teeth

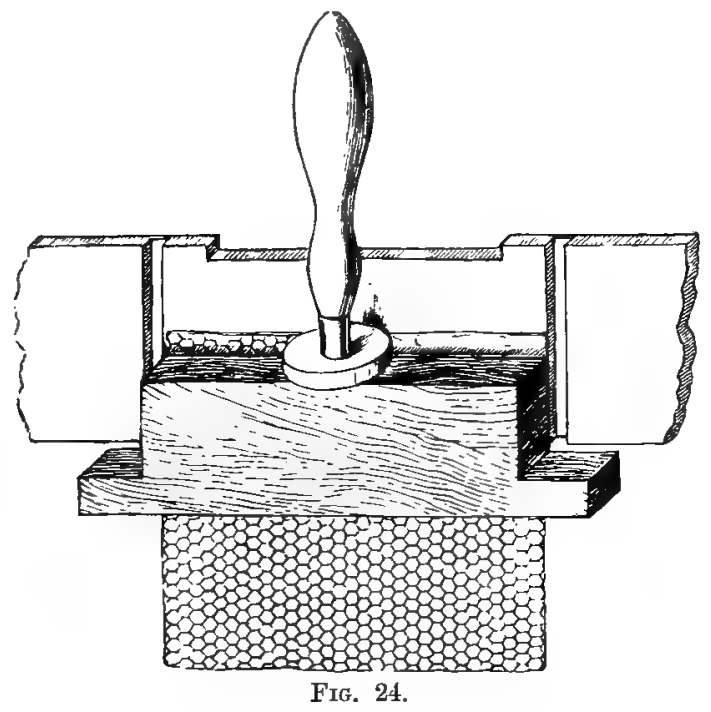

of the wheel should not be too near, otherwise the foundation is cut through as it is run along.

\section{Preparing Sections.}

Starters. After the sections have been properly folded they must, before being placed in the rack or crate, each receive a starter or guide, in the centre of the top, otherwise the comb will be irregularly built 
and attached to the separators. An objection to the use of full sheets of foundation in sections is raised by some consumers, for they desire that as little of the comb as possible shall be made from wax that has passed through the operations necessary to convert it into foundation. A small triangular piece of thin foundation is therefore attached to the middle of the upper part of the section by means of melted wax or one of the contrivances termed foundation fixers. The Messi's. Abbott Bros. roller fixer (Fig. 24) was one of the first devices of this kind to become popular,

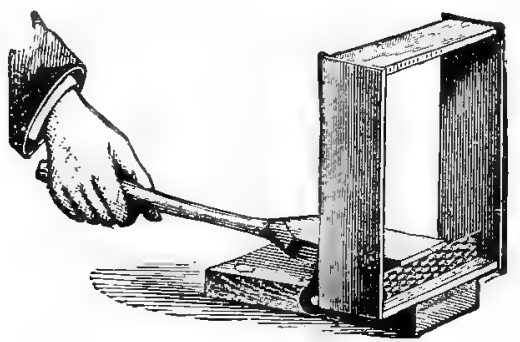

FIG. 25.

and is still much used. As will be understood from the illustration the piece of foundation, of whatever size and shape preferred, is laid upon that quarter of the section which, when folded, will be at the top, just a trifle beyond the centre. The guide is then placed upon the foundation, so that when the roller, previously dipped in starch to ensure easy running, is run along, the pressure exerted causes the wax to adhere to the wood. The foundation is then bent upwards and the section is folded ready for use. Another and expeditious method of fixing the founda- 
tion is by using the "Parler" fixer (Fig. 25). The guide is laid upon that part of the folded section to which it is to be fixed, and then by a lever arrangement the flat surface is pressed upon the foundation, thus fixing it as before. At the same time the guide is drawn into an upright position.

Full sheets, though taking up a little more time in fixing, and adding to the outlay, render the section

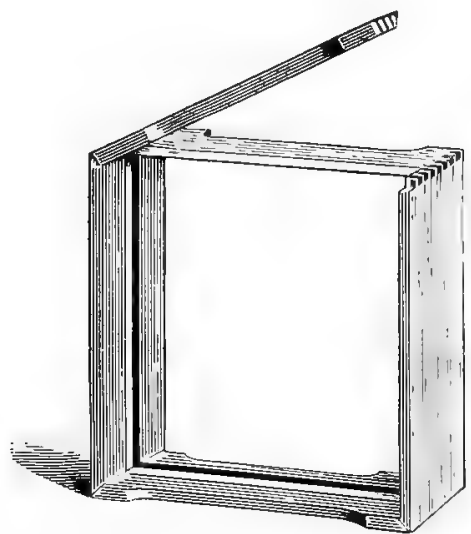

FIG. 26.

more secure for transit when full, as the bees build cells and attach them all round to the wood. At the same time the work of the bees is accelerated at a time when every saving of time means a great addition to the amount of honey stored.

If the Abbott or Parker fixer is used to fix the top of the sheet, a little melted wax at the sides will be an advantage in keeping the sheet in the centre of the 
section; or being cut to the exact size with a die, the foundation may be secured all round with melted wax.

Messrs. Abbott Bros. devised a means of fixing the foundation in the section without the aid of melted wax, which they have patented. The section is folded, except half of the top which has been divided (Fig. 26). When the edge of the foundation has been laid on the

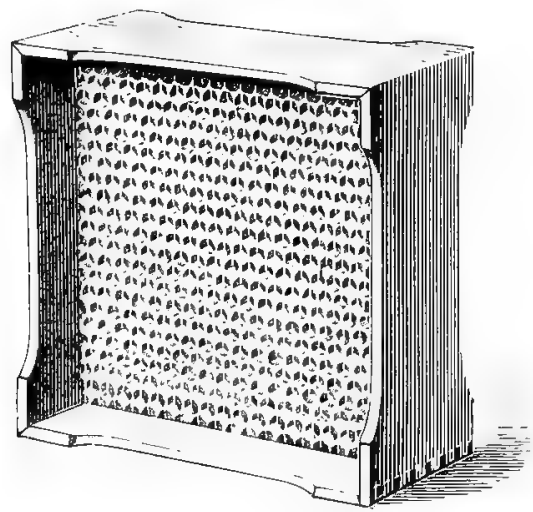

FIf. 27.

bevel, the loose half of the section top is put into position, and firmly fixed by a slight tap with a hammer.

Messrs. T. B. Blow and J. H. Howard introduced the all-round groove into which the square of foundation, accurately cut with the die, is slid, as in the illustration. When the top is closed the foundation is held loosely, and therefore a little melted wax run along the top is advisable. Mr. Lee some years ago introduced dove-tailed frames and sections, and as the 
top and bottom were in halves, the foundation was fixed by pressing it between the two edges (Fig. 28).

Mr. Howard's section (F'ig. 29) block holds the section

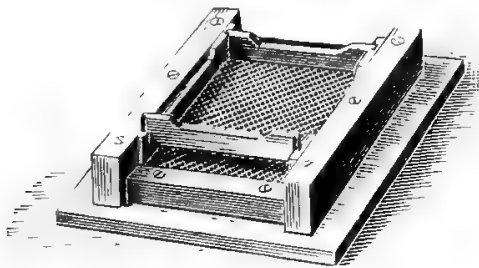

Fig, 28 ,

so that the groove is level with the top of the block. Then, by laying the foundation on the latter, it may be pushed gently into the groove. The edge is bent down on the bevel of the lower half of the section top, and on completing the section, as in the Abbott patent, the foundation is not only secure in the all-round groove, but the top of the sheet is held tightly between

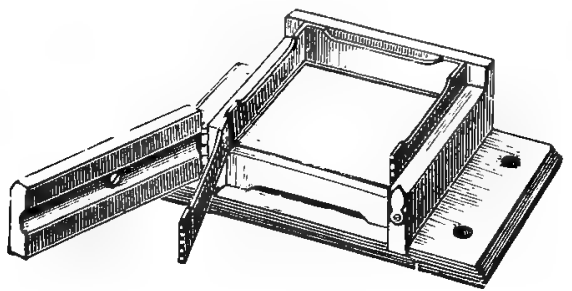

Fig. 29.

the halves of the top of the section. By using the split top har full sheets or starters are quickly and securely fixed. 


\section{Feeding.}

Why feed and when. Feeding has been truly described as "the bee-keeper's lever to success," for unless bees receive attention in this respect the fullest profit cannot be secured. There are doubtless many cases where feeding has not been necessary either to encourage brood-rearing or to ensure a sufficient supply of food for the use of the bees during the winter. This can only occur, as a rule, in those districts where there are early and late crops of honeyproducing flowers.

As a case in point, feeding during the autumn of 1893 was not necessary in "Ivo" apiary, as a late crop of mustard, and another of brank or buckwheat, provided the bees with ample food, which not only kept up the breeding until late in September, thus ensuring strong colonies of young bees, but enabled the bees to store in the brood-chamber an amount of surplus sufficient to carry them safely through the winter.

Feeding is needed first to prevent starvation during the winter, and, secondly, to induce the queen to lay eggs early and late in the season. As the amount of food gathered and stored by the bees is dependent upon the weather, there are, of course, times when only a moderate quantity of food is stored, as was the case particularly in 1888 , and the result is, that only in those apiaries where a liberal supply of food is given, will the bees live through the winter.

The loss of stocks in the spring, after an unfavourable season, is simply astounding, due in some cases to want of knowledge, but more frequently to neglect. 
In early spring a colony of bees should be as strong in numbers as it was when closed up in the previous October for the winter. This satisfactory state of things can only be brought about by a late supply of food, either from natural sources or through the feeder, which will have the effect of continuing the breeding until, say, about the middle of September. Such a colony when opened in the spring will be found to contain a satisfactory quantity of brood, and a large number of young bees, without which progress must of necessity be slow.

As the greater the number of worker bees, at the commencement of the honey-flow, the greater will be the amount of honey stored, the efforts of the beekeeper must be directed to getting the hive as full of bees as possible by the time the honey-flow commences. By feeding this object may be attained.

In many districts the last source of honey of any importance is white clover, and as this crop ceases blooming, as a rule, by about the middle of July, egglaying gradually ceases, the consequence being that very few young bees will be found in the hive on October 1st. The bees then in the hive, compared with young ones, will be of little service the following spring, and rapidly die off in consequence of the hard work that they have to perform, and then the cry is, "My stocks are becoming weaker and weaker instead of stronger in numbers." The first step towards preventing spring dwindling is to feed from the close of the honey-flow, and thus ensure that the bulk of the bees going into winter quarters are young ones.

Again, when the surplus honey, gathered during the 
honey-flor, has been almost wholly taken into supers which the bee-keeper removes, the small amount of food given after the honey-flow, to induce further egglaying, will not enable the bees to store sufficient for winter use, and therefore whatever further supply is needed must be given in September.

\section{What to Feed.}

This is a very important matter, and requires much more attention than is generally supposed. Oldfashioned bee-keepers have thought a mixture of sugar and beer a useful compound, but the feeding of bees upon such stuff, and during winter, is calculated, by causing dysentery, to do them more harm than good.

The natural food of bees is composed of honey and pollen, which may be termed heat and force producers. Honey is the carbonaceous, heat-giving and fat-forming, and pollen is the nitrogenous element necessary as a force producer and tissue former. The former is the food upon which the bees exist during the winter, when they are in a semi-dormant or inactive state. But as soon as spring work commences pollen is needed, as it is an essential part of the food given to the grubs, and required by the bees themselves when their arduous work is being performed. When, for any reason, either of these foods, or both, run short, the assistance of the bee-keeper is required, and not just as it were at the last gasp, when it is a matter of life and death with the bees, for if a stock is allowed to get into that condition, it is more than probable that though kind 
treatment may save it, it will be of little use during the summer.

Honey, Nature's food for the bees, must take the first place among the supplies given to bees, but before being given it should, if candied, be liquefied and supplied as a syrup. The best substitute for honey is sugar converted into syrup, or given in its raw state according to directions following. Only the best cane sugar in the loaf or crystallised form should be used. Beet sugar must be avoided on account of the chemicals used in its manufacture.

Pollen, the fertilising dust gathered by the bees when they visit flowers in search of nectar, may occasionally run short in the hive, owing to stress of weather or a lack of pollen-producing flowers. When this food is scarce, pea-flour will be found a good substitute. It may be scattered on some fine shavings in an inverted skep, or mixed with the candy placed above the broodnest. If the bees are to obtain a supply of this artificial pollen from a skep or other receptacle in the apiary, a little syrup or honey must be sprinkled upon whatever is used. Once the bees are thus enticed to the supply prepared for them, they will not desert it, as long as they are unable to obtain pollen from natural sources, and in sufficient quantities for their requirements.

Dry sugar feeding. To distinguish this from the method of feeding with syrup, the name dry sugar feeding has been given. The term is, however, not quite correct, otherwise white crystallised, which is wholly unsuitable, might be used. This method of feeding was introduced by Mr. S. Simmins in 1884, and 
it has since been proved a boon to many bee-keepers. During the autumn of the same year it was my privilege, representing the British Bee-keepers' Association, to visit the bee-keepers in Pembrokeshire and Cumberland. In the former county I learnt that sugar-feeding had been in vogue as long as my informants could remember. When spoken to about the system, they told me that having taken the honey away in the supers, it was as little as they could do in return to give the bees a small quantity of food. Their plan was to fill a basin with brown sugar, press it down, cover it with thick brown paper, push a hole or two through the centre, and then invert the basin, placing it over the feed-hole in the top of the skep. The results, where this practice was properly carried out, were uniformly high, when compared with others kept on the let-alone system.

\section{How to Feed.}

The manner in which food is given must depend upon whether it is to be used as a stimulant to broodrearing, or simply for the bees to store in the cells for future use.

If it is required for stimulating purposes, there must be a slow but continuous supply. This has been assured, with syrup, by using a graduated feeder (Fig. 30). The metal cap, perforated with nine holes, extending half-way round, is, when covering a full bottle, placed on a stage in which is cut a long narrow semicircular hole. Through this, when the bottle is properly placed, the holes in the metal cap are visible. To the 
metal cap is attached an index, and as it is pointed to the figures 1, 2, 3, \&c., marked on the stage, that number of holes remains uncovered, and thus the rate at which the food is taken down by the bees is regulated.

There is one great objection to this method of feeding, viz., that all the food taken by the bees after the first few hours, when the food is given warm, must be cold. On the giving of cold syrup Mr. Cheshire remarks, "Syrup holding 3 lbs. of water, and given at the temperature of the external air, will abstract more heat from the cluster of bees than $\frac{1}{4} \mathrm{cwt}$. of zinc placed cold in their midst." Coming from such an authority; this pronouncement against the giving of cold syrup should emphasise the necessity for giving warm syrup.

There is no reason why, if we conclude that a stock of bees requires a pint of food, it must be four days taking it down. Far better is it to

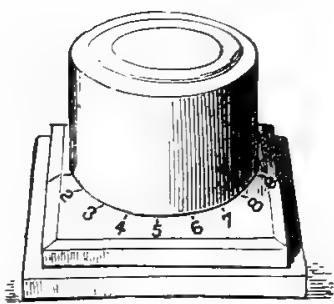

FIG. 30. turn on the full number of holes and allow the pint to be taken down in a few hours while warm. It is then placed where the bees require it for immediate use, and will remain at the temperature of the inside instead of the outside of the hive.

A very simple method of feeding is by a bottle and stage. The stage is about 5 inches: square, the sides being raised and grooved to allow a piece of glass to slide along the top of the stage. The raised sides and grooves may be dispensed with, and the glass laid flat 
upon the surface of the stage, which will then consist of a piece of wood 5 inches square, with a hole in the centre $1 \frac{1}{2}$ inches across, and a rim underneath to raise it $\frac{1}{2}$ inch. This stage may be used on any hive by simply placing it over the feed-hole. When placing it on a skep it is advisable to set it on a slight ring of barley meal or other paste. The bottle selected should be a narrow-mouthed honey-jar or pickle bottle. Fill
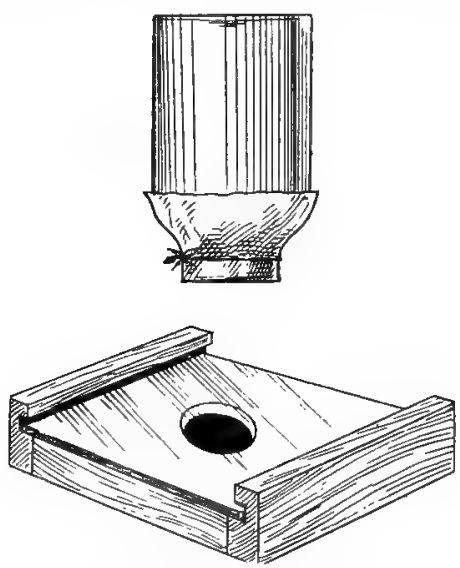

FIG. 31 .

it with warm syrup, and then tie tightly over the mouth one or two thicknesses of muslin or canvas. Now a caution must be given. Very frequently the syrup is found to run from the bottle into the hive, and thence out of the entrance to the ground. If the syrup is of the proper consistency this leakage results from slowly turning over the full bottle, and allowing the air to reach the top of the bottle above the syrup 
where there should be a vacuum. To avoid this loss and incentive to robbing, place a piece of paper over the mouth above the canvas when the bottle is ready for inverting. If, then, the hand is pressed tightly upon the paper, while the bottle is quickly inverted no syrup will escape. The bottle must then be placed upon the glass, which then withdraw. When the bottle requires refilling it must be slightly raised while the glass is pushed underneath, so as to prevent the escape of bees.

\section{Sugar-Feeding.}

The preparation and giving of syrup every three or four days entails a certain amount of trouble; but this may be considerably reduced, without diminishing the benefit of feeding, by adopting sugar-feeding. The most suitable sugar for this purpose is Porto Rico, a fine-grained, pure cane, moist sugar.

To feed stocks in skeps, fill a basin or jar with the sugar, press it down, and then place upon it a thin piece of wood, in the centre of which two or three holes have been made with an auger or a red-hot poker. Next invert the basin, and set the wood so that the holes are just above the feed-hole. The wood should be set level upon a ring of paste or mortar. The moisture arising from the cluster will pass through the holes in the wood and be absorbed by the sugar, which, being converted slowly into syrup, will afford the bees the gradual but continuous supply of food they need.

In the place of a basin or jar, a box 5 inches by 4 inches, inside measurement, and $4 \frac{3}{4}$ inches deep, may 
be used. The hole in the bottom should be 3 inches by $\frac{1}{2}$ inch, running towards two grooves $\frac{1}{2}$ inch apart, $\frac{1}{8}$ inch wide, and $\frac{1}{8}$ inch deep, cut in the middle of the 5 -inch sides. Into the grooves slide two pieces of an old section, pushing them down to within $\frac{1}{4}$ inch of the bottom. There will then be left a space of $\frac{1}{4}$ inch above. Into the compartments thus eut off from the hole in the centre of the bottom, the Porto Rico sugar must be placed. The moisture arising from the brood nest will have access to the sugar above and below the section slides. The cover to the box may be a sheet of glass, which will act as a condenser of the moisture; but a piece of cloth should be placed upon it to keep the feeder dark.

A simpler box, made 4 inches square and 4 inches deep, might be used in the following manner. In the bottom make a square or circular hole $1 \frac{1}{2}$ inches across, and over that place a false bottom kept by nails or any other contrivance $\frac{3}{8}$ inch from the bottom and the same from the sides. When the sugar is put into the feeder the bees will have access to it all round the false bottom, which will be $3 \frac{1}{4}$ inches square.

The above sugar-feeders may be used on any hive, but a dummy feeder will be found of great service for use in a movable-comb hive.

\section{Dumay Feeder.}

As originally devised by Mr. Simmins, the feeder is faulty, inasmuch as the syrup, formed by the sugar absorbing the moisture that enters at the top, falls to 
the bottom, thus making a sticky mess on the floorboard, unless the dummy is made $\frac{1}{k}$ or : $: 3$ inch short of the bottom. An excellent pattel'n (Fig. 32), first illustrated in the British Bec Journal, by Mr. T. B. Blow on his return from a tour among beekeepers in the East, is the only style that ought to be used. The parallel openings in the side turned towards the bees, expose the sugar to the influence of the

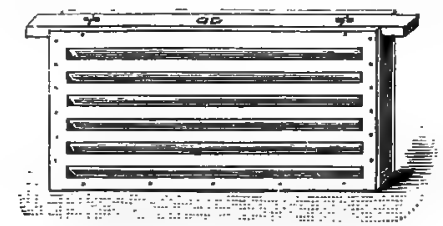

FIg. 32.

moist atmosphere, and allow the bees to feed at the top or bottom, or wherever syrup is being formed.

\section{Rapid Feeders.}

The feeders hitherto described have been for use chiefly when food was required for stimulating the queen to brood-rearing, but when an examination of each colony is made in the middle of September, there may be found a satisfactory state of things from every point of view but one, viz., an insufficient supply of food to carry the stock through the winter. Whatever quantity of food is then required should be given in the form of syrup containing six pounds ( 3 for spring food) of sugar to the quart of water. The amount of syrup required may be given in one or two doses warm 
at night, in a rapid feeder of the Canadian pattern (Fig. 33). By morning a strong stock will have emptied the feeder and stored the food in the combs below. At this time, supposing the stock to contain a good population, sufficient heat would be generated to evaporate

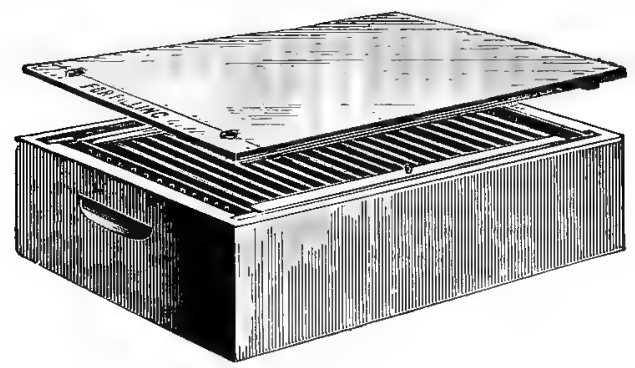

FIG. 33.

the superfluous moisture contained in the syrup, and then it would be sealed over for future use.

If syrup is given later in the season the bees may be thin in numbers and the weather cold, and then it will be impossible for them to ripen it and seal it over. 


\section{CHAPTER IX.}

\section{COMMENCING BEE-KEEPING.}

To many would-be bee-keepers the cost of starting acts as a deterrent, often, it may be, because they hear of the great outlay of some bee-keepers who have not made their venture pay. For the guidance of beginners I will give a list of the necessary appliances for properly commencing on the three systems described in this Guide, and the cost of each article. The price given must in each case be taken as approximate, for prices vary according to the quality and workmanship of the articles in question.

No hive should be considered complete without at least two supers; it is, therefore, wise to procure at starting whatever is likely to be required for properly working each stock. At the same time I strongly advise all who commence bee-keeping to "make haste slowly," and only add to their apiary as they become more expert in the management of the bees, and feel that they can with equal success look after a greater number of hives.

\section{The Skep System.}

On this system the outfit per stock will be as 
follows, at the lowest estimate: brood-chamber, 1s. 6d. ; 2 supers, 1s. 3d. each; floor-board, 1s. 3d.; pan for cover, 1s. 3d. ; swarm, 10s. 6d. Total cost, $17 \mathrm{~s}$. The cost of a swarm will depend upon whether it can be purchased from a neighbour or a dealer some distance away. In the former case a good ordinary swarm may be obtained for the price named; but if supplied by a dealer, who guarantees a young queen and a certain weight of bees, the price will be about 3s. 6d. per lb. It is then good policy to procure a 4-lb. swarm. The extra cost and carriage will require adding to the estimate above.

\section{THE "Ivo" BaR-Hive.}

The cost of any hive, as of other articles, depends very materially upon the demand for it. Now, by the increased demand for this hive it is made by machinery instead of by hand, and the cost has been greatly reduced. Those who can use tools will find the hive simple in construction, and therefore easily copied. The floor-board costing 1s. 4d.; broodchamber, 2s. ; two supers with bars, window, and door, 2s. 2 d. each, and roof, $1 \mathrm{~s} .9 \mathrm{~d}$., will cost about $9 \mathrm{~s} .6 \mathrm{~d}$. ; paint, 6d. ; foundation, $2 \mathrm{~s} .6 \mathrm{~d}$. ; and swarm, 10s. $6 \mathrm{~d}$. Total, 23s.

\section{Movable-Comb Hive.}

Hives of this description with single walls may be obtained from about $10 \mathrm{~s}$, , but with the extras needed for a complete outfit a much larger sum must be expended. As a matter of economy, double-walled 
hives are strongly recommended, the extra cost being very little when the greater protection to the bees both winter and summel is considered, as a means towards obtaining full supers. Stocks in doublewalled hives are warmer in winter and cooler in summer than those in single-walled hives. In favour of single-walled hives, it has been remarked that the rays of the sun in the early spring, penetrating the thin walls, warm the brood-nest, but such walls afford only moderate protection against the low temperature of the nights in spring. The best progress is made

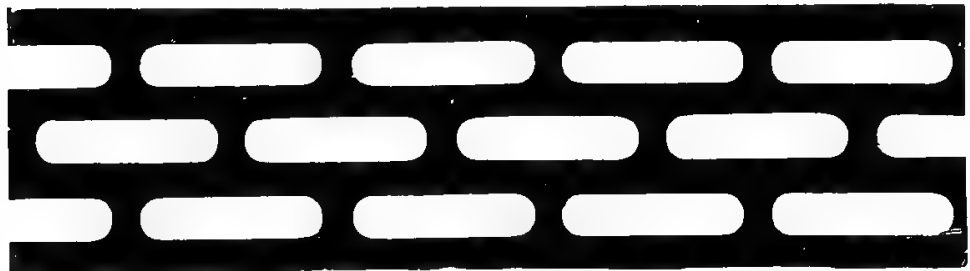

FIG. 34.

by a stock that is kept as nearly as possible at a uniform temperature. Hence the supreme importance of good non-conducting walls around the broodnest.

For a well-made hive with double-walls front and back, the use of dummies being equivalent to double walls at the sides, the cost will be about as follows: floor-board, 2s. ; brood-chamber, with standard frames and distance-keepers, 5s.; two shallow-frame supers, with frames and distance-keepers, $4 \mathrm{~s}$. each; lift, 1s.; roof, 2s. 6d.; square of excluder zinc, 1s. (Fig. 34); foundation, 5s. 6d.; swarm not less than $4 \mathrm{lbs} ., 14 \mathrm{~s}$. 
Total cost, 39s. Full sheets of foundation for the brood-nest will take $1 \frac{1}{2} \mathrm{lhs}$., and a like amount at least must be allowed for the two supers, full sheets not being necessary there. In the lower parts of the shallow frames not filled with foundation, the bees will build drone comb, but this is of little consequence, and rather an advantage, for the bees will use the wax they are secreting during the height of the honey-flow in completing the combs to the bottom bar. The use of a queen-excluder between the broodchamber and the supers (Fig. 13) is desirable at all times, in order to keep the queen confined to the brood-chamber; but it is imperative if the frames in the supers contain drone comb.

If sectional. supers are used instead of bodies of shallow frames the cost will vary very little, as extra lifts and an adapting board will be required, also super foundation instead of brood, except for the broodframes.

The following appliances may be considered extras to be obtained as the apiary is extended, and honey, both sectional and extracted, are produced: Smoker, from 2s. 6d.; honey-cistern (Fig. 40), with treacle tap and strainers, 15s.; honey knives (Fig. 39), each, 2s. 3d.; spatula or scraper, 1s. 3d.; wax extractor (Fig. 60), 10s. 6d.; feeders, from 1s. each. A stock of honey jars tie-over or screw-capped, labels and parchment, brood and super foundation, sections in the flat, 14-1b. or 28-1b. cans for extracted honey to be sold in bulk, and travelling crates for sections should be obtained in advance of requirements, so that no delay occurs when further super room or other 
attention is required by any of the stocks in the apiary. To the above list of stores should be added a packet of Naphthol Beta, 1s., and a box of Naphthaline, 1s., foul brood remedies, which should be at hand in every apiary.

\section{Location of the Apiary.}

Most unsuitable places are often given to the apiary, whereas considering its importance more thought should be given to the selection of the site. While a nice open spot not too sheltered from the sun, though as much as possible from the north and east, is best, it should not be where there is constant traffic. A rather low position on rising ground should be chosen if we are to render the return of heavily-laden bees easy. The ground upon which the hives stand must be kept free of weeds, and a few feet in the front should be kept clean and clear of crops. A lady who recently commenced bee-keeping by buying five stocks placed them at the middle of one side of the tennis lawn, fully believing that play would go on uninterruptedly, but a move of the stocks to another part of the garden had to take place before much tennis was indulged in.

The entrances of the hive should face the south or south-east, and the hives should be placed so that a path is immediately behind them. In many gardens hives are so placed all round without annoyance to any one, unless it be the gardener who works in the front of the hives at times the bees consider unsuitable. 


\section{Distance Apart.}

The hives may be placed as near together as three feet, but in that case some variation in the shape of the hive at intervals or some mark should be used to break the monotony. Six feet apart in the row where the space can be given, and twelve feet from row to row, is a more convenient arrangement.

\section{BeE-FuIght.}

In selecting the position of the apiary some consideration should be given to the location or probable location of honey-producing crops around. If the site chosen is surrounded by scanty crops, but with abundant forage two miles away, a grave mistake is made, as partly filled supers will prove. Very great ignorance prevails on the subject of bee-flight. That drones fly some miles is a well-known fact, but not so the workers. In my own district during recent years crops of mustard within two miles in direct line of flight have been neglected, and similar crops much nearer home have proved of less benefit than one could wish.

When writing on the subject of bee-flight in 1890 the late Rev. G. Raynor said that his Ligurians were working on crops three miles away, while his blacks were idling at home. This shows the former to be stronger on the wing and better foragers than the natives. Mr. Cheshire also stated that some stocks were moved four miles at night to the moors, and the next morning a cluster of drones was found on the old stands, but no workers. Mr. Baldwin moved a stock 
of bees in 1877 to St. Mary Cray, a distance of three to four miles, and in the morning he noticed that a number of bees had returned.

Taking the lesser distance-three miles-as the correct measurement in a direct line, it is evident that the radius of flight of those bees on their previous stands was at least one and a half miles. Most bee-keepers of experience, however, agree that crops one and a half to two miles away are practically valueless, while the nearer they are the greater the prospect of full supers. It is, therefore, a question worth considering as to whether stocks should not, as on the Nile and in other parts of the world, be moved to those spots where they are likely to do the greatest amount of work. By following the crops in this way, each move being not less than two miles away in a direct line, the honey returns are enormously increased, thus proving not only the practicability, but the advisability of moving bees "to pastures new."

\section{Moving Bees.}

The ordinary removal of stocks to fresh sites in the same apiary should invariably take place in the depth of winter, preferably in the midst of frosty weather, when the bees have for some days been confined to their hives. The old position should be changed in appearance as much as possible, and to draw the attention of the bees, when they leave the hives for the first cleansing flight, to their new position a small branch should be placed in the ground and made to stand in the front of the entrance. The bees must 
then take note of their surroundings on leaving the hive. This means of drawing attention to a change of position is more essential when, for any reason, stocks are moved a short distance, say twenty or thirty yards, at a time of the year when the bees are daily on the wing. At such times a move of a yard or two every day, or alternate day, when the bees are flying freely, is a better plan, as they become accustomed to a change of position by degrees.

In moving stocks from one apiary to another beyond bee-flight, that is, at least two miles away, the early part of the year, or at the end of February, should be chosen, for then there will not be much brood, and the move will act to some extent as a stimulant to breeding. Later on, say in March or April, a better idea of the value of stocks could be ascertained, and no harm would result from the moving if it took place before much work had been done on the orchard bloom.

\section{Packing Stocks and Swarms.}

Swarms are easy to transport, but the following directions may be followed. Hive the swarm in a straw skep, and let it remain until the evening. Weigh the swarm box, examine the perforated zinc to see that it is securely nailed on the bottom and also on the lid, mark one side of the box and the side of the lid near to it; then set the box close by the swarm. Lift off the lid and place it down by the side of the box so that it can be picked up and placed upon the box as soon as the swarm is in. Now lift up the skep gently without moving the cluster, and 
when it is turned mouth upwards give it a sharp bump on the lower side of the skep, and before the bees recover, roll them into the box, give the skep a sharp clap on the sides with the palms of the hands, and then lift up the lid and place it on the box, carrying it a little distance away to put in the screws. If this operation is performed as directed in the evening, just when the bees have begun to settle down, say about seren o'clock, all but perhaps a dozen or two will in less then half a minute have been safely fastened in the swarm box. If any bees drop over the side of the box, leave them, but look carefully round to see if the queen is among them; if she is, at once carry her on a piece of paper or something else along with a few bees to the swarm box. To get her in without allowing the bees to escape unscrew the lid, give the box a shake to throw the bees to the bottom, draw the lid a little to one side, and drop in the queen.

Swarms may also be sent in good-sized skeps with a square of canvas at the top and another at the bottom for ventilation. Two or three wisps of straw or balls of paper should be tied underneath the skep to keep the bottom off the ground and thus ensure a current of air passing through the skep.

To pack stocks in skeps proceed as follows: Procure a cheese box if of sufficient diameter; if not, any light square box will do, and with a piece of thick string make a handle on each side near the top; put into the bottom a good layer of straw, or roll pieces of nerspaper into balls and cover the bottom with them, as a buffer must be provided to protect the 
stock from the effects which rough handling of such packages would produce. The box is now ready to receive the stock. Take a square of canvas and proceed to the stock, which should have previously been raised off the stand, and the front left an inch or two off the floor-board so that the cool evening air will drive the bees up amongst the combs. Puff a little smoke into the entrance, then take a corner of the canvas between the thumb and forefinger of each hand, place the palms of the hands on the sides of the stock, which turn quickly over, letting the canvas fall over the mouth of the hive. Before the bees rise tie a string round the canvas. The hive may then be placed in the box, and if the space around the sides be padded with straw or paper, it will travel safely. To ensure extra care in handling while in transit the following words in large type should be written on the label:

\section{LIVE BEES ON COMBS-WITH CARE.}

It must be borne in mind that only stocks on fairly tough combs can be expected to travel safely. Sticks which are put through the hive in such a manner that they may be easily withdrawn are a great help to the safe transit of stocks, for the combs will be built to them, and so held securely.

Supposing the stock to be particularly strong in bees, the canvas will not be placed over the mouth of the hive with the ease it will over a moderately strong colony; but in that case the hive should first be lifted off the stand, the bees brushed off the latter, and then the canvas spread upon it. Now return the stock, leaving the front raised, and most of the bees 
will be secured later in the evening by raising the canvas and tying it round the skep before the latter is inverted.

\section{How to Start Bee-heeing.}

Whether by swarms or stocks is a matter to be settled mainly by the buyer, who will start with the latter if he can procure good healthy stocks at a reasonable price in the spring. Stocks in skeps may be bought from cottagers when "taking up" time comes in the autumn, or in the early spring, for about the price of a good swarm later on in May or June, and with careful management each lot may be expected to give a swarm, and probably a cast or two, with which to stock new hives.

The most satisfactory start would be with new, wellpainted hives and strong swarms; and, presuming this mode of commencing to be adopted, the swarm will be hived in the following manner:-

Swarms sent by rail should always travel in boxes with holes in the top and bottom, covered with perforated zinc, and the lid screwed on. If the swarm has come a long distance and arrives at night, a little syrup may be given over the perforated zine in such a manner that no bees are drowned. The zinc smeared occasionally with honey or syrup will afford just that taste of food which will render the bees quiet on being turned out of the box.

The hive properly prepared should be placed on a spot cleared of weeds and made perfectly hard and level, then a piece of wood should be placed so that 
the upper edge, previously bevelled, will lean against the front edge of the alighting board, the bottom resting on the ground. This board is to afford the heavily-laden bees that fall short of the alighting board an easy means of reaching the hive.

The entrance to the hive, when introducing a swarm, should be as wide as possible, and, in addition to giving the full entrance, it may be raised slightly from the floor-board, and kept in that position by placing wedges at either end. The swarm box must be placed near the hive. First, remove the screws without allowing any bees to escape. Then take hold of the box with a hand on each side, the lid being held down by the thumbs, raise the box, and then set it down sharply. This will have the effect of throwing the bees into a heap on the bottom. Quickly throw off the lid, and, holding the box mouth downwards, shake a few bees out on to the alighting board as near as possible to the entrance.

As soon as they commence running in throw down more until all are in the front of the hive. If the queen is seen she should be lifted with a feather to the entrance, to ensure that the swarm. will enter, which it will not do if the queen should get lodged beneath the alighting board or remain elsewhere outside the hive.

When the bees have become settled inside the hive, the entrance should be lessened during the time that the bees will be busy working the foundation into combs. In a few days the brood-chamber of the "Ivo" will be in a sufficiently forward state for supering operations to be commenced; but the swarm 
in a bar-frame hive will require additional frames of foundation every few days, until the hive is full of combs, unless the brood-nest is limited, for supering with divisional sectional supers, until after the honeyHlow. 


\section{CHAPTER X.}

\section{HONEY PRODUCTION.}

THE aim of improved methods of bee-keeping is to augment profit by an increased output of honey per hive. Consequently the bee-keeper must direct his efforts towards the preparation of those receptacles in which the surplus honey is to be stored. This is, of course, after care and attention have been bestowed upon the brood chamber, which at the commencement of the honey-flow should contain a large quantity of worker bees.

The first question naturally arising is: "Shall I produce run or drained, extracted or sectional honey?" This question must be answered by each bee-keeper according to the facility with which he can dispose of his produce, always bearing in mind, first, that sectional honey should only be produced largely in those districts where crops producing honey that quickly granulates are scarce; and, secondly, whether the non-sectional honey shall be obtained by extracting honey from the combs, or by simply slicing them and draining the honey therefrom, must be determined by the size of the apiary, and the interest a bee-keeper 
takes in his hobby. Returns in both drained and extracted honey are generally allowed to be considerably in excess of the amount taken in sections, and, unless there is for the latter a quick sale at remunerative prices, it is preferable to confine our efforts entirely to producing either drained or extracted honey.

When to super? is a query put very frequently to the editors of Bee Journals, and others who are responsible for replies to queries on bee-culture in newspapers. A definite date cannot possibly be given, as seasons and crops vary so much. To insure good results there must be a strong stock of bees, ample crops of honey-producing flowers in bloom near the apiary, and atmospheric conditions favourable to the secretion of nectar by the flowers. With strong stocks, and the above conditions fulfilled, surplus will be gathered and stored in large quantities, if only proper super accommodation is given.

Some idea as to when the time for supering has arrived may be formed by noticing the district around, and the manner of the bees, but more particularly by a glance at the upper cells of the combs, for, as soon as honey is being brought into the hive in quantities much beyond the daily requirements of the colony, the upper cell walls will be lengthened with newlymade wax, as the cells are being filled with the surplus honey. The earlier crops, such as fruit bloom, are found before the majority of colonies have made much headway, therefore little beyond what is required by a daily-increasing brood-nest is stored. Still, by confining the stock to a smaller number of frames than it is usual to allow a full stock, a very fair amount of 
surplus may be stored in small-sized supers. On the removal of these supers the stock may be stimulated, and converted into one of very satisfactory dimensions by the time the next honey-How commences.

The lack of surplus, when favourable conditions for the secretion and gathering of nectar are present, is due to the fact that stocks, for want of proper management, are not sufficiently strong at the commencement of the honey-flow, and that supering is too long. delayed, sometimes to such an extent that the putting on of supers is too late for any advantage to be derived from the honey-flow. In order to emphasise the necessity for timely supering, I may state that of three swarms in one apiary, about the same weight, and treated in an exactly similar manner as far as the brood-nest was concerned, two gave over $40 \mathrm{lbs}$. of surplus each; while another, not supered, gave, of course, nothing. The supers were intentionally left off the last-mentioned swarm to prove to visitors the inevitable result of procrastination when the time for supering had arrived.

\section{Drained Honey.}

Upon the brood-chamber of stocks in skeps, and the "Ivo" bar-hive, the surplus honey will be stored in a manner that renders it necessary to remove and slice the combs in order to obtain the honey. To this process of obtaining honey from the combs there cannot be any reasonable objection, for, during the honey-flow, sheets of foundation are very rapidly converted into combs, and therefore little, if any, time is lost by this method of procedure. 
The late Mr. C. N. Abbott, when editor of the British Bee Joumal, advised, in 1888, the cutting up of combs made from foundation when they were filled with honey, insterd of resorting to the extractor. Again, very recently a well-known manufacturer of appliances, who owns a large apiary, sold his own extractor because it would, as he said, be quicker work to cut out the full combs, slice and drain from them the honey, and return the frames refilled with foundation.

The supers on movable-comb hives need not of necessity be shallow frames or sectional supers, and therefore any other kind of super in which foundation can be fixed may be chosen. Among such supers is the "Ivo," which is exactly as prepared for the "Ivo" hive, except that the plinths are omitted. Before such a super is placed upon the frames of a movable-comb hive, a sheet of queen-excluding zinc (Fig. 34) must be laid upon them. The perforations, $\frac{1}{6}$ inch in width, allow only the workers to pass through, as the drones are altogether too bulky; and the queen, unless young, is stopped by the breadth of the thorax. The sheet of queen-excluding zinc is an absolute necessity, if bracecombs are not to be built by the bees to unite the combs of the brood-chamber with those in the super. Bees build brace or joining combs, because they apparently prefer to travel from one part of the hive to another on comb; and it may also be, though in a lesser degree, owing to a desire to ensure firmness of the connection between the two stories. The sheet of excluder zinc remains on the frames for the whole of the season, or, at any rate, until the close of the honey-How; and by its use not only will 
the queen and drones be kept below, but the bees will finish off their combs, so that in removing the super there will, as a rule, be no attachments to the work below.

Among other supers under this heading may be mentioned bell-glasses, but they are not recommended,

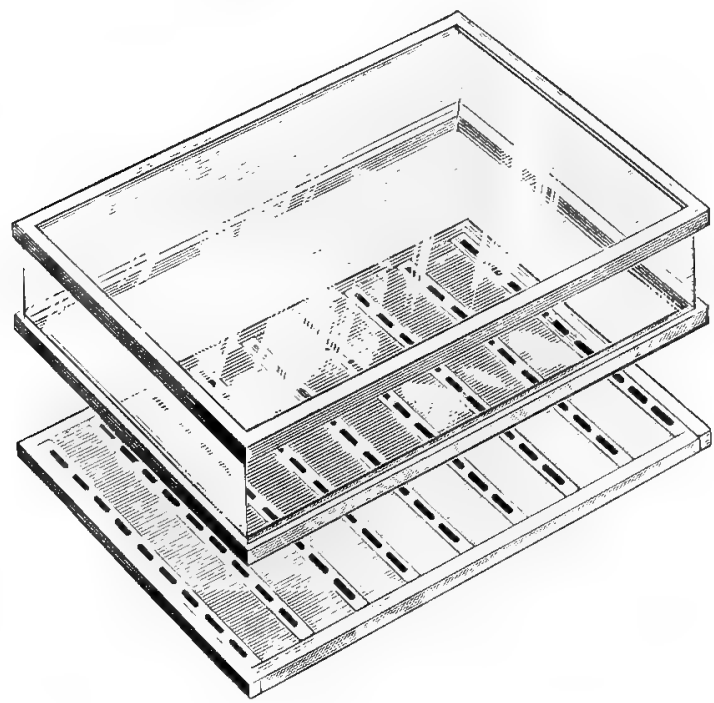

FIG. 35.

as it is with great trouble that foundation is fixed in them, and when filled they are not much sought after. Abbott's cottager super with glass sides is a very pretty little super, holding, when full, about $7 \mathrm{lbs}$. of comb honey. It possesses an advantage over the bell-glass in a provision for receiving foundation guides. A most charming and at the same time effective 
super is the "Castle Douglas Super" (Fig. 35), holding about $26 \mathrm{lbs}$. of honey, and designed by Mr. W. Hogg, of Castle Douglas, N.B. Foundation guides are tixed with fish glue to the glass top, by inverting the super and placing it upon a board, the same size as the top of the super, marked where the sheets of foundation should run. The lines are shown

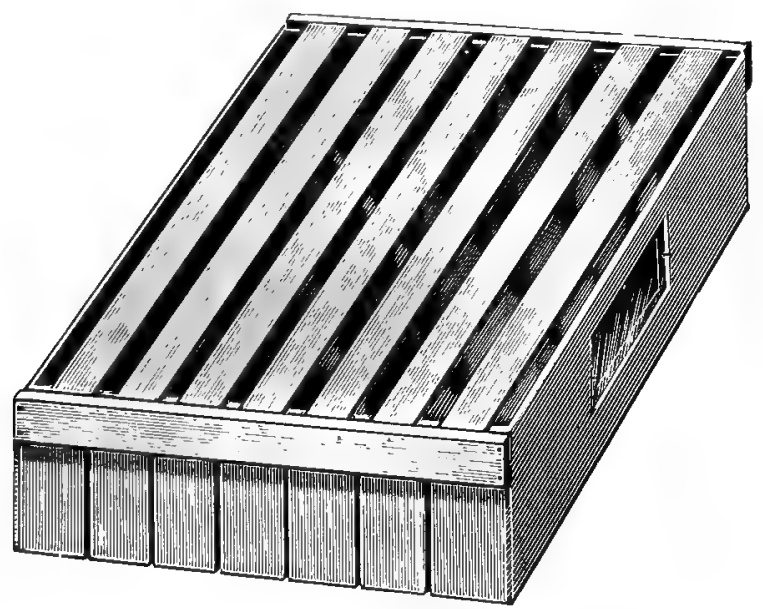

Fia. 36.

through the glass, and while the foundation is held over the line the glue is run along, and when dry holds it securely. The "Castle Douglas Super, No. 2" (Fig. 36), was also designed by Mr. Hogg as a divisional super, the idea being that combs may be cut away with that part of the super to which they are attached. 
Extractors and Extracting.

By giving supers of clean comb during the honeyflow the labours of the bees are saved in one direction, and utilized in another. The time they would spend in producing wax and building combs is more profitably spent in gathering, storing, and ripening honey; and the quantity thus obtained is amazingly increased, and to an extent that is impossible under any other system. The advantage of such a system cannot be called in question; and, further, it is the surest means of preventing swarming, as more room may,

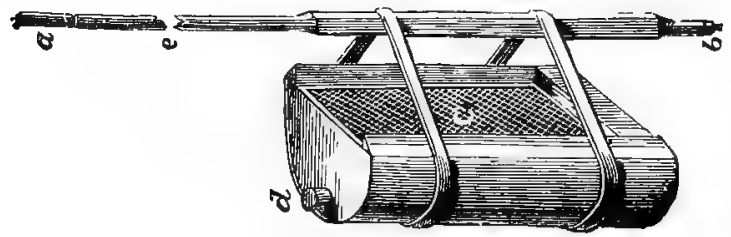

FIG. 37.

without disadvantage, be given to stocks worked for extracted honey. The honey is ejected from the combs by centrifugal force, and then the empty combs are returned for refilling.

One of the simplest and cheapest of extractors is the "Little Wonder" (Fig. 37), designed by Mr. C. N. Abbott nearly twenty years ago. As will be clear from our illustration, the comb when uncapped is placed against the wire backing; then the iron point at the bottom of the shaft is placed in a hole in the floor or a heavy piece of wood. The top of the shaft, through which an iron bolt passes, is then held firmly while 
the cage is made to revolve until the honey is thrown out. To those who do not mind hard work this form of extractor will be acceptable, but as the holding capacity below the cage is small, the can requires frequent emptying, otherwise clothes are spoilt and honey wasted.

About the same period a cylinder extractor was

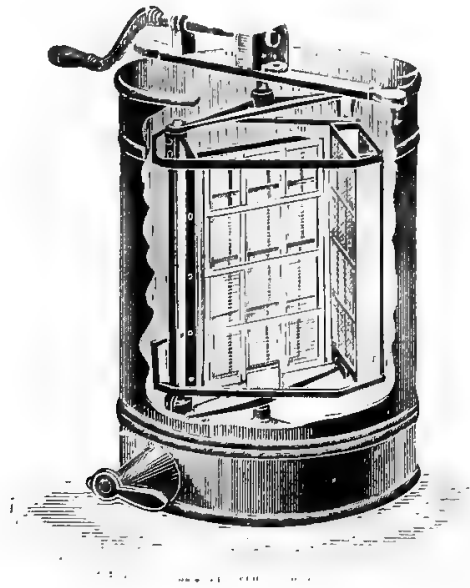

FIG. 38.

designed by Mr. I'. W. Cowan, and is still, with various alterations, a well-known machine. It consists of a cylinder in which are fixed two cages revolving round a central spindle turned with or without multiplying gear. Beneath the cages there is space for a large quantity of honey, which allows of several combs being extracted before the honey is run off. 
Mr. Meadows, who has earned fame as a manufacturer of these useful machines, introduced into the cylinder pattern a special backing which prevents the bulging and consequent breaking of the combs. This has now been fitted to the latest pattern "Cowan" extractor, as manufactured and sold by Mr. A. I. Root in America, and forms a machine which, compared with its predecessors, is perfection. The cages are moved by gearing fixed at the side of the extractor, a much more convenient arrangement than if at the top. In some extractors of the "Cowan" pattern the cages are fixed on pivots, so that when one side of the comb is emptied, a move of the cage places it against the next side of the square of ironwork, with the other side towards the wall of the extractor, thus doing away with the necessity for removing the combs for reversal. The speed at which the cages must revolve to effectively drive out the honey, without at the same time breaking the tender combs, can only be learnt by practice.

Honey should be extracted from sealed combs only, and in warm weather. It is a great mistake to leave this work until late in the season, for then the bees quickly decrease in numbers, and the internal heat of the hive being thereby lessened, as well as the external temperature, the honey becomes thick and difficult to eject from the combs, even by turning the cages at great speed. This is especially the case with honeys that quickly candy. Therefore, though it is advisable to leave the honey on the hive to allow of proper ripening, it must not remain during cold weather. 


\section{Extracting.}

Having cleared the frame super of bees, remove it while the combs are warm to the room in which the operation of extracting is to be carried on. Now lift out a frame, stand it on end, and, commencing at the bottom, shave off the cappings with a long, sharp, uncapping knife (Fig. 39) that has been heated in a can of hot water or special knife-heater. The knife should be drawn along with an up-and-down saw-like movement, and by holding the upper end of the frame forward the cappings will hang in a sheet from the comb and fall into a dish below, or into the can of

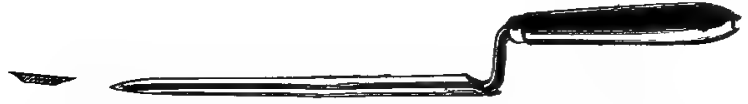

FIg. 39.

the comb-holder, if such a useful article is used. Both sides of the comb must be uncapped and then the frame placed in one of the cages of the extractor.

- To balance it, and make the running easy, another comb similarly prepared is put into the opposite cage.

It will be recollected that in a previous chapter the upward pitch of the cells was referred to, and this peculiarity must not now be ignored; in fact, if it is, the work of extracting will not be satisfactory. When putting a frame into the cage of the extractor it should be so placed that the bottom bar moves round first, when the cages are set in motion. The honey will then be thrown out in the direction in which the cells are built. The wheel, or handle, attached to the spindle round which the cages revolve, must then be 
turned round slowly, and the speed gradually increased. The effect is that the honey will be thrown out upon the tin walls of the cage, or the inner wall of the extractor, and run down to the bottom, to be afterwards drawn through a treacle-tap. When one side of the comb is emptied it must be reversed, that

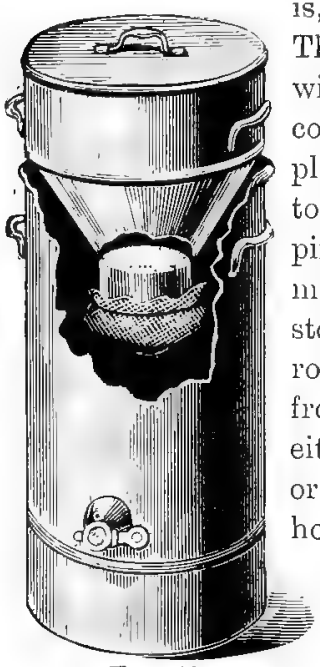

FIt. 40. is, simply turned over, not round. Then the bottom bar of the frame will again move round first. The combs, as emptied, may be replaced in the super, and allowed to remain until some of the dripping honey has fallen. The super may then be placed upon any stock requiring additional super room, or returned to the stock from which it has been taken, either for additional super room or for clearing of the dripping honey.

$A$ honey cistern (Fig. 40) is a necessity, even though only a few stocks are kept for the production of drained or extracted honey. The price need not deter any bee-keeper from investing in such a useful article, for one fair colony will produce surplus sufficient to pay the cost the first season. A convenient size is $2 \frac{1}{2}$ feet deep and 12 inches in diameter, holding over one hundredweight. The name first given to these cisterns-honey ripeners -is being dropped, and rightly so, as it is found that extracting honey before it is properly ripened in the 
hive does not pay either in quantity or quality. The sliced combs, or the honey from below the cages of the extractor, is put into the upper compartment, and the honey is drained through perforated tin or woven wire. It then passes through a piece of fine canvas tied over the neck as shown, so that all pieces of comb, however small, must be left behind.

There is still a further strainer required, as the first is apt to get choked with pieces of comb. One with a little larger mesh, strengthened with bars and movable, if arranged to rest half-way down the upper compartment, would prove of great service. Effective straining also necessitates early removal of supers, as thick honey refuses to pass through any but coarse strainers, and the result must be unsatisfactory.

\section{Sectional Honey.}

Sectional honey of prime quality is much sought after, and usually commands a very remunerative price. Therefore it must be obtained in the largest quantity possible per stock, and presented for sale in an attractive form. Two crates will at all times be needful if a stock is to have a fair amount of surplus room available, but very often three or even more will be required on a strong stock, so fast does the honey come in during a good honey-flow. The sections must be perfectly white and smooth, and provided with either two or four bee-ways, so that passage ways for the bees are allowed above and below or on all sides. The size most generally used when evenly filled holds $1 \mathrm{lb}$. of honey, and is $4 \frac{1}{4}$ inches square by $1 \frac{7}{8}$ inch wide. 
wood (Fig. 43). The former are of thin tin, cut with or without the two perpendicular holes by means of which, when four-way sections are used, the bees are able to pass from end to end of each row of sections.

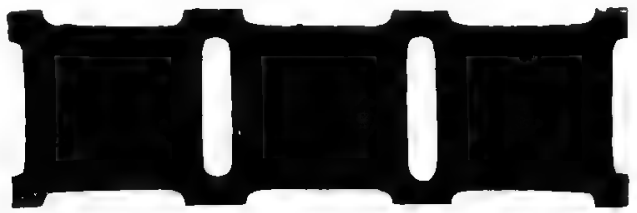

Frg. 43.

If two-way sections are used, the grooves in the separators are only cut in the top and bottom, making each $\frac{3}{10}$ inch short of the top and the bottom of the section. Without these grooves being cut in the separators the bees would be unable to enter the sections at all.

The latest introduced separator (Fig. 44), the "Sheppard Divider," is of perforated zinc, and perfect sections are said to be guaranteed by its use.

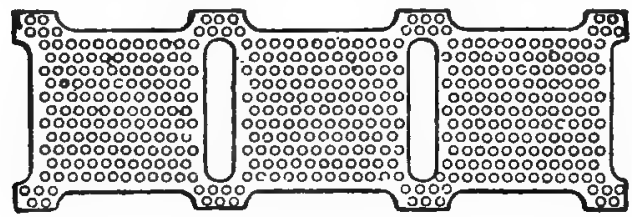

FIg. 44.

Most bee-keepers prefer two-way sections, and plain thin wood separators, also of American manufacture. Whatever kind is used must be placed close up to the sections. Between the last separator and the end of 
the crate a spring is inserted to keep the sections in position. This is very necessary, for if held loosely and vacant spaces are left, the bees will find a place for propolis, to the subsequent annoyance of the beekeeper.

The crate being now ready, the quilts are removed from the frames in the brood-chamber, and it is placed in position. The sections rest upon $\frac{1}{4}$-inch laths running from end to end of the crate, but between the top bars of the frames in the brood-chamber there

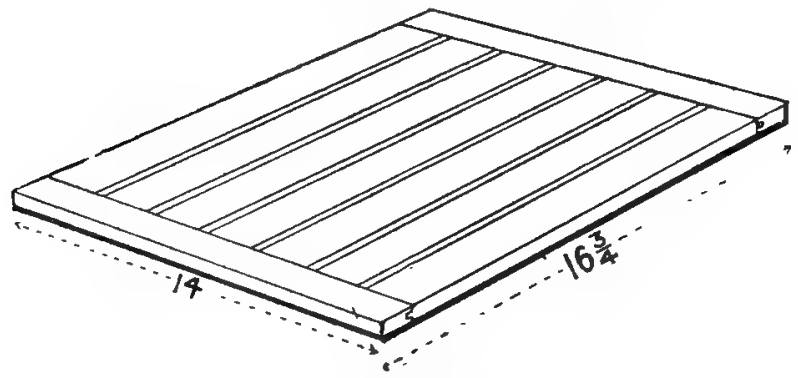

FIG. 45.

is a space of $\frac{1}{2}$ inch. In the extra space thus given the bees invariably build combs to the bottoms of the sections, already alluded to as brace-combs, which, when the crate is removed, are difficult to break, and the bees are consequently greatly irritated by the unavoidable jar. There is, however, a much more important drawback. The sections to which the brace-combs are attached will almost certainly be damaged, and often thereby rendered unfit for sale.

All this trouble may be avoided by using a wider 
top bar to the brood-frames, leaving a space of $\frac{1}{4}$ inch only, or by using an adapting board (Fig. 45). This board is 14 inches $\times 16 \frac{3}{4}$ inches. On the underside there is a rim $\frac{1}{4}$ inch in depth, which raises the board that distance above the frames. Running nearly from end to end are six holes $\frac{1}{4}$ inch wide, two beneath each row of sections. There is then only a space of $\frac{1}{1}$ inch under the sections which the bees respect, and brace-combs are avoided. The adapting board is placed upon the frames in the brood-chamber at the beginning of the honey-flow, when the first crate is given, and need not be removed until all supering operations are at an end. Under the board will then be found the brace-combs that would otherwise have been attached to the sections.

The boon such a device is to the producer of sections cannot be fully appreciated until it is seen with what ease crates are raised or remored without irritation to the colony. It is not too much to say that the prising off of crates with chisels, \&c., has had much to do with the apparent natural irritability of many a stock of bees. Gentleness in every operation is much to be desired, and the use of this board will be one means to that end.

Queen-excluders are not required when sectional supers are used. This is the case, particularly when the brood-chamber has been properly manipulated, and the combs are not allowed to become clogged with honey before the super is in place. Full sheets of worker foundation also act as a deterrent to the queen entering the sections. If starters only are giren above a badly arranged brood-chamber, drone 
comb is built in sections, and the queen will frequently leave her own domain to deposit eggs therein.

Sections are also placed in wide frames instead of crates, and were used and recommended many years ago by Messrs. Abbott and Cheshire, but of late they have been heard little of. Quite recently a crate of

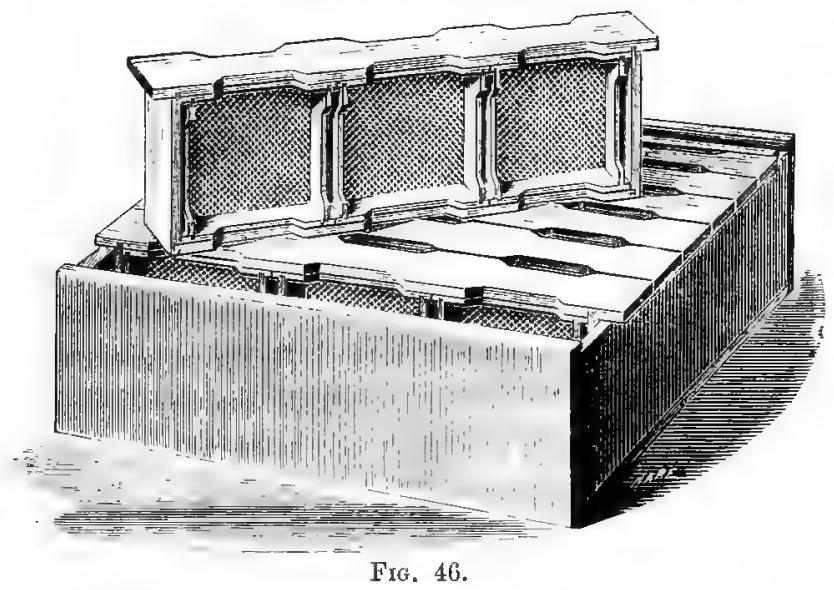

wide frames or section hangers, introduced by Mr. W. Broughton Carr, has sprung into farour. These hangers are cut to receive three sections. Separators are then fixed to one side, and the whole set is then held tightly by a spring, forced between the last hanger and the crate end. 


\section{CHAPTER XI.}

\section{BEE-ESCAPES AND SUPER-CLEARING.}

$\mathrm{I}_{\mathrm{T}}$ is generally remarked that one difficulty is no sooner overcome than another is presented for solution. If we take the preparation and filling of supers as a difficulty overcome, we are soon brought face to face with another, viz., how to take from supers their contents when full, seeing that the stores are so safely guarded by the bees. An old practice, when the super happened to be a skep, was to shake out the bees while walking round the garden, but frequently the tender combs gave way and followed the bees. At other times a favoured plan was to place the full super in an out-house, and leave the door slightly ajar. As long as the place remained perfectly dark, except for this slight opening the bees would leave without difficulty. At the present time these and other difficult and troublesome methods of ridding supers of bees have already been, or shortly will be, superseded by simpler and more satisfactory methods.

Some years ago, on his return from a visit to beekeepers in the East, Mr. T. B. Blow illustrated and described in the British Beo Journal a box, on the top 
of which was fixed, over a small hole, a perforated zinc or wire tube. The super to be cleared was placed in the box from which the bees left by the tube and did not return. In 1890 a modified form of this device was advised by $\mathrm{Mr}$. Harbordt for fixing over the ventilation hole in the roof, as a means of exit for the bees, and now the cone is greatly valued as a means of ridding supers of bees. It is equally effective whether used on a box or over the ventilating hole in the roof of the hive.

When a box is used a hole is needed in the lid about

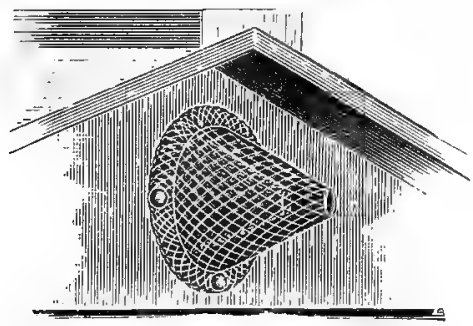

FIG. 47.

6 inches in diameter, and another in the side about 1 inch in diameter. Over the latter the cone is tacked with small nails. This cone, made of tinely perforated zinc, is $3 \frac{1}{2}$ inches long, 2 inches wide at one end, and $\frac{1}{4}$ inch at the other. The super to be cleared of bees is then placed over the hole in the lid, and if the beekeeper will see that no bees can leave except by passing down into the box, and thence out by the cone, no anxiety need be felt as to the result. In a very short time all the bees will have left by the exit provided, and have returned to their own hive. 
An "Ivo," or other super, may be cleared in the following manner. First, fix over one of the ventilating holes in the roof of the hive, a cone, and then after administering a little smoke to the bees, raise the super with as little disturbance as possible, and place under it a cloth, or sheet of paper; anything in fact that will cut off the communication between the brood-chamber and the super, or between the topmost and next lower super, if more than one are on the hive. Draw back the quilts that remain upon the super and replace the roof. As soon as the bees find that they are cut off from the brood-chamber, they will leave the super, attracted by light which will then be coming in through the perforated zinc cone. This is a quick and thoroughly satisfactory method of clearing supers of bees, but as all roofs are not beeproof, they must be made so, otherwise the bees will leave by other exits than the cone, and, if they do, so surely, if the super is left on long enough, will they return and carry off the honey.

\section{Pin Trap.}

One of the earliest mechanical contrivances to act as a super clearer was the Cheshire pin trap, the holes in which may be made either on a separate piece of wood to fix on a box side, as made by Mr. Clutten, or they may be made in one side of a box, if it is fixed at a small angle. The trap may be constructed according to the following directions given by $\mathrm{Mr}$. Cheshire in his work "Bees and Bee-keeping." Over a large opening in the box is placed a thin piece, slanting at an angle of about $45^{\circ}$ to the horizon; in this are made 
clean holes $\frac{1}{4}$ inch in diameter. Four rather small pins are driven in, two above and two below each opening, each pair so close together that a fifth pin can lie between the two pairs, exactly across the centre of the hole, while its head cannot slip between the other two. Instead of using two pins above the hole I prefer a pin deprived of its head and driven in somewhat like a bell-hanger's staple, to suspend the centre pin running across the opening. Three or four of these will be sufficient. The bees coming to the light, press up the pin which crosses the hole; it freely rises, and gives the exit, while entry, as it falls back into position, is effectually barred.

Either of these methods can be used with supers containing combs from which the honey is to be drained or extracted; but sectional supers require more care in removal, because the bees, after being disturbed and before leaving the super, will perforate the cappings of the cells in order to obtain honey, as they invariably do, when disturbed. Sections or other comb honey for exhibition would thus be spoilt. A more satisfactory appliance for this purpose is the Webster clearer, designed by Mr. W. B. Webster. It also is a cone clearer, but the cones of wire cloth are fixed beneath a board exactly underneath a hole through which the bees must pass to get to the lower compartments. The board is raised $\frac{1}{4}$ inch by a ledge runuing round on the under side. The clearer should be placed under the super without in the least disturbing the bees in their work, if possible, then they will pass down through the cones leaving the cappings of the combs in the super untouched. 
The Porter escape (Fig. 48) is very ingenious and perfect in action. It is an oblong tin case open at one end. Above this is fixed a tin cover, with a hole in the end away from the opening in

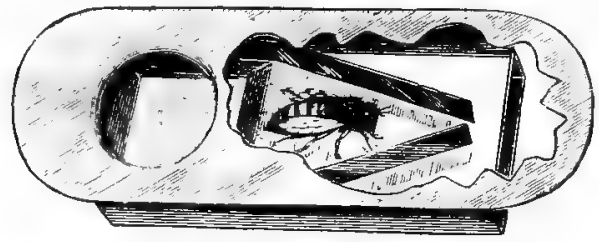

FIG. 48.

the case below, and being extended beyond the sides of the case forms a flange all round, resting upon the sides of a hole eut in the board to receive the oblong case. When this board (Fig. 49) is placed below the super, which it is made to fit, the bees leave by the circular hole shown in the illustration, but they can only leave the small case below by pressing against two fine brass springs. As soon as

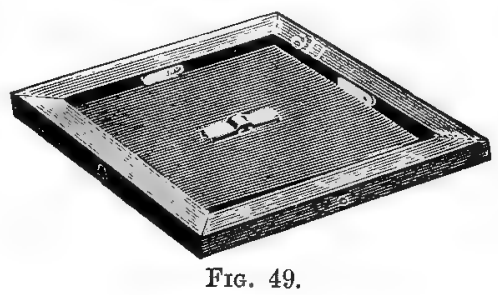

a bee has passed through, the springs return to their former position and prevent bees passing upwards. It is best to move supers bodily, but when long hives are used the back frames will be used as honey recep- 
tacles. Each frame from which the honey is to be extracted must in such cases be lifted out separately, so that the adhering bees may be returned by a sharp jerk of the frame. Any bees not detached may then be dislodged by a wing or feather, or the Yucca brush.

\section{Removing Sections.}

From a section crate the honey must, as has already been pointed out, be removed carefully to avoid damaging the comb. If the crates have been placed upon an adapting board, and removed before much propolis has been used, there will not be much difficulty in getting the sections out without damage. Their removal will be rendered easier if the laths, upon which they rest, have been slightly rubbed over with a little vaseline before putting in the sections. It is certain that there will, at times, be some sections not properly finished. These ought to be placed together and given to a stock requiring more super room, or to any other stock likely to complete the work. 


\section{CHAPTER XII.}

QUEEN RAISING AND INTRODUCING.

THE heading of colonies with young, and consequently vigorous laying queens, is of great importance, hence the necessity for rules to guide in the rearing and introducing of queens to stocks that have lost their queens, or have queens of inferior quality. It does not follow that, though queens are of little use to an advanced bee-keeper after their second season, they must be removed from every stock which has not sent out a swarm for two successive seasons, because bees undoubtedly raise queens to supersede those failing in their power of egg-laying.

A few years ago a bee-keeper, owning a large apiary, noticed during the manipulations of a particular colony that there were newly-formed queen cells in the hive, though at the same time the queen was laying. This circumstance would have received little notice, but for the fact that it was not near swarming time, and the colony was evidently not preparing for swarming. The progress of events was carefully watched, and during a subsequent examination a young queen was found on the combs, whilst the old queen was also 
still laying. In a few days the virgin queen left the hive on her wedding trip, and, the object of her visit having been obtained, she entered the hive and killed the old queen. This instance proving, if proof were necessary, that stocks do requeen themselves, is given to show the necessity for removing any queen known to be of inferior quality. A young queen may be easily recognised by her downy appearance, but the appearance of a queen must not alone be the guide as to whether or not she is to be superseded.

Work in the form of egg-laying is what we require in a queen; therefore it is the manner in which she lays that must decide her fate. It is impossible to say what quantity of brood should be in a hive at any particular date, for seasons vary. The earlier the season the more forward will be a good stock. It is, therefore, chiefly by comparison that the merits of queens must be decided. When a stock, apparently equal to others in the apiary in point of numbers and amount of stored food, shows a small amount of brood while others are in this respect fairly equal, the conclusion we may fairly come to is that the queen in question is not worth keeping, and consequently must be replaced by one of better quality. In some wellmanaged apiaries it is rarely that a queen is allowed to remain at the head of a colony beyond her second season, as she is, from a bee-keeper's standpoint, worn out or has reached that stage in her existence when to keep her means a lowering of the profit obtainable from that particular stock.

These remarks will doubtless be sufficient to emphasise the necessity for keeping a strict account 
of the age of every queen. It is not a difficult matter for a cottager to know the ages of his queens, for a stock out of which a swarm issued, say in 1894, will have a queen of good quality in 1895 , one that may be expected to do good work that season and probably equally so in 1896 , because, being provided with brood-chambers of limited capacity, queens heading stocks in skeps do remain profitable longer than those whose energies are directed to filling with eggs, the combs of an extensive brood-nest such as is found in a bar-frame hive.

In case the idea should be entertained that no harm can result from stocks requeening themselves, it is well to state that every effort should be directed to obtaining and keeping in each colony only queens exhibiting the most desirable qualities. This cannot always result if requeening is left to the bees, for when the necessity for superseding a queen arises the stock will, in all probability, be thin in numbers; and as the nurse bees play an important part in the rearing of bees, it is best to ensure the raising of queens in full colonies.

\section{Queen Raising.}

Movable combs render the operations of queen raising and introducing comparatively easy.

Having selected the stock from which it is desired to raise queens, remove the queen about noon on a warm day, when most of the old bees are out foraging. By giving very little smoke the bees will not be disturbed, and the queen will most likely be found at 
work on one of the centre combs. If a queen of good quality she must not be sacrificed, but given to another stock known to possess a poor queen. When the bees in the queenless stock find out their loss, they commence the formation of queen cells around some of the cells containing worker eggs or grubs that have just emerged from such eggs.

To ensure the best results queen raisers prevent queen cells being formed over grubs a few days old, as queens so produced are not of the best quality. Ten days after the removal of the queen the queen cells will be sealed over and ready for removal to other colonies from which we take the inferior queens. The day before it is decided to remove the queen cells all hives to which queen cells are to be given should be deprived of their queens; but in order to ensure that no stocks are left queenless at the close of the season, these queens, or the best of them, should be placed in nuclei until the stocks from which they are taken have fertile queens. There should be as many queenless colonies as there are well-shaped queen cells to spare.

The day following each queen cell should be cut out carefully with a little comb attached, and one placed between the centre combs in each queenless hive. The comb attached to the cell will prevent it falling down, and a gentle pressure on the comb will fix it to the bar. Lay the quilts lightly over the frames and make no further examination until the sixteenth day from the removal of the first queen. Then examine all the queen cells, and if a well-shaped hole has been made at the mouth of the cell the queen has hatched 
out properly, and an examination of the combs need not, in fact, should not, take place for another week, by which time some, if not all, the queens may have been on their wedding flight and be found laying.

As soon as it is ascertained that a queen cell has failed or been destroyed, one of the queens reserved must be introduced, and the others not required may be destroyed. Instead of killing the queens two or three nuclei may be united to form one colony, the queens being allowed to settle the question as to which shall remain alive. If more stocks are not required by the uniting of nuclei, a nucleus colony may be united to each hive near which it has been standing.

\section{Requeening Skeps.}

Swarming will be the best method of requeening stocks in skeps or other fixed-comb hives, as the old queen always leaves with the first swarm. The queen that, later on in the season, is found laying will therefore be a young one, and of the same age and quality as queens accompany after-swarms or casts. It is not an unusual occurrence for three or more swarms to issue from a good stock. The hives into which all but the first are placed should be marked with the figure 1, to show that the queen is in her first season. The hive into which the first swarm is placed must be marked 2 or 3 , according as to whether or not she issued with a swarm the previous year.

At the end of the season bees taken from condemned stocks should be used for strengthening weak ones 
and giving new queens. When bees are added for the purpose of requeening, the bees of the stock must first be driven and the queen captured. The two lots can then be united according to the directions given for uniting.

\section{QueEN InTRoduction.}

If for any reason it is desirable to introduce a queen to a colony of bees, certain precautions are necessary, otherwise the stranger will be at once killed by the bees of the stock to which she is introduced. Bees apparently distinguish one another to some extent, if not entirely, by scent, and it is very amusing to see how a well-dusted bee flying home from the artificial pollen box is received by the guards. It is not an unusual occurrence for such a bee to be refused admission to the home from which she so recently issued to find and bring home food for the colony.

Each colony has a distinctive odour, but how it emanates is not clear. Any bee-keeper of experience will know that after handling a queen the bees of that colony will cluster upon the spot where she has been, and behave in a manner that appears to betoken pleasure on scenting the queen. In order, therefore, to introduce an alien queen successfully, we must adopt a means of giving the queen an opportunity to form an acquaintance with the bees, and acquire the scent peculiar to the hive before being liberated; or steps must be taken to deprive her of the scent, to some extent, peculiar to the stock from which she has been taken.

The first object is attained by imprisoning the 
queen on or between the combs of a colony that has lost its queen, or by her removal has been rendered queenless. The simplest form of cage is known as the pipe-cover cage (Fig. 50), a small cylinder of tin covered with fine-woven wire. The queen should be taken alone and placed in the cage, which should be standing upon a piece of thin wood or cardboard. It should then be laid upon

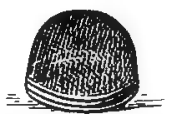

FrG. 50. a part of the comb where the cells contain unsealed honey. After withdrawing the cardboard the cage is pressed down into the comb, and there the queen remains confined for twenty-four hours or more, when an examination of the hive should be made. Very little smoke should be administered to the colony, as the cage is to be raised and the behaviour of the bees to the liberated queen noticed. Sometimes they will seize and ball her, that is, so surround her that they form a ball of bees. If she is not at once liberated by gently smoking the cluster, she will be crippled or

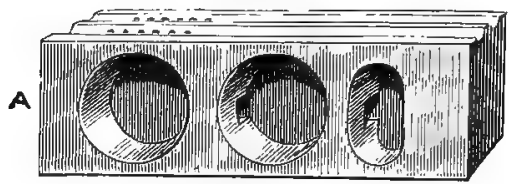

FIG. 51.

killed. After such a reception the queen must be re-caged until the bees receive her kindly.

Queens received from queen raisers at home or abroad are usually sent in a small travelling cage (Fig. 51), accompanied by a few workers to prevent the 
lowering of the temperature, which would impair, if not destroy, the value of the queen. To liberate the queen take the cage into a room and remove the lid. The bees will at once commence a general buzz and creep over the sides of the cage. The queen must be looked for and allowed to run into a small matchbox. This receptacle is suggested because it is always at hand, and in it the queen may remain for a few minutes without harm. The box may

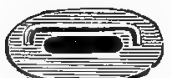
then be put into the trousers or waistcoat pocket for warmth until introduction takes place. Other cages to let down between the combs are also used. The queen is put into this-the Raynor pattern cage (Fig. 52)-at the top, and when liberated, by pressing a wire which opens the lower part of the cage, it is without disturbing the colony. The Abbott cage is very similar, but the queen is liberated by withdrawing a wire from the side of the cage.

FIG. 52. Mr. Howard, in using a cage of this pattern, recommends discarding wires and spring doors. The lower end of the cage is open, and closed after introducing the queen by filling the lower part with Good's candy. The queen would then be liberated as soon as the candy had been consumed between the bees and the queen. This method is said to be uniformly successful.

Direct Introduction.

Several years ago Mr. S. Simmins promulgated a 
system of direct introduction, which he had proved in practice to be not only safe but speedy. So confident was he of the success of this method that in supplying queens to customers he guaranteed successful introduction, if the rules he laid down were faithfully carried out. In "Ivo" apiary, since the system was first made public, scores of queens have been introduced according to the following instructions, and up to the present time not one failure has been recorded.

The stock amongst which it is intended to introduce an alien queen, if not already queenless, must be rendered so by removing the queen on a fine day at noon-in fact, the same day that the queen arrives, if received from another apiary. The hive is then closed and not touched again until evening, when all the bees are in the hive. Just before dusk the queen to be introduced must be taken alone, and placed in a match-box or other receptacle, where she will be free from a chill, and kept there for about half an hour. Then go to the queenless hive, taking a light if necessary, gently draw back the corner of the quilts, give a slight puff of smoke between the combs, and let the queen run into the hive. Return the quilts, replace the roof, and make no examination of the hive for twenty-four hours or more.

The Howard queen cage for transmitting queens by post and introducing them on arrival, is really the well-known "Benton" cage (Fig. 51), with an arrangement for liberating the queen. On the arrival of the queen by post, the lid must be removed from the cage, when its place is taken by a piece of perforated zinc. The cage is then placed over the space between 
two combs, and allowed to remain so for some hours. The box is then moved along the zine until the hole containing the Good candy is over a circular hole in the zinc. The bees of the stock then commence to eat the candy, and thus in a short time a union with the strangers is effected. 


\section{CHAPTER XIII.}

DISE ASES.

BEEs, like animals, are subject to disease, but fortunately for bee-keepers there is only one, foul brood, of a serious nature and highly contagious. By careful attention to the symptoms characteristic of bee diseases, it is easy to detect their presence, and by applying known remedies, cure the affected stocks.

Occasionally it is said, "If bees have such a dreadful disease that works such havoc, I will let the hobby alone." Such faint-hearted persons may like to know that in the midst of infected areas there are many apiaries in which foul brood has never shown itself, not because the germs of the disease are absent, for that seems an impossibility, but because they have no means of development, in consequence of the care and attention the bee-keeper bestows on his apiary to ward off an attack. Nearly every bee-keeper of note has had his apiary affected with foul brood. The late Rev. G. Raynor once expressed the opinion that his apiary had remained free from disease, while many bad cases were known to exist around him, simply 
because in using carbolic acid as a bee quieter he had at the same time used a powerful antiseptic.

Of the diseases to which bees are subject we need only notice here two, dysentery and foul brood.

\section{DYSENTERY.}

This is a disease due chiefly to the carelessness of the bee-keeper, and is much too frequently met with in the winter and spring. Its presence is known by the bees voiding the excrement on the combs, which may result from confinement in a damp or badly ventilated hive, but is more frequently the result of bees being fed upon unsuitable food and at the wrong time of the year. On fine warm days early in the year it will frequently be noticed that the bees soil their hives and everything about the apiary. This is often from a cleansing flight which the bees need when breeding has commenced, and they have been confined to their hives for several days.

Bee-keepers who ignore the directions for feeding up their stocks with syrup of a proper consistency, while they are in numbers sufficient to maintain the heat needed to evaporate the superfluous moisture, must expect this disease to break out, for thin syrup which the bees cannot seal over is almost certain to ferment during the winter. By carefully carrying out the instructions given under the heading "Wintering," this disease may be almost entirely avoided.

The remedy, when the disease exists, is to remove the bees and combs into a clean hive, and give them fresh food. This may be effected in a warm room. 
At the same time a little warm syrup and a cake of soft candy should be given. If the weather be mild the changing of quarters might be quickly performed in the open air, the warm syrup would then have the effect of sending the bees out for the cleansing flight they so much need.

\section{Foul Brood (Bacillus alvei).}

This is indeed a disease that bee-keepers may well dread, when they read of the sad havoc it has played in apiaries at home and abroad; but thanks to the untiring energy of scientists who love the hobby, the ravages of the bacillus may be stopped. It is only within recent years that this disease has become so widespread, but this cannot be surprising seeing to what extent stocks, swarms, and queens have been conveyed from one part of the country to the other, and to this country from various parts of the continent, where the disease has long been known to exist. There appears to be no definite record of the disease being in existence in Britain until foreign bees were introduced. Before the traffic in bees became so general, if the disease existed it remained in a confined area and the stocks died out. Mr. Woodbury and other bee-keepers attributed the advent of the disease in their apiaries to feeding with foreign honey supposed to contain germs of the disease. On this point it is satisfactory to learn that $\mathrm{Mr}$. Cowan, a very eminent authority, has not discovered germs of the disease in any sample of honey when examining it under microscopes of very high power. But at the same time it 
is now very generally believed to be a medium by which the disease is carried. Bee-keepers cannot, therefore, be too careful when introducing low-priced honey into their apiaries for feeding purposes.

The disease is due to the presence and propagation of a particular microscopic germ, to the bacillus of which the name alvei has been given by Mr. Cheshire. The presence of the germ is absolutely necessary to account for the outbreak of the disease. It has frequently been stated that chilled brood will cause foul brood, but this is an error. It will, however, afford a resting-place for the germs, should they be in a district, and therefore we must avoid, as far as possible, providing the germs with a propagating medium. The germ has great vitality and is most difficult to destroy. When it enters a proper medium it develops into a bacillus, which multiplies at a remarkably rapid rate, until the nourishing matter upon which the bacilli feed is exhausted, and then spores or germs are produced, which, when the opportunity occurs, germinate and produce the disease.

Being of a microscopic character the germs are easily transmitted from one district to another, or from a diseased to a healthy hive. When examining hives supposed to be infected every precaution against spreading the disease must be taken. A cake of Calvert's carbolic soap should always be within reach, so that the hands may be washed after each manipulation. As a further precaution the manipulator should stand with his back to the wind.

Symptoms of foul brood. The first symptom usually noticed by the novice is a very unpleasant odour arising 
from the hive, and perceptible even before it has been opened. The disease is then in a bad form, and the combs will be found in a state that will necessitate the burning of combs and in fact everything movable in the hive. When the disease is in such an advanced stage it is true economy to destroy bees, combs, quilts, dummies, and even the hive, if it is not of much value. The name foul brood was given to the disease, as it was found that in a diseased stock the brood quickly exhibited a putrid appearance. Instead of being pearly white, the grubs, when attacked by the bacillus, turn yellow, and ultimately become a coffee-coloured, sticky mass at the bottom of the cells. The cappings of the brood combs are sunken and pierced with numerous small and irregularly shaped holes.

In spring, by inexperienced bee-keepers spreading the brood during fine weather, and at an unsettled period of the year, much of the brood becomes chilled and dies. This is sometimes taken for foul brood, but chilled brood is not like foul brood, a dark putrid mass. When there is the slightest suspicion of foul brood, any stocks that have been doing good work and become listless should be examined without delay, particularly if the bees are noticed fanning at the entrance.

Remedies. The remedies proposed to deal effectively with the disease are various, and the results after treatment by them the same. In many instances it is not the remedy that is at fault, but the bee-keeper, who uses it in a half-hearted manner and carelessly carries out the directions given.

Salicylic acid is a well-known remedy, and when properly administered effective. It is most effective 
when administered by means of a fumigator according to the directions given by the inventor, M. Ed. Bertrand, but few bee-keepers go to the trouble of fumigating. As the bacilli are found in the alimentary canal of the bee all food given should be medicated. "The salicylic acid solution for this purpose is made, according to Mr. Cowan's directions, as follows:-Salicylic acid, 1 oz.; soda borax, 1 oz.; water, 4 pints. Half an ounce will be about the correct amount of the solution to six pounds of sugar.

Phenol. Mr. Cheshire, in a paper read at an important meeting of bee-keepers in 1884, gave a means of cure by phenol; but as bees have a reluctance to take food medicated with this remedy the syrup must be poured into the empty cells around the brood, in order that the bees may be compelled to take and use this cure. In the hands of the painstaking bee-keeper success by this method is certain.

Formic acid was first advocated by Mr. R. Sproule, of Dublin, who also used phenol with success previous to the reading of Mr. Cheshire's paper. The chief merit of this means of dealing with the disease is its simplicity. The acid penetrates all parts of the hive, and in a short time, by its use, apiaries have been rid of the pest. The following directions are by Messrs. Bewdley \& Draper, Dublin, who prepare the remedy. "Select a frame of clean empty comb and pour about four ounces of formic acid into it by placing it on a table and dropping the acid on it from a height of a few inches. Contract the hive to as many frames as the bees can cover, and hang the frames containing the acid at the rear of the hive, cover up warmly, and 
put a sheet of paper between the layers of the quilt so as to prevent the escape of the fumes of the acid as it evaporates. If the weather is warm it will be found in the course of a week that the odour of the foul brood has disappeared, and that the bees (if not too weak in numbers) have cleared the putrid matter out of the cells. It is seldom necessary to refill the comb more than once unless the disease has been re-introduced by infected combs, \&c. If foul brood is prevalent in the district it may be well to keep some of the acid always in the hive as a prophylactic. In case of an ordinary ten or eleven-frame hive this can be done while honey is being stored, by putting the acid into a section of empty comb and placing the section at the end of the crate farthest from the hive entrance, so that the acid has to pass over all the combs before the bees fan it out. 'Storified ' hives can be treated by filling a comb and hanging it in the upper storey. For spring and autumn feeding add a spoonful of acid to each quart of syrup. As formic acid does not affect the flavour of the honey, it can be used with perfect safety while honey is being stored, and as a remedy it will be found superior to either phenol or salicylic acid."

Naphthol Beta, for which, as an antiseptic, we are indebted to Dr. Lortet, is the most recently introduced, and, being simple in application and inexpensive, it is now the most generally used remedy. To facilitate the use of Naphthol Beta the Editors of the British Bee Journal have prepared packets containing sufficient for a given quantity of food. The directions on each packet are as follows:- "For every pound of sugar used in making syrup or candy dissolve three 
grains of Naphthol Beta in alcohol or rectified spirits of wine. Naphthol dissolves freely in alcohol, but is insoluble in cold water. Pour just suffcient spirits on the Naphthol to dissolve it and make it a clear liquid. Pour the solution of Naphthol into the syrup when sufficiently boiled and while still hot. In making candy, pour in the Naphthol solution when the syrup is of the proper consistence, and just before taking it off the fire."

The difficulty of taking the required number of grains for the amount of sugar to be used may be overcome by the contents of the packet (sufficient to medicate 145 lbs. of sugar) being put into a small long bottle along with the necessary spirit, then pasting a slip of paper on the side of the bottle as high as the top of the solution. It would then be a very simple matter to divide the paper proportionately to the amount of food to be medicated at a time. This any chemist would do when putting into the bottle the small amount of spirit needed.

Naphthaline is used in conjunction with Naphthol Beta, though not in syrup. It is to be obtained in balls about the size of marbles, two being split and dropped to the bottom of the hive as a dose. The fumes circulate through the hive and destroy the bacilli. As a precaution against the introduction of the disease Naphthaline and Naphthol Beta should be used in every apiary. 


\section{CHAPTER XIV.}

\section{ENEMIES OF BEES.}

BeEs, like other creatures, have enemies to contend with. Among birds, the most persistent in carrying off bees is the blue-tit, which may be seen to fly down to the apiary and carry off bee after bee. It is surprising what a number of bees a single pair of these birds will take in a very short time. Means should, therefore, be resorted to in order to keep down these birds near the apiary.

The wax moth, which effects an entrance more particularly into weak hives, lays its eggs on the combs or in the débris. From these eggs issue grubs, which burrow in the combs and consume the wax until they build their cocoons, from which again issue moths. If allowed to gain headway the ravages of the grub will soon destroy a colony. By keeping stocks strong we are more likely to keep out the wax moth, because the bees on guard drive it away. On the quilts should be laid pieces of naphthaline, which will keep away moths and other insects. During the spring and autumn examinations, all débris should be removed, and the combs searched for grubs or cocoons. 
Wasps in some apiaries do much harm, but as they generally direct their attention to weak stocks, which they effectually clear out, the oft-repeated advice, "Keep all stocks strong," is applicable to this case. Narrow entrances will enable moderately strong colonies to more effectually guard their home from these persistent robbers. Now and again wasps may be seen to seize heavily-laden bees that fall short of the alighting board, and frequently they sever the abdomen from the thorax, and fly away with the former, which contains the honey-sac. "Prevention is better than cure," and in order to limit the production of wasps, queens seen in the early spring should be killed, otherwise they will be the means of bringing into existence multitudes of wasps. They have undoubtedly their place in the economy of nature, but bee-keepers cannot afford to look on complacently while the enemies of the bees are multiplying at such a rate as to endanger the existence of all but the strongest stocks.

Ants' nests are sometimes found near hives, and if they are the ants become a great nuisance. To prevent their getting into the hive, the legs should stand in small pans of water, or be daubed with something objectionable to the ants, and over which, therefore, they will not pass.

Mice are partial to both wax and honey, and they may be found not only among old combs, but also in hives tenanted with bees. By keeping an entrance only $\frac{3}{8}$ inch in depth, mice will be kept on the right side of the hive. 


\section{CHAPTER XV.}

\section{WINTERING.}

How to winter bees successfully is a problem apparently difficult to solve, when we consider the losses that are recorded in the spring, and the complaints made of slow progress made by so many colonies early in the year. That successful wintering depends upon the manner in which bees are prepared for their long season of inactivity, no one will deny. Still it is astounding that, having a desire for profit, beekeepers will be so neglectful of their bees just at the very time when attention, with a view to ultimate success, is really needed.

By observing the progress of work around us we see most unmistakably that there cannot well be a period of real inactivity in any branch of industry. The farmer, for instance, immediately one harvest is over commences preparations for the next, and how frequently do we notice that he who is well ahead with his work achieves the greatest success! With bee-keeping, though the amount of work that must be bestowed upon the hobby is exceedingly small, yet it is of vast importance that what ought to be done 
should be done well and at the right time. In fact we may take it as a rule that at the close of one honeyflow, or the last of the season, preparations should be made for the following year.

The requirements for successful wintering are, briefly: a young queen, a large quantity of young worker bees, ample sealed stores to last the stock well into the spring, quilts, the upper ones of woollen material, and ventilation without draught.

\section{The Bees.}

It was years ago remarked by an able bee-master, the late W. Raitt, that the best packing for bees was bees, and of course this truism will be generally admitted. The stronger the stock is in bees, the better is the prospect of its wintering well, and making a good start the following spring. A well-stocked hive will show a much larger amount of brood than one containing only a moderate quantity of bees, for, in the latter case, there is not a temperature sufficiently high to warrant any great extension of the brood-nest.

Bees are thought by many to be in a state of hybernation during the winter. This is not exactly so, for, though bees should be inactive during the winter, and they do well if the temperature does not fall below $45^{\circ}$, they are quickly roused to activity, and may leave the hive for a cleansing flight when the temperature rises to $50^{\circ}$ or over. While the bees are in a quiescent state there will be no wasting of energy; hence the necessity for a style of hive with arrangements which to the greatest possible extent prevent the cluster 
being affected by outside changes of temperature. Of the quality of the queen enough has already been said to show the necessity for each stock being headed by one not more than two years of age.

\section{The Stores.}

To prevent unnecessary activity during the winter, we must ensure that the food upon which the bees are to exist is not only of good quality but sealed. Stocks in skeps should weigh at least $25 \mathrm{lbs}$, or $20 \mathrm{lbs}$. if the combs are new; but it is best not to limit a stock to the exact amount of food that will be required to carry it safely through the winter. Twelve to fifteen pounds, according to the strength of the colony, will suffice for this, but the latter would serve better as the minimum amount of stores.

As stores are drawn upon largely by a weak stock when a low temperature prevails, it is good policy to unite weak stocks in the autumn, and thus ensure a higher temperature being maintained, without a continual consumption of the stores. A colony properly prepared for winter will seldom consume on an average more than $1 \frac{1}{2}$ oz. of food per day until breeding commences, when the amount is at once considerably increased.

Stocks in bar-frame hives should be much larger than those in skeps, and a larger amount of stores must be allowed. The minimum weight should be $20 \mathrm{lbs}$., and this may be calculated without difficulty by considering an evenly filled standard frame to contain $4 \frac{1}{2}$ to 5 lbs. Four or five frames would thus supply 
all the food needed, but a good stock will well cover six to eight frames. Though it is advisable to allow not less than $20 \mathrm{lbs}$. of stores, they must be judiciously distributed. If full combs are left on the outside, the food may candy when cold weather compels the bees to cluster in the middle of the hive. Another reason for carefully distributing the food is that empty cells are preferable to slabs of honey for the bees to cluster upon, provided that above the cluster food is within reach. The best arrangement is to allow the centre frames to be about half filled with sealed stores, while the remaining frames on either side contain in increasing proportion the remaining quantity of food allowed.

\section{Winter Passages.}

When stocks are wintered in thin single-walled hives, it may occasionally be noticed, more particularly than in double-walled hives, that the spring examination brings to light seams of dead bees-bees that have perished from want, though in other frames ample stores still remain. The cause is not far to seek. Having consumed the food above them, the bees must travel round or under the frames to reach further supplies. This they cannot do during very severe weather, for as soon as they leave the cluster with this object, they are numbed by the cold and die. Consequently the whole cluster or clusters die. To prevent this loss passages over the tops of the frames must be provided.

A very simple contrivance, the " Hill Device," placed upon the frames raises the quilts and allows the bees 
to travel to all parts of the hive over the top bars of the frames. Three or four pieces of wood, $\frac{1}{2}$ inch square, laid across the top bars, $\frac{1}{2}$ inch apart, before putting on the quilts, will be equally effective in providing passages from comb to comb.

\section{Quilts.}

The first of the quilts or cloths that are placed above the frames should be of good stout calico, or, better still, ticking, which the bees will not quickly bite through. The others should be of some woolly material, such as felt or carpet. The number required will depend upon the thickness and non-conductivity of the material. There should be sufficient covering to ensure the heat of the cluster being preserved. In the place of the upper quilts, trays filled with chaff, or chaff-cushions, may be given.

Impervious quilts of American oilcloth, smooth side downwards, are used in many apiaries in place of the first quilt. They are clean, and prevent the escape of moisture from the brood-nest. No objection can be raised to their use on strong stocks, if other quilts or chaff-cushions are given above. During the spring such a quilt may be a distinct advantage, as a moist atmosphere is needed during the breeding season, and also when a dummy feeder, filled with Porto Rico sugar, is placed at the side of the brood-nest.

Ventilation without draught is needed for successful wintering, and may be provided, after the quilts, \&c., have been given, by allowing an entrance of about 6 inches in width, until breeding commences and 
flights are frequent. In the place of a wide entrance the object will be attained by raising the hive a couple of inches, and placing under the brood-chamber what is termed a raiser. 


\section{CHAPTER XVI.}

DRIVING, TRANSFERRING, UNITING.

Aт the close of the season a plan very generally pursued by cottagers in taking their honey, is to select those stocks by weight which are to be "taken up." At the end of the day each marked hive is lifted off its stand and placed over a hole dug in the ground, in which a piece of sulphur is burning in a cleft stick. In a few minutes the busy workers are stifled, some falling to the bottom of the pit, others dying in the combs, where many remain during the whole process of slicing and draining and the making of mead. No wonder that the fluid, resulting from such a method of procedure, should fail to find ready purchasers. Happily, this distasteful system is giving way gradually to more satisfactory methods of taking the honey in its purest form, without destroying the bees, which latter prove of great service if properly disposed of. First, they may be united to weak stocks, and thus 'ensure their passing safely through the winter, as the greater the number of bees, the less the consumption of stores for the purpose of keeping up the normal 
temperature of the hive; or they may be united, two or three lots together, to start a new colony.

\section{Driving.}

If it is decided to remove the bees from a condemned stock, that is, one marked for taking up, and utilise them in one or other of the ways mentioned above, we must proceed on a fine evening to the stock, drive a puff of smoke into the entrance, and then, in a minute or two, move the hive bodily to another part of the garden away from the hives, so that the operation may be conducted without disturbance from other bees. Before the hive is moved throw over it a piece of canvas, and on the stand place an empty skep to keep the flying bees from entering adjoining stocks.

On returning to the full stock remove the canvas and drive down the bees among the combs by a slight puff of smoke, while an empty skep is placed above the full stock. Now tie round the junction of the two hives at cloth to prevent the escape of bees. This preparation is for what is termed close driving, and will be adopted by timid bee-keepers, or when a sight of the queens is not necessary, and there is a fear of robbing. The empty hive must be of the same size, with regard to its diameter, as the stock hive, in order to facilitate the escape of bees from the lower to the upper hive. The bees will at once commence to ascend if the combs below are jarred by gently beating the sides of the stock hive with a stick, or with the palms of the hands. In a few minutes all the bees will have left the stock, and will be found clustering in the skep above. 
Open driving is a more interesting operation, and should be practised, when the presence of the queen among the bees driven must be noted. When placing the empty skep above the stock hive, driving irons (Fig. 53) are used to fix it at an angle of $45^{\circ}$ or more to the latter. The junction of the two hives should be at a point to which the combs run, so that the bees may leave their hive without the labour of climbing over the combs. The driving irons are fixed one on each side, and the ends are driven lower into the side of the stock hive, and the upper into the side of the empty hive, a skewer being used to hold the hives together at the junction.

When the hives are thus fixed the jarring of the combs will take place as for close driving; but gently at first, or many bees will leave the combs, and, flying about,

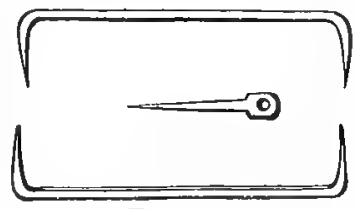

FIG. 53. become a source of annoyance to the operator. A few bees flying about will do no harm, unless they are robbers from other stocks in search of exposed sweets. If there is a danger of robbing, the entrances to other stocks should be closed before driving operations commence, in such a manner that the bees are not harmed by the confinement.

After a few strokes on the side of the stock hive, the bees will commence to run along the combs towards the junction of the hives, and there enter the upper one. They may move in great numbers when once started, and, if so, must be prevented by cloths from congregating at the back of the hive. Moving the 
cluster with the finger, and giving a slight puff of smoke to those congregating at the junction of the hives, will hurry them up into the empty one. A sharp look-out must be kept for the queen, in order that she may be removed, if the bees are only required for uniting to other stocks. In case no queen of two or three lots is of particular merit, the bees may be allowed to settle the question as to which shall remain at the head of the united colony.

Open driving is adopted in the making of artificial swarms, a proceeding not recommended, unless increase of stocks is desired; but even then it is a risky operation in the hands of the novice, who had better trust to natural swarming for increase of stocks. Artificial swarms never work with the same vigour as those that issue naturally.

In making an artificial swarm care must be taken to imitate nature as far as possible, and see that sufficient bees are left in the hive to attend to the brood-nest, and keep up a temperature that will prevent the brood being chilled. Unlike a natural swarm which may be placed in any new position, an artificial swarm must be placed on the stand occupied by the stock, which may be moved to another part of the garden.

Presuming that the operation is performed in the middle of the day, account must be taken of the flying bees, that is, those flying to and from the fields, in estimating the quantity to be driven out of the stock, for all those not in the hive will, of course, join the swarm on returning home.

Bumping is an expeditious method of taking the 
combs from the skep while the bees are in, but it is a method that should only be resorted to when the hive contains old combs; or, if the combs are new, the hive should only be bumped in cool weather, when the honey will be stiff and the combs rather brittle. Bumping should certainly never be attempted in warm weather, or when much thin or unsealed honey is in the combs. The bees are first intimidated by smoke, and directly afterwards the skep is turned mouth upwards. It is then taken hold of by the hands in such a manner that the combs run from hand to hand or side to side, and gradually turned away from the operator. If it is then set down or bumped sharply on the lower edge of the bottom of the skep, the shock will be sufficient to break the combs away from the hive sides, and cause them to fall, by their own weight, one upon the other on the far side of the hive. The combs are then taken out one at a time by letting them rest on the palm of the hand, and the bees are brushed back into the skep or into an empty hive standing close by. The whole operation should not last more than a minute, and then the hive containing the bees may be returned to its former position till the bees have cleared up the dripping honey. With care small supers may be bumped to empty them of their surplus after they have been cleared of bees.

Transferring is an operation usually understood to refer to the removal of bees and combs from a straw skep to a movable-comb hive; but to use a common expression, it is " a game not worth the candle." As a rule the skep will contain few combs of a size to fit into the frame from top to bottom, and if not, pieces 
as regular as possible must be cut out of the best combs and arranged to fit the frames. It will seldom occur that more than two, or at the most three, frames can be filled by the cutting up and fitting of the combs in the skep. Again, one lot of bees in a straw skep to start a bar-frame hive is ridiculous. Two or three lots making a weight of 4 or $5 \mathrm{lbs}$. would produce a lot likely with proper attention to be converted into a good colony for the spring, particularly if new combs or full sheets of foundation are given. It is much more satisfactory to proceed in the manner indicated, and do away with the old combs, cutting out all worker comb containing brood. These pieces of comb, joined together by a skewer or two, a space of half an inch being left between them, should be placed over the feed-hole of any hive, and securely covered first with a small wooden box, and above that with quilts. The bees will hatch out the brood, and thus no great loss of bees will accrue.

Uniting has been referred to as a means of strengthening stocks in the autumn, and thus ensuring more satisfactory wintering; or, in the spring, to ensure rapid progress and hence more surplus. This will, of course, also be the natural result of uniting in the autumn, for the increased strength of the colony will, by assisting to winter a colony successfully, also be a means towards obtaining a good working population at the commencement of the honey-flow.

Bees of different colonies, having an odour peculiar to their respective lots, have a natural antipathy one to the other, and though a comb taken out of a stock without disturbing the bees during the honey-flow, 
may without detriment be placed directly into the midst of another colony, no uniting of bees on combs or bees alone with other bees on combs should take place without steps being taken to deprive the bees of the inclination to fight. By sprinkling both lots with thin syrup scented with peppermint, their peculiar scent is destroyed and they unite peaceably. Uniting usually takes place at a time of the year when bees are prone to rob, and the least use of syrup is almost certain to cause bees that are on the alert to start robbing.

It is often said that there is nothing new under the sun, and when, a few years ago, uniting by the aid of flour was advised, it was quickly stated to be an old method revived. It is, nevertheless, though only recently brought into favour, a more satisfactory means of uniting than is sprinkling the bees with scented syrup, as no inducement to robbing is made. By gently sprinkling both lots with flour from a dredger, uniting becomes easy, and no one who has tried this method will ever think of again resorting to the use of scented syrup. Flour being a substitute for natural pollen, there is a danger of overloading the combs, hence the necessity for a thin but at the same time effective sprinkling. 


\section{CHAPTER XVII.}

\section{MARKETING HONEY.}

"WHAT is the use of keeping bees if we cannot sell our honey?" is a remark made only by those who lack that amount of energy and business ability necessary to achieve success in any undertaking. Honey, though one of the most delicious of foods, and of great nutritive value, is rarely found in the houses of those who can well afford to purchase what to many is a real luxury. Honey should not be considered a luxury, but a necessary food, and as such it should appear on the table of every householder in the land. It is the work of the bee-keeper to create a demand for that which it is his especial aim to produce.

Low prices are complained of by some bee-keepers, but to a very great extent they have only themselves to blame. The bulk of the honey, being produced nearly at the same time throughout the country, is no sooner obtained than it is put upon the market. No wonder, considering this glut, that the price falls. The great importation of foreign and colonial honey does to some extent affect the price of home produce. Still, as none, unless it is that which comes from New Zea- 
land, can compare with English clover honey, beekeepers have only to adopt the most improved rnethods of production to increase the amount of surplus per hive. And, if of excellent quality, it must realise a sum per colony which will leave no doubt as to the profitableness of bee-keeping.

From one class of bee-keepers, and they are the most successful in a large as well as a small way, complaints are seldom heard, and the reason is not far to seek. They work up a good local retail trade, and thus dispose of the bulk of their surplus near home, at very remunerative prices. A more general complaint from such bee-keepers is of their inability to supply the demand when their produce has become known and appreciated.

If bee-keepers cannot, or do not feel disposed to, create their own retail trade, they had better offer their surplus first to other bee-keepers who have this means of disposing of their produce, and failing a sale in that direction, they might apply to wholesale dealers, but from them only a moderate price can be expected except for honeys of the finest brand. Very much depends upon the time of putting the surplus upon the market, the first gathered honey being the most likely to realise the best price. And, it may be, an equally good price will be fortheoming for that which has been properly stored to meet a demand when the supply is scarce.

Bee-keepers' Associations are recognising slowly, led by the example of the Berkshire Association, the necessity for extending a helping hand to their members in the sale of their produce. Years ago I 
advocated this course, but without effect, and it is gratifying to find that the only Association which has really made strenuous efforts to assist members in the sale of their produce has been remarkably successful. In Ireland the Irish Bee-keepers' Association has, on a larger scale, and by means of central depôts, disposed annually of a very large amount of honey sent in by its nembers.

The Berkshire Association arranges with shopkeepers throughout the county to dispose of the honey, bearing distinctive labels supplied to members. As these labels are numbered and the secretary keeps an account of those issued, any complaint or abuse of the privilege would quickly bring down punishment on the wrong-doer. Until the question as to the best means of assisting members in the disposal of their produce is taken up by the Associations, there is no reason why there should not be formed, in each village, a little club. The members could arrange not only for the sale of their honey, which, when graded, would be of similar quality, but they could procure hives, frames, foundation, bottles, and, in fact, all necessary appliances at a reduced rate for quantities and save on the carriage.

\section{Grading.}

Honey varies in quality and aroma according to the source from which it is obtained by the bees, but this fact is often lost sight of or ignored, and all kinds are mingled together, thus producing a sample of moderate quality. All honey, therefore, should be graded 
whether it is in comb or extracted. The selection can be made by the colour of the capping, which is a pretty safe guide as to the similarity of the contents of the combs, particularly if they are from hives in the same apiary.

Sections most evenly flled and sealed will be classed as of first quality. There can be no question as to what style of filling is best. For exhibition purposes the tastes of the judges have to be considered, some preferring sections from which the comb can be cut all

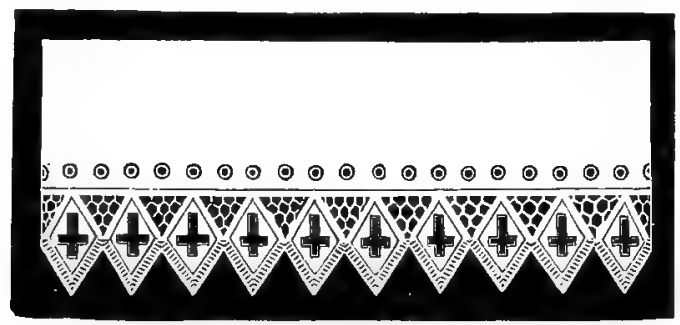

FIG. 54.

round without spilling much honey. But, however nice this may appear, such sections do not travel well, and therefore a well-filled section should be aimed at, with the cells built up to the wood all round, as well as filled and sealed. When so completed, they will, if properly packed, travel with safety. Thin sealing is preferred by the consumer, but the liability to weeping must be considered. A slight jar may crack a thin surface of comb and cause the honey to ooze out or "weep," and thus spoil the appearance and attractiveness of the section. A fairly thick and even 
capping is decidedly to be preferred, in order to ensure with the all-round sealing a perfect because the most marketable section of honey. Badly filled sections that are unfit for sale should be cut up and put into the honey cistern when the grading takes place.

Before sections leave the producer they must be scraped free of propolis, and placed in cases with glass on one or both sides. These cases are either made of enamelled tin or cardboard. Instead of using these boxes the faces of the section may be glazed and the

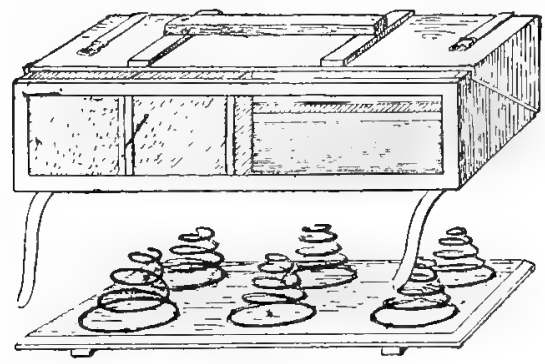

FIG. 55.

glass fixed on by a slip of paper being pasted round the section $\frac{3}{8}$ inch of which ornamented is fixed on the glass, thus not only holding it securely to the section, but making a most attractive article of commerce. For safe transit to and from shows, and at the same time proving a means of effective display, show cases may be used, which fit into or are attached to spring travelling crates (Fig. 55).

These and other travelling crates add so much to the cost of the outfic that other means must be devised for the safe carriage of sections to the dealer or 
consumer. For this trade, unless otherwise ordered, glazing should be omitted, and the sections placed side by side, six in a row. At each end place a square of wood the size of the section, then a lath above and another below the row. A parcel may then be made of the half-dozen, and if well and tightly packed in newspaper, they may afterwards be packed on straw in a box, and breakages will be the exception and not the rule. A firm which to my knowledge bought twentytwo tons of English honey in one season, positively

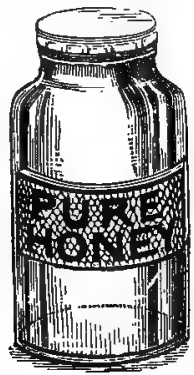

Fra. 56.

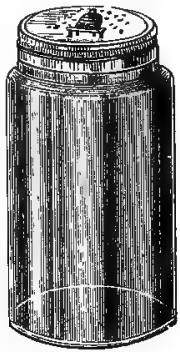

FIG. 57.

refuse to deal in sectional honey, for they say that the packing is so bad that they rarely receive a parcel in good condition. By adopting the above method of packing much loss and expense may be avoided, and more satisfaction given to the purchasers.

Drained or extracted honey is easier to deal with than comb honey, and being of a less perishable nature is more generally produced. Small quantities such as whatever amount is required for home consumption, and what is sold in the neighbourhood of the apiary, should be put up in neat 1-lb. glass jars, either to be 
covered with parchment (Fig. 56) or with a metal cap (Fig. 57), and have affixed to them an attractive label.

\section{Bottle Covers and Labels.}

Upon the label it is an advantage to draw attention to the fact that it is the nature of honey to candy or set, and that this change will take place early or late according to the crops from which it is gathered, the

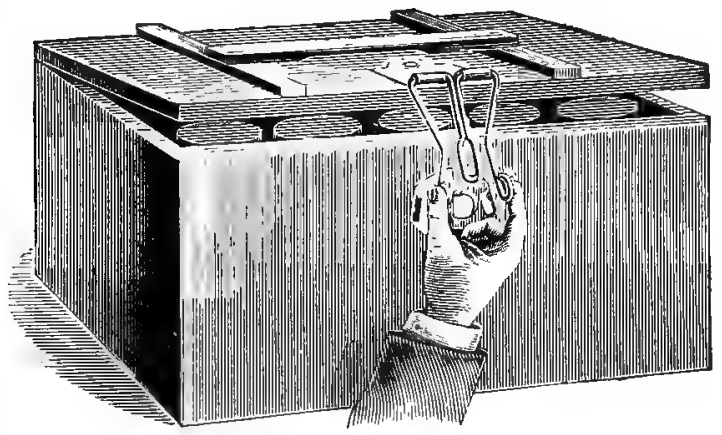

FIG. 58.

nature of the soil, and the character of the season. It might also be stated that candying is a sign of purity, and that the honey may be re-liquefied by standing the jar in hot water.

Bottling and the filling of cans should take place a day or two after extracting, and before the honey begins to candy : 28-lb. cans, square with patent lids, are sold at very reasonable prices, and may be packed two in a box.

Candying may be deferred, if not altogether pre- 
vented, by subjecting the honey to heat, but there is a liability in thus treating it to drive off the delicate aroma, and therefore heating honey should be

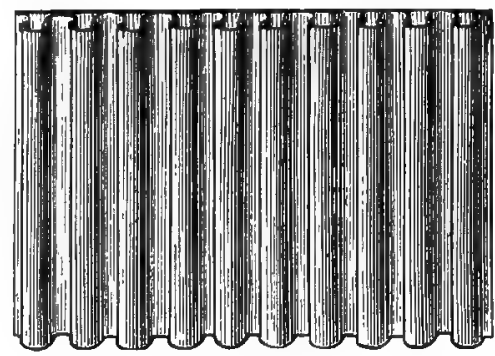

FIG. 59.

aroided as much as possible. Jars may be despatched to customers in boxes (Fig. 58) after being separately surrounded by a sheet of corrugated paper (Fig. 59). 


\section{CHAPTER XVIII.}

\section{WAX EXTRACTING.}

THE wax resulting from the sliced combs, or the cappings taken from combs that are passed through the extractor, is of very good quality. There is no difficulty in dealing with such scraps of comb, but it is not every apiary where such combs are dealt with. Until wired foundation, or wired frames, become more general there will always be some frames containing combs that, through falling, buckling, or stretching, are unsuitable for breeding purposes. These should be removed, when not occupied with brood, and melted.

The methods now employed to separate wax from the cocoons, \&c., render the operation simple, and not, as was once the case, the most distasteful, because the most messy of all the operations in the apiary. Wax melts at a temperature of $146^{\circ}$, consequently any arrangement that will hold the refuse from which the wax will, as melted, run away, may be adopted.

A very simple plan, devised by Mr. Cowan in 1888, is to place the combs upon a sieve over a pan of 
water. When placed in a moderately hot oven the wax will fall down as it melts into the water below, and unless subjected to too great heat will not be harmed by this method of extracting. An extractor on this principle was designed by Mr. Killick in 1887 . A bowl with a perforated bottom is placed upon a pan of water, and the action of the heat upon the combs is as stated above when a sieve is used.

Refuse scraps of comb are by some bee-keepers stored away for a general melting operation, but this plan may cause loss, for should the wax moth gain access to the store much, if not all, will be rendered useless. When a small quantity has accumulated it should be put, without further delay, into some kind of wax extractor, for the wax will keep indefinitely though the combs may be quickly spoilt. The solar wax extractor, which has recently been recommended, consists of a case with a glass front, placed at an angle to collect the direct rays of the sun. A box with a front wall of 2 inches, and back wall 6 inches, will prove effective in dealing with small quantities of comb. Upon the slanting front is placed a sheet of glass. Inside the case is fixed a pan covered with a sheet of perforated zinc. Upon the zinc is placed the scraps of comb to be operated upon. If the extractor is now placed in the direct rays of the sun on a hot day the wax will be quickly melted and run through the zinc into the pan below. This method may be used at any time when the rays of the sun are sufficiently powerful to melt the wax.

The most popular extractor is the "Gerster" (Fig. 56), in the form of a saucepan and steamer. 
The lower compartment is simply to hold water for the purpose of producing steam. In the bottom of the upper section is fixed a tin plate communicating with the outside by a small tube. Upon the plate, slightly raised by legs, stands a cylinder of perforated zinc, into which are placed the scraps of comb. When the apparatus is placed over the fire the steam

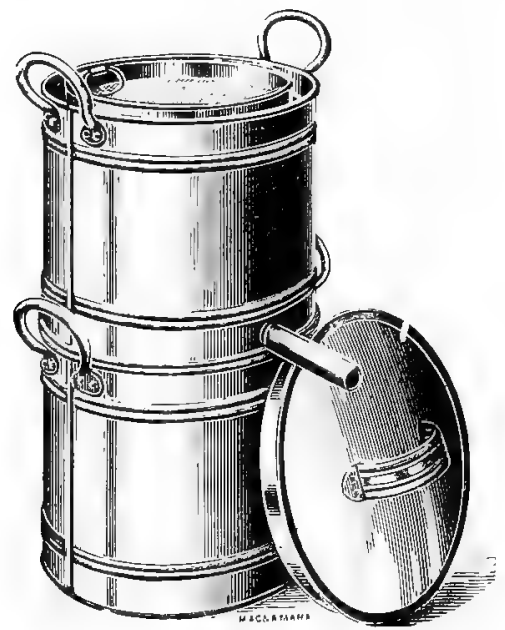

FIG. 60.

from the lower passes to the upper compartment, and melts the wax, which runs through the zinc, falls upon the plate and runs thence through the tube, finally dropping into a basin placed beneath. A little water should always be placed in the basin.

The following is a simple means of extracting the wax from old combs when neither of the above 
methods are employed. Tie the scraps of comb in a piece of muslin or canvas, with a stone, or something weighty, and drop it into a pan of water. The stone is used to keep the bag below the surface of the water. The wax will then melt and rise to the surface of the water. If the bag is occasionally pressed with a stick, lodgings of the wax among the refuse will be prevented. When it is thought that all the wax has been melted the pan should be removed from the fire and placed on one side until the water is cold. The wax will then be found in a cake at the top, and it then can be removed for remelting and refining if necessary. 


\section{INDEX.}

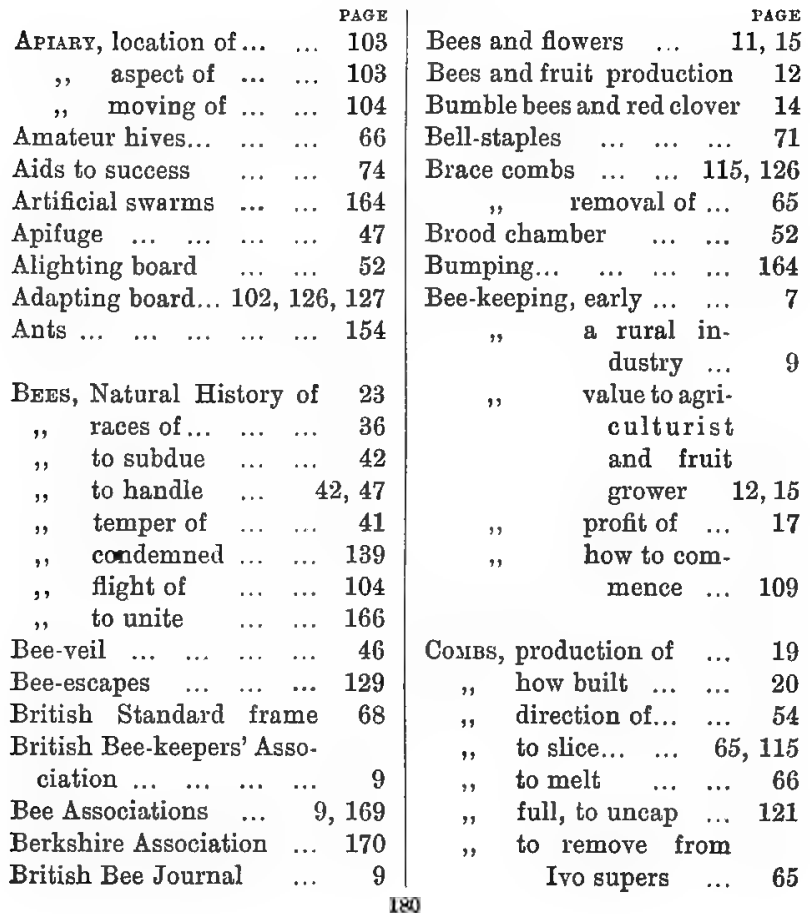


PAGE

Combs, renewal of $\ldots \quad \ldots \quad 76$ Cells, size of $\ldots \begin{array}{llll}\ldots & \ldots & 20\end{array}$ " worker, necessary 55 " queen $\quad . . . \quad \ldots \quad 21,56$ " pitch of ... ... 21, 121 ," cappings of ... $\quad . . \quad 29$ Condemned bees $\ldots . \quad \ldots \quad 139$ " , disposal of 161 Colony of bees, a good ... 89 Cone escape $\quad \ldots \quad \ldots \quad 65,130$ $\begin{array}{llllll}\text { Casts ... } & \ldots & \ldots & \ldots & \ldots & 32\end{array}$ $\begin{array}{lllll}\text {, sign of issue } & \ldots & \ldots & 33\end{array}$ $\begin{array}{lllll}\text { Cyprian bees } & \ldots & \ldots & \ldots & 38\end{array}$ $\begin{array}{llll}\text { Carniolan bees } & \ldots & \ldots & 39\end{array}$ $\begin{array}{llll}\text { Carbolic spray... } & \ldots & \ldots & 45\end{array}$ $\begin{array}{llll}\text { Carbolic cloth ... } & \ldots & \ldots & \mathbf{4 5}\end{array}$ $\begin{array}{llll}\text { Carbolic solution } & \ldots & \ldots & 46\end{array}$ Crowding bees, advantage $\begin{array}{lllllll}\text { of } & \ldots & \ldots & \ldots & \ldots & \ldots & 64\end{array}$ Clubbing, advantage of ... 170 Commencing bee-keeping 99 Cleansing flight $\quad . . \quad \ldots \quad 156$

$\begin{array}{llllll}\text { Drones } & \ldots & \ldots & \ldots & \ldots & 26\end{array}$ "when produced ... 26 , massacre of... ... 26

Drone comb, disadvantage $\begin{array}{lllllll}\text { of } & \ldots & \ldots & \ldots & \ldots & \ldots & 77\end{array}$

Distance-keepers $\quad \ldots \quad \ldots \quad 69$ $\begin{array}{llll}\text { Dysentery } \quad \ldots & \ldots & 90,146\end{array}$

Dry sugar feeding $\ldots . . . \quad 91$ $\begin{array}{lllll}\text { Diseases } & \ldots & \ldots & \ldots & 9,145\end{array}$

Extractor (honey)... ... 118 Little Wonder 118 ", Cowan ... 8, 119 " Meadows ... 120 ", how used ... 121
Extractor (wax), Gerster 178 Killick ... ... 177

Cowan ... ... 176

Cost of ... ... 102

$\begin{array}{llll}\text { Solar } & . . & \ldots & 177\end{array}$

Eggs, quantity laid daily 29

Egg-laying, sole work of queen 24,90 when com. menced ... 29 when stopped 29,89 Excluder zinc 64, 102, 115, 127 Enemies of bees ... ... 153

Fodndation $\quad \ldots \quad \ldots \quad 9,56,63$ " advantage of 74, 85 " casts for ... 75 " wired ... $\quad \ldots \quad 76$ , wiring ... 81,82 , brood ... ... 75 " $\quad$ super $\ldots \quad 75,102$ , fixing $\quad \ldots \quad \ldots \quad 78$ " why use full sheets 75,85 , 102,127

Foundation fixer, Abbott's 83 Parker . 84 Foundation mill $\quad \ldots \quad \ldots \quad 75$ Flowers, how fertilised ... 12

, nectaries of ... 12

" colours of, attractive... ... 12 odours of ... $\quad \ldots \quad 12$

Fruit production, value of $\begin{array}{lllll}\text { bees in } \ldots & \ldots & \ldots & \ldots & 13\end{array}$ Fumigator, Webster's $\quad . . \quad 44$ Bertrand ... 150 Fixed-comb hives ... ... 52 Frames, British standard 67 


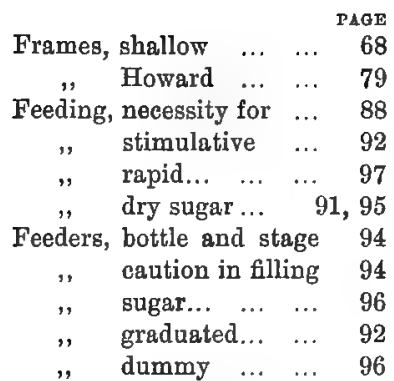

Food, what to use ... 90,91

,, how prepared ... 97

Flowers, honey-producing 12

Fertile workers $\quad \ldots . \ldots .28$

$\begin{array}{rrr}" & \text { to detect } & 28 \\ \text { how got } & \\ & \text { rid of... } & 28\end{array}$

Foul brood $\quad \ldots \quad \ldots \quad \ldots \quad 145$ symptoms of 148 how propagated 148 remedies for... 149

$\begin{array}{lllll}\text { Formic acid } & \ldots & \ldots & \ldots & 150\end{array}$

Gadntlets $\quad \ldots \quad \ldots \quad \ldots \quad 49$

Gloves, objectionable $\quad \ldots \quad 47$

Honey, a food $\quad 7,21,91,168$ , gathering of ... 21 $\begin{array}{lllll}\text {, } & \text { aroma of } & \ldots & \ldots & 22\end{array}$

$\begin{array}{lllll}\text { " } & \text { clover ... } & \ldots & \ldots & 22\end{array}$

" heather ... $\quad . . .22$

" run or drained 114,173

". candied, to liquefy

91,175

, marketing ... ... 168

" local market for... 169

, to retail $\quad \ldots \quad \ldots \quad 169$

," grading $\quad \ldots \quad \ldots \quad 170$
PAGR

Honey, to pack $\quad \ldots \quad$... 175

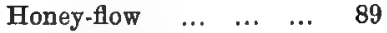

Honey-cistern ... ... 102,122

$\begin{array}{lllll}\text { Honey-knife } & \ldots & \ldots & \ldots & 121\end{array}$

$\begin{array}{lllll}\text { Honey-jars } & \ldots & \ldots & \ldots & 173\end{array}$

Honey-labels $\ldots . . . \quad \ldots \quad 174$

Hives, cottager $\quad . . \quad \ldots \quad 51$

, amateur ... ... 66

, distance apart ... 104

, single-walled ... 101

, double-walled . 101

$\begin{array}{llll}\text { Holyland bees ... } & \ldots & \ldots & 39\end{array}$

Handling bees... ... 42, 45, 48

$\begin{array}{lllll}\text { INTIMIDANTB }_{\text {NTM }} & \ldots & \ldots & \ldots & \mathbf{4 2}\end{array}$

, moderate use

of $\ldots . . .48$

Iro bar hive $\quad \ldots \quad \ldots \quad 57,100$

$\begin{array}{llll}, & \text { parts of } & \ldots & 60 \\ , & \text { supers for } \ldots & 60\end{array}$

" lifts for ... 60

, bars for ... 61

" to prepare ... 62

KNIFE, uncapping ... ... $10 \%$

LitTLe Wonder Extractor

8,118

$\begin{array}{lllll}\text { Ligurian bees } & \ldots & \ldots & \ldots & \mathbf{3} 6\end{array}$

, , home of ... 37

" " when intro. duced ... 37

peculiarities of ... ... 37

advantages of $\ldots . \ldots 37$

Lift for hive $\quad \ldots \quad \ldots \quad \ldots 59,73$

Marketrna honey ... 168 
PAOE

Movable-comb hive... 7, 67, 100 advan.

tage of 8 entrance

to ...

supers

for... 72

cost of 100 to make 7 J

Manipulations... $\quad \ldots \quad \ldots \quad 48$

proper time for... ... 49

Metal ends, Lyon .. $\quad . .69$

W. B. C. ... 70

Howard $\ldots 70$

Metal runners ... ... ... 73

Meadows' boardand clearer 133

$\begin{array}{llllll}\text { Mice ... } & \ldots & \ldots & \ldots & \ldots & \mathbf{1 5 4}\end{array}$

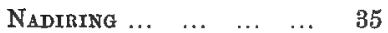

Naphthol Beta... ... 103, 151

Naphthaline $\ldots \quad \ldots \quad 103,152$

Pollen $\quad \ldots \quad \ldots \quad \ldots \quad$ 22, 91 " colours wax ... 23

, artificial $\ldots \quad y 1,167$

$\begin{array}{lllll}\text { " } & \text { baskets } & \ldots & \ldots & 22\end{array}$

$\begin{array}{llllll}\text { Propolis } & \ldots & \ldots & \ldots & \ldots & 23\end{array}$

Painting hives... ... 5ั5, 63

$\begin{array}{llllll}\text { Pin trap } & \ldots & \ldots & \ldots & \ldots & 131\end{array}$

Porter bee-escape $\ldots . \quad \ldots \quad 133$

Phenol ... ... ... $\ldots .150$

Packages for honey $\ldots 174$

Porto Rico sugar ... ... 95

QUEEN, sole duty of... $\quad 24,136$ ,, how produced 24, 137

,, age of ... ... 24, 137

" when in prime ... 25
Queen, when to remove 25,136

"wheu fertilised 26,139

,. young, importance $\begin{array}{lllll}\text { of } & \ldots & \ldots & \ldots & 135\end{array}$ young, to recognise 136 introduction of .. 140 direct introduction

$\begin{array}{lllll}\text { of } & \ldots & \ldots & \ldots & 142\end{array}$

$\begin{array}{lllll}\text { Queen jelly } & \ldots & \ldots & \ldots & 28\end{array}$

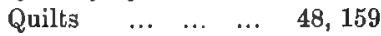

Queen cages, pipe cover 141

,"

Howard 142, 143 Rayner Puttern

$\begin{array}{lllll}\text { RequeENING } & \ldots & \ldots & \ldots & 135\end{array}$

$\begin{array}{llllll}\text { Swarming... } & \ldots & \ldots & \ldots & 30\end{array}$

,, caluse of,... ... 34

, to control 34,118

Swarms, to hive $31,54,110$

, to shade ... $\quad . . \quad 32$

, removal of $\ldots . \quad 32$

,, to feed $\ldots . . . \quad 55$

, work of ... $\quad . . \quad 58$

,, when to super... 55

,, artificial $\ldots . \quad \ldots \quad 164$

, sold by weight... 100

, pucking $\ldots . . \ldots \quad 106$

$\begin{array}{lllll}\text { Supers } \quad \ldots & \ldots & \ldots & 58,72\end{array}$

how given $35,64,110,113$

when given ... ... 55 additionul $\ldots . . . \quad 56$

filling of $\quad \ldots \quad \ldots \quad 35$

removal of $\ldots \quad 57,65$

to empty $\quad \ldots \quad 63,129$

Abbott's cottager 116

Castle Douglas ... 117

Sting, to remove ... 48 


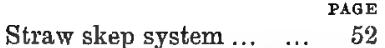
" $\quad$ " $\quad \begin{gathered}\text { cost of } \\ \text { manage- }\end{gathered}$

Smoker, invention of

, fuel for

, how charged ...

,

Bingham .

Starvation, sign of ... $\quad \ldots \quad 27$

Subduing bees... $\ldots . . . \quad 41$

Saw-cut for foundation ... 78

$\begin{array}{lllll}\text { Syrian bees } & \ldots & \ldots & \ldots & 39\end{array}$

$\begin{array}{llll}\text { Shallow frames } & \ldots & \ldots & 68\end{array}$

Stocks, keep strong... $\quad \ldots \quad 88$

" how strengihened 89

", weight of ... ... 26

, to requeen ... 25,139

" to move ... 104, 106

, to pack $\quad \ldots . \quad \ldots \quad 107$

" "taking up" ... 161

Sections, in flat $\quad \ldots \quad \ldots \quad 124$ to fold $\ldots . . . .6124$

" $\quad$ preparing . $\quad 83,124$

", $\quad$ grooved $\ldots . . . \quad 86$

$\begin{array}{lllll}\text { " Lee's } & \ldots & \ldots & 86\end{array}$

, crate for ... ... 124

, removal of ... 134

, perfect ... $\quad \ldots \quad 171$

,$\quad$ to glaze $\ldots{ }_{17} \ldots \quad 171$

$\begin{array}{llll}\text { Section hanger } \quad \ldots & \ldots & 128\end{array}$

Section block ... $\quad \ldots \quad \ldots \quad . \quad 87$

$\begin{array}{lllll}\text { Separators } & \ldots & \ldots & \ldots & 125\end{array}$

Sectional honey $\quad \ldots \quad \ldots \quad 123$

Sectional super's, to remove 132

Sugar, to use for food ... 91

Spring dwindling $\quad \ldots \quad \ldots \quad 89$
PAGE

126

$\begin{array}{lllll}\text { Transferrinct } & \ldots & \ldots & \ldots & 165 \\ \text { Travelling crates } & \ldots & \ldots & 172\end{array}$

$\begin{array}{llllll}\text { Unrting } & \ldots & \ldots & \ldots & \ldots & 166\end{array}$

$\begin{array}{lllllll}\text { VEIL }_{1} & \ldots & \ldots & \ldots & \ldots & \ldots & 46\end{array}$

$\begin{array}{lllll}\text { Ventilation } & \ldots & \ldots & \ldots & 159\end{array}$

WIDE-SHodLdERED frames 69

Webster's super clearer... 132

$\begin{array}{llll}\text { Woodbury hive } & \ldots & \ldots & 67\end{array}$

$\begin{array}{lllll}\text { Wintering... } & \ldots & \ldots & \ldots & 155\end{array}$

, young bees for 156,24

" stores for ... 157

", arrangement of stores in comlus $\begin{array}{llll}\text { for } \ldots & \ldots & \ldots & 158\end{array}$

$\begin{array}{llll}\text { Winter passages } & \ldots & \ldots & 158\end{array}$

$\begin{array}{lll}\text { Wax, production of } \quad \ldots & 19\end{array}$

$"$ involuntary secretion of... $\quad \ldots \quad \ldots \quad 82$

" honey consumed in elaboration of ... 20

$\begin{array}{lllll}\text {, melting of } & \ldots & \ldots & 176\end{array}$

$\begin{array}{llll}\text { Wax extracting } & \ldots & \ldots & 176\end{array}$

$\begin{array}{lllll}\text { Wax moth } & \ldots & \ldots & \ldots & 153\end{array}$

Woiblet spur embedder... 83

$\begin{array}{llllll}\text { Wasps } & \ldots & \ldots & \ldots & \ldots & 154\end{array}$ , destruction of, in $\begin{array}{llll}\text { spring } \quad \ldots & \ldots & 154\end{array}$

$\begin{array}{lllll}\text { Worker bees } & \ldots & \ldots & \ldots & 27\end{array}$

" their work ... 27

" length of life of $\ldots \quad \ldots \quad 27$ 
Manufacturer of the IYO HIYE as approyed and authorised by Mr. C. N. White.

\section{IIEOMIAS B. BIOLI}

Begs to call speoial attention to the following sonsonable articles, which for high quality bave never been excelled:-

Lewls \& Co.'s SNOW-WHITE POLISHED SECTIONS.-These Sections are snow-white, and nothing like them has ever belore been seen in this country. They can be had in both '?-way and 4-way, also in the form called Blow's Patent Grooved and Split-top Sections.

Blow'S Soft Gandy (Pure Cane Sugar with Honey). Specially prepared in One-Pound Boxes. 6d. per Box; 58, per Dozen.

SUPER AND BROOD FOUNDATION OF PURE BEESWAX.

New Remedy for FOUL BROOD.-Half-pint Bottles 2o. $6 d$. ; Pint Bottles, 4s, Norrerous UnSODICITED Testimonials.

Enamellea Metal Section Cases.-Fxhibitors at Shows, and those who have large quantities of Comb Foney for public sale, have become keenly alive to the fact that one of the greatest induoements to Shopkeepers to consent to stock Honey, and to the Publio to buy it, is the appearance and neatness of the get-up of the package containing the Honey in Comb. They can be had with or without fastenings.

Tomey Bottles.-Special attention is called to the Metal Screw-top Honey Botrle for use at Shows, these beivg of very fine quality.

Perfection and Fapid Fin Feeders.-Now is the time for Feeding-up Stools that are short of aupplies. For quick feeding, the RAPID TIN FEEDER is all that can be desired. My Feeders hrve stood the test of many years, and are still the best in the market. In the Catalogue mentioned below fall descriptions and illustrations will be found.

Honey Extractors, Honey Ripeners and Honey Presaes wilh all the latest improvements. Also Smokers, Tinware of every description. Best Shefield Knives and Cullery of all approved patterns. Special Terms offered to the Irade. Send for 74-page Catalogue, Fith 120 Illustrations. Also my New Horticultural Gatalogue.

T. B. BLoux, Welyym, England.

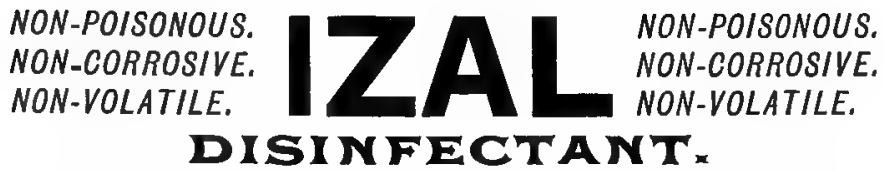

AN ENTIRELY INET DISCOVERY. ITOT A COAL-TAR PRODUCT.

THE SUREST PROTECTOR AGAINST

FEYERS, SMALL-POX, CHOLERA, DIPHTHERIA, \& INFECTIOUS DISEASES.

\section{To BEE-KEEPERS.}

IZAL is acknowledged by experts to be THE LATEST AND BEST CORE for FOUL BROOD.

DIRECTIONS FOR USE.-To medicate food mix $\frac{1}{4}$ oz. IZAL with 15lbs, of honey or byrup. For cleansing bives use loz. of IZAL (tablespoonful) to 10 pints of water.

Sold by Chemists, Grocers, Stores, dc., in Bottles 1s., 2s. 6d., 48.6d. Gallon Tins, 108. The 2s. 6d. Bottle makeg 30 Gallons of gtrong reliable DISLNFEOTANT. 


\section{J. H. HOYYARD,}

MANUFACTURER, THE "MODEL APIARY,"

HOLME, PETERBOROUGH,

LEOTURER AND CERTIFIED EXPERT,

SOLICITS APPLICATION FOR HIS

\section{CATALOGUE (POST FREE),}

IN WHICH FIRST PRIZE APPLIANCES AND ALL IMPLEMENTS PERTAINING TO SUCCESS IN BEE CULTURE ARE SHOWN.

THE "IYO" HIXE is manufactured by J. H. H., under special directions and permat from Mr. C. N. WHITE.

Now Ready at all Booksellers and Libraries.

\section{In a Gloucestershire Garden.}

BY

\section{HENRY N. ELLACOMBE, M.A.,}

VICAR OF BITTON, GLOUCESTERSHIRE, AND HONORARY CANON OF BRISTOL; ADTHOR OF" "PLANT LORE AND GARDEN-CRAFT OF SHAKESPEARE."

\section{WITH ILLUSTRATIONS.}

Crown 8io, elegantly bound, $6 s$.

cONTENTS.

A GLOUCESTERSHIRE GARDEN, JANUARY TO DECEMBER, MON'TH BY MONTH.

SPRING FLOWERS.

SHRUBS.

PALMS AND BAMBOOS.

LITIES.

ROSES.
BRAMBLES AND THISTLES.

CLTMBING PLANTS.

GARDEN WALLS.

TREES IN THE GARDEN.

AUTUMN LEAYES.

BIRDS IN THE GARDEN. PARSONAGE GARDENS.

GARDEN ASSOCIATIONS.

London: 'EDWARD ARNOLD, 37, Bedford Street, Strand, W.C. Publisher to the India Office. 


\section{WORKS BY}

\section{THE DEAN of ROCHESTER}

(THE VERY REV. S. REYNOLDS HOLE).

MORE MEMORIES : Being thoughts about England spoken in America. With Frontispiece. Demy 8vo, $16 \mathrm{~s}$.

" There is not a page in this volume without its good thing, its touch of wit or wisdom, quaint drollery, apt illustration, or quick association, kind counsel, grave truth, or happy aneedote."-Irorld.

\section{THE MEMORIES OF DEAN HOLE. With the} original Illustrations from sketches by LEECH and THackeray. Twelfth Thousand. One rol., crown 8vo, 6s.

"One of the most delightful collections of reminiscences that this generation has seen."-Daily Chronicle.

\section{A LITTLE TOUR IN IRELAND. By AN Oxonian}

(the Very Rev. S. R. HoLe, Dean of Rochester). With nearly forty Mlustrations by JoHN LEECH, including the famous steel Frontispiece of the "Claddagh." Large imperial $16 \mathrm{mo}$, handsomely bound, gilt top, 10s. 6d.

** Only a few copies of this edition now remain.

\section{A BOOK ABOUT THE GARDEN AND THE}

GARDENER. Second Edition. Crown 8vo, cloth, 6s.

"A delightful volume, full not merely of information, but of humour and entertainment."-World.

\section{A BOOK ABODT ROSES. Twentieth Thousand.}

Crown 8ro, cloth, 2s. 6d.

"A perfeetly charming book."-Daily Telegraph.

"A well-known and delightful book."-Guardian.

\section{ADDRESSES TO WORKING MEN FROM PULPIT AND PLATFORM. One vol., crown 8vo, 6s.}

Londox: EDWARD ARNold, 37, Bedford Street, Strand, W.C. Publisher to the India Office. 


\section{COLONEL KENNEY HERBERT'S}

\section{POPULAR WORKS ON COOKERY}

\section{COMMON-SENSE COOKERY FOR ENGLISH}

HOUSEHOLDS. Based upon Modern English and Continental Principles, with Twenty Menus worked out in detail. By A. KENNEY Herbert ("Wyvern"), Don of the Order of the Cordon-Rouge, Author of "Culinary Jottings," \&c. Large crown 8vo, cloth, price 7s. 6 d.

"A book which is sure to have a large circulation, since the author, the well-known 'Wyrern,' has been for some time generally accepted as perhaps the chief English authority on the art of cookery."-The Times.

"An eldborate treatise on the culinery art. The rules are laid down simply and clearly, and the recipes are given with such precision as to quantities that migtakes ean scarcely occur if proper attention is paid to the instructions." - Morning Post.

"Colonel Herbert has already proved his fitness for the task he has undertaken in the present volnme, and the work will confirm his reputation as one of the most lucid and practical writers upon the culinary art. Alike to learners and adepts the bool will be found useful and suggestive."-Manchester Courier.

\section{FIFTY BREAKFASTS. By A. Kenney Herbert}

("Wyvern"). Crown 8vo, cloth, price 2s. 6d.

"All who know the culinary works of 'Wyvern' are aware that they combine a remark. able conviction and (on the whole) excellent taste with an exceptional practicalness and precision in detail. His "Fifty Breakfasts' will well sustain this reputation." - Saturday Review.

"An admirable collection of menus for the opening meal of the day. The majority of the dishes deseribed in these pages are not merely dainty and appetising, but are hardly of a kind seriously to tax either the resources of an ordinary kitchen or the aptitude of an ordinary cook. Colonel Ferbert's book is one of the best of its kind, for it is thoroughly practical from beginning to end."-Speaker.

"Autolycns," in a review of a column, says: "Distinctly it is a book to be read and studied." -Pall Mall Gazette.

TWO NEW VOLUMES by COLONEL KENNEY HERBERT will be published very shortly, in uniform style with "Fifly Breakfasts." Price 2s, 6d, each.

\section{FIFTY LUNCHES. FIFTY DINNERS.}

London: EDTfard ARNOLD, 37, Bedford Street, Strand, W.C. Publisher to the India Office. 


\section{MR, EDWARD BROWN'S}

\section{POPULAR WORKS ON POULTRY.}

\section{PLEASURABLE POULTRY KEEPING.}

\section{By EDWARD BROWN,}

Lecturer to the County Councils of Northumberland, Cumberland, Hampshire, Kent, de., Author of "Industrial Poultry Keeping," dc.

One vol., crown 8vo, cloth, $2 \mathrm{~s} .6 \mathrm{~d}$.

"This handbook is as useful as it is comprehensive."-Scotsman.

"Mr. Brown has established for himself a unique position in regard to this subject, and what he has to say is not only sound counsel, but is presented in a very readable form." Nottingham Daily Guardian.

\section{POULTRY KEEPING AS AN INDUSTRY}

\section{FOR FARMERS AND COTTAGERS.}

By EDWARD BROWN, F.L.S.

With Fourteen full-page Plates by LudLow, and nearly Fifty other Illustrations.

One vol., demy 4to, cloth, $6 \mathrm{~s}$.

"One of the most complete manuals on the keeping of poultry."-County Council Times.

"The most useful book of the kind ever published."-Farming World.

\section{INDUSTRIAL POULTRY KEEPING.}

\section{By EDWARD BROWN, F.L.S.}

A small handbook chiefly intended for cottagers and allotment holders. Paper boards, 1s.

"The book is one of very easy reference, and ought to be in the hands of not only every farmer, but also of all cottagers throughout the country."-Newcastle Journal.

London: EDWARD ARNOLD, 37, Bedford Street, Strand, W.C. Publisher to the India Office. 


\section{Mr. Edward Arnold's List.}

\section{Yolumes of Biography and Reminiscence.}

\section{THE LIFE AND LETTERS OF MARIA}

EDGEWORTH. Edited by Augustus J. C. HARE, Author of "The Story of Two Noble Lives," \&c. Two vols., crown 8vo, with Portraits, 16s. net.

"As we read the two charming volumes of 'The Life and Letters of Maria Edgeworth,' we cannot but wonder why the publication of such excellent material was delayed so long. $A$ book which will not oniy be widely read in its season of first freshness, but which will probebly rank high in future years among the standard memoirs of our language." - Times.

\section{THE RECOLLECTIONS OF THE DEAN OF}

SALISBURY. By the Very Rev. G. D. Boyle, Dean of Salisbury. With Photogravure Portrait. Demy 8vo, 16s.

"One of the most delightrul volumes of its kind published for many months past."Atheneum.

"A very delightful book. He has something to tell us which is worth hearing of most (f the great men of his time, and his pages teem with telling aneedote and shrewd but always kindly observation."-Times.

THE MEMOIRS OF THE LATE SIR JOHN A. MACDONALD, G.C.B., first Prime Minister of Canada. Edited by Josepr Pope, his Private Secretary. With Portraits. Two vols., demy 8vo, 32s.

\section{ALPHONSE DAUDET. A Biography and Critical}

Study. By R. H. Sherard, Editor of "The Memoirs of Baron Méneval."

"An excellent piece of journalism, the kind of personal journalism which is both ontertrining and useful."-Saturday Review.

\section{SEVENTY YEARS OF IRISH LIFE. Being} the Recollections of W. R. LE FANO. Third Edition. One vol., demy 8vo, 16s. With Portraits of the Author and J. Sheridan Le Fanu.

"It will delight all readers-English and Scotch no less than Irigh, Nationalists no less than Unionists, Roman Catholics no less than Orangemen."-Times.

\section{RIDING RECOLLECTIONS AND TURF}

STORIES. By Henny Custance, three times winner of the Derby. One vol, , crown 8vo, cloth 2 s. $6 \mathrm{~d}$.

"An admirable sketch of turf history during a very interesting period, well and humorously written."-Sporting Life.

\section{ECHOES OF OLD COUNTY LIFE. Recollec-}

tions of Sport, Society, Politics, and Farming in the Good Old Times. By J. K. Fowser, of Aylesbury. Second Edition, with numerous Illustrations. 8vo, 10s. 6d. Also a large-paper edition, of 200 copies only, 21s. net.

"A very entertaining volume of reminiscences, full of good stories."-Truth.

London: EDWARD ARNOLD, 37, Bedford Street, Strand, W.C. Publisher to the India Office. 


\section{Mr. Edward Arnold's List.}

ENGLAND IN EGYPT. By Alfred Milner, C.B.

Popular Edition, with an Additional Prefatory Chapter on Egypt in 1894. Large crown 8vo, with Map, oloth, 7s, 6d,

"No fournalist or public man ought to be permitted to write or apeak about Egypt for the next five years unless he can solemnly declare that he had read it from cover to cover."-Daily Chronicle.

THE BRITISH MISSION TO UGANDA IN 1893.

By the linte Sir Gerald Poktal, K.C.M.G. Edited by Renneli Rodd, C.M.G. With an Introduction by the Right Honourable Lord CROMER, G.C.M.G. Illustrated from Photos taken during the Expedition by Colonel RHoDes. Demy 8vo, 21s.

SELECT ESSAYS OF SAINTE-BEUVE. Chiefly bearing on English Liternture. Translated by A. J. BUfLen, Translator of "The Alemoirs of Baron Marbot." Crown 8vo, cloth, 58. net.

GREAT PUBLIC SCHOOLS. ETON-HARROW-

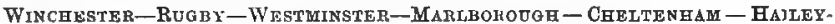
BURY-Clifton-C'Bartergouse. With nearly a hundred Iilustrations by the best artists. One vol., large inperial 16mo, handsomely bound, 6s.

WILD FLOWERS IN ART AND NATURE. By J. C. L. Sparkes, Principal of the National Art Training School, South Kensington, and F. W. Bursidas, Curator of the Unipersity Botanical Gardens, Dublin. With 21 Full-page Coloured Plates by H. G. Moon. Royal 4to, bandsomely bound, gilt edges, 218 .

\section{FICTIO}

ORMISDAL: a Novel. By the EarL of Dunmore, F.R.G.S , Author of "The Pamirs." One vol., crown 8vo, cloth, 6s.

"In this breezy and entertaining norel Lord Danmore has given us a very readable and racy story of the life that centres in a Highland shooting about the end of August."Glasgow Herald.

STEPHEN REMARX. The Story of a Venture in Ethics. By the Hon. and Rev. JAMes ADDerLey. Twenty-second Thousand. Small 8vo, elegantly bound, 88. 6d.; al wo in paper cover, 1s.

"Let ak express our thankfolness at enconntering for once in a way an author who can amuse us." - Saturday Reviezo.

LOVE-LETTERS OF A WORLDLY WOMAN. By Mrs. W. K. Clifrorid, Author of "Aunt Anne," "Mrs. Keith's Crime," \&cc. One vol., crown 8vo, cloth, 2s. 6 d.

"One of the cleverest books that ever a woman wrote."-Queen.

DAVE'S SWEETHEART. By M M rol., 8ro, cloth, 3s. 6d.

"In every respect one of the most powerful and impressive novels of the year."-Daily Telegraph.

THE MYSTERY OF THE RUE SOLLY. Translated by Lady KNotsford from the French of H. De Balzac. Crown 8ro, cloth, 8s. 6d.

"Lady Knutsiord'в translation of Balzac's famous story is excellent."-Scotsman.

MISTHER 0'RYAN. An Incident in the History of

a Nation. By EDWARD McNulty. Small 8vo, elegantly bound, 3s. 6 d.

"An extremely well-written satire of the possibilities of blarney and brag."-Pall Mall Gazette.

THE TUTOR'S SECRET. (Le Secret du Précepteur.) Translated from the French by Vigron ChenBuliez. One vol., crown 8vo, cloth, 6 .

London: EDWARD ARNOLD, 37, Bedford STREeT, STRAND, W.C. Publisher to the India Office. 

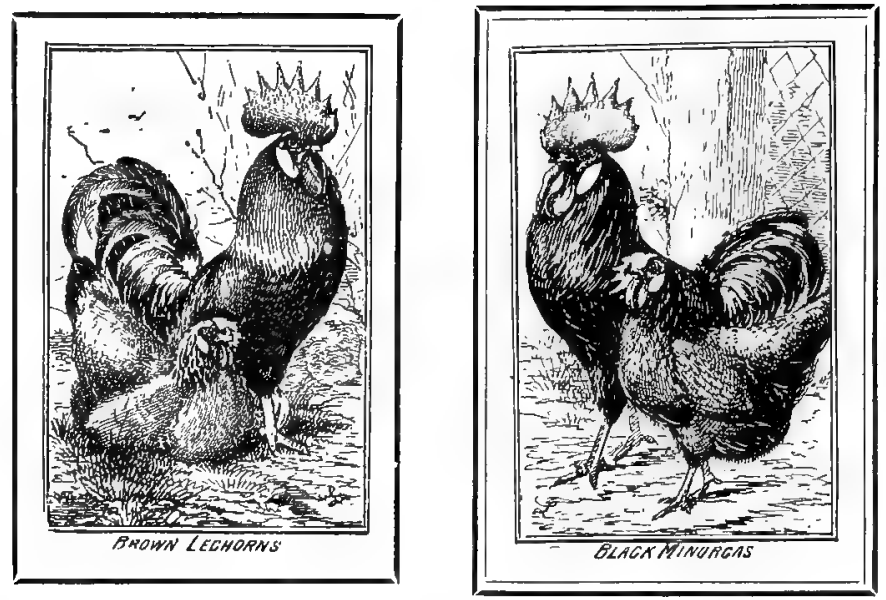

\section{Reared from Shell to Show Pen ON}

\section{SPRATTS PATENT}
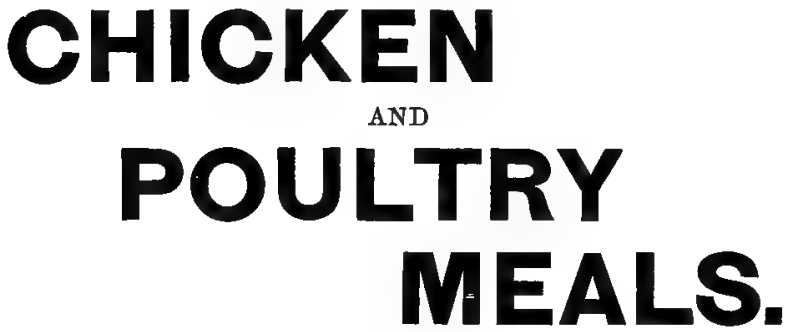

Samples of Foods Post Free.

Pamphlet on Poultry Rearing Post free for One Stamp. SPRATT'S PATENT Ltd., Bermondsey, London, S.E. 





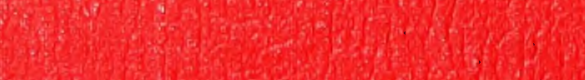

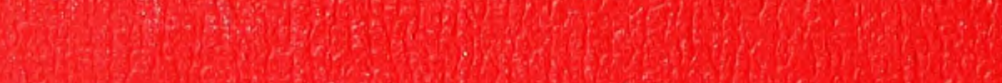

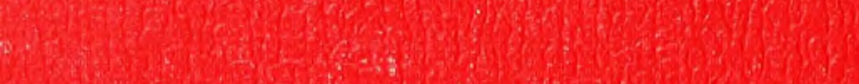
W.

(3):

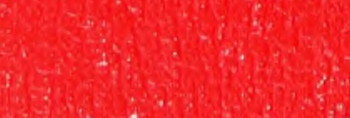

$3 y^{3}$

$\sin ^{2} \sin ^{2}$ is

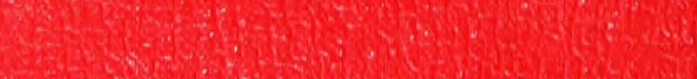

